\title{
Improving adolescent reproductive health in Bangladesh
}

\author{
Ismat Bhuiya \\ Population Council \\ Ubaidur Rob \\ Population Council \\ Asiful Haider Chowdhury \\ Population Council \\ Laila Rahman \\ Population Council \\ Nazmul Haque \\ Population Council
}

See next page for additional authors

Follow this and additional works at: https://knowledgecommons.popcouncil.org/departments_sbsr-rh

Part of the Demography, Population, and Ecology Commons, Health Services Research Commons, and the International Public Health Commons

How does access to this work benefit you? Let us know!

\section{Recommended Citation}

Bhuiya, Ismat, Ubaidur Rob, Asiful Haider Chowdhury, Laila Rahman, Nazmul Haque, Susan E. Adamchak, Rick Homan, and M.E. Khan. 2004. "Improving adolescent reproductive health in Bangladesh," FRONTIERS Final Report. Dhaka: Population Council. 


\section{Authors}

Ismat Bhuiya, Ubaidur Rob, Asiful Haider Chowdhury, Laila Rahman, Nazmul Haque, Susan E. Adamchak, Rick Homan, and M.E. Khan 


\title{
Improving Adolescent Reproductive Health in Bangladesh
}

\author{
Ismat Bhuiya,Ubaidur Rob \\ Asiful H.Chowdhury, Laila Rahman, Nazmul Haque \\ Population Council, Dhaka \\ Susan Adamchak, Rick Homan \\ Family Health International, USA \\ ME Khan \\ Population Council, India
}

\begin{abstract}
November 2004
This study was funded by the U.S. AGENCY FOR INTERNATIONAL DEVELOPMENT (USAID) under the terms of Cooperative Agreement Number HRN-A-00-98-00012-00 and Population Council in-house project 580013027 and subcontracts CI00.05A and CI02.20A. The opinions expressed herein are those of the author(s) and do not necessarily reflect the views of the USAID.
\end{abstract}

\section{(2) Population Council FRONTIERS}




\section{SUMMARY}

Adolescents constitute one-fourth of the population of Bangladesh. The effects of globalization, rising age at marriage, rapid urbanization and greater opportunities for socialization have heightened the risk of STIs, HIV/AIDS and unwanted pregnancy. While adolescents have unmet needs for reproductive health information and services, these are not addressed by parents, schools or the existing health care systems. An operations research project was launched in northwestern Bangladesh with the objective of preventing adverse outcomes and promoting healthy lifestyles among adolescents by providing reproductive health education and services. The Population Council, in collaboration with the Urban Family Health Partnership (UFHP) and its three nongovernmental service delivery partners, working in urban sites of Pabna (Site A), Dinajpur (Site B), and Rangpur (Site C) carried out the study. Sites A and B were intervention sites while Site $\mathrm{C}$ served as a control. A quasi-experimental design with prepost measurements and two experimental strategies was used. Strategy I (Site A) provided reproductive health education to out-of-school adolescents linked with adolescent-friendly services at health facilities while Strategy II (Site B) provided reproductive health education to both in-school and out-of-school adolescents linked with adolescent-friendly services at health facilities. Teachers and facilitators were trained to provide reproductive health education to in-school and out-of-school adolescents respectively, while service providers were trained to offer friendly services to adolescents at the health facilities. Two population-based surveys among about 6000 adolescents were carried out; the baseline and endline data were collected during February to April 2000 and April to June 2002, respectively.

Bivariate and multivariate analyses were done to measure the effects of the interventions. Knowledge of HIV/AIDS increased in the intervention sites compared to the control sites, with greater improvement in Site B with the additional school-based intervention. The knowledge of contraceptives improved in both intervention and control sites, with the greatest improvement seen in Site A. The effect of the interventions on knowledge of the fertile period and potential health risks of early pregnancy was also clearly observed with greater improvement in Site B than Site A and no improvement in the control site.

Adolescents exposed to the interventions in Site B were more likely to support use of contraceptives by unmarried adolescents than those in Site A, and a similar pattern was seen for contraceptive use by married adolescents. Adolescents who were exposed to the intervention showed more favorable attitudes regarding use of condoms by unmarried adolescents than the non-exposed in both Site A and B. The analysis also revealed a more positive attitude towards health facilities for contraceptive and STI services compared with pharmacies as a source of supplies and services.

While few unmarried males reported having ever had sex, the proportion increased significantly in the control area while it remained statistically unchanged in the intervention areas. The use of condoms also increased in the intervention sites compared with the control, with greater improvement in Site B than Site A. 
A comparative analysis of service statistics found that the utilization of services from health facilities doubled in Site A and increased ten-fold in Site B, compared to the change in utilization in Site C. Again, comparing the two intervention sites, Site B experienced six times greater utilization of services than Site A. Thus, for most key indicators, Strategy II produced greater improvements than did Strategy I.

On the basis of study findings, the following recommendations are made. First, a combination of reproductive health interventions at the school, community and health facility levels, accompanied by community sensitization, is needed to effectively respond to adolescent reproductive health needs. Any reproductive health information intervention should be combined with health facility based services to improve adolescents' overall reproductive health. However, in the case of constrained resources, schools and health facilities should be targeted first for they have existing structures that can be strategically leveraged. Moreover, a large majority of the adolescents were in favor of introducing reproductive health education in school.

Second, information providers such as teachers and facilitators should be trained to effectively convey reproductive health education to adolescents. Similarly, service providers should be trained on elements of adolescent friendly services.

Third, since the adolescents showed positive attitudes towards health facilities for contraceptives and STI services, relevant authorities should prepare health facilities for adolescent-friendly services. A similar opportunity also exists in terms of promoting and distributing condoms for HIV/AIDS and FP programs since over three-fourths of the adolescents had favorable attitudes towards condom use for preventing pregnancy as well as infections.

Finally, while the three-pronged intervention suggested several positive impacts, particularly among in-school adolescents, it was not effective in reaching unmarried sexually active adolescents many of whom are not enrolled in school. Hence, future interventions should be designed focusing on unmarried sexually active adolescents. 


\section{CONTENTS}

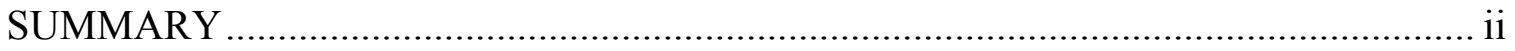

LIST OF TABLES, FIGURES AND BOXES ……………………………….......... vi

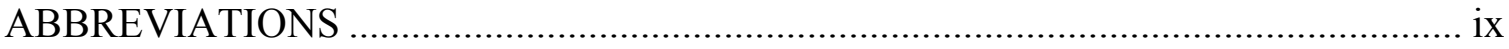

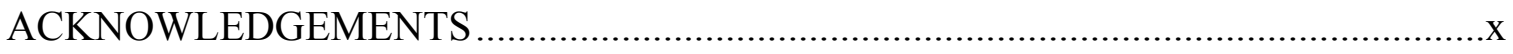

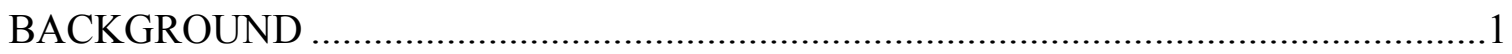

STATEMENT OF THE PROBLEM …………………................................................

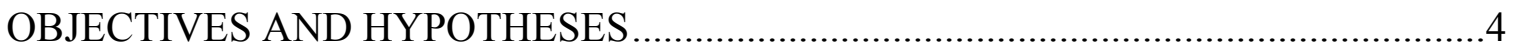

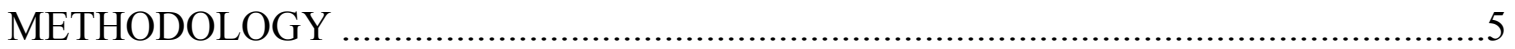

Study design

Selection of the study sites

Map and description of the study sites

Household enumeration survey

Sampling design

Independent variables

Dependent variables

Data collection

Data analysis

Limitations of the study

DESCRIPTION OF INTERVENTIONS

Development and distribution of RH curriculum

Development and distribution of BCC materials

Conducting sensitization meetings among gatekeepers

Training on RH curriculum and adolescent friendly services

Conducting RH sessions and providing adolescent friendly services

Provision of bulletin board, post-box facility and telephone hotline

Peer educators' activities

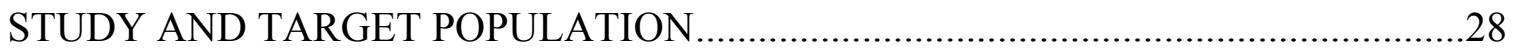

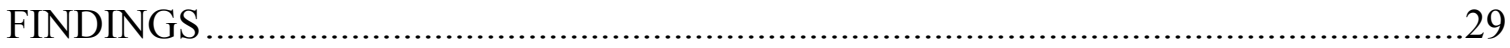

Socio-demographic characteristics of adolescents

Exposure to RH education

Knowledge of reproductive health issues

Attitude towards reproductive health issues

Reproductive health behavior 
Multivariate analysis

Service statistics analysis

Cost analysis

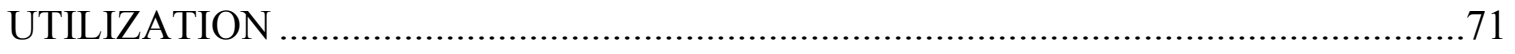

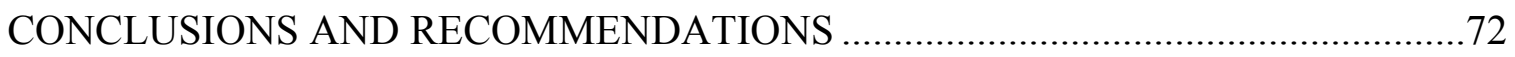

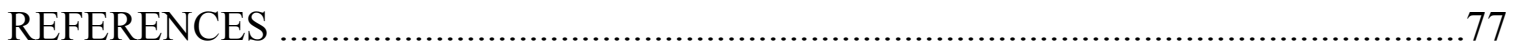

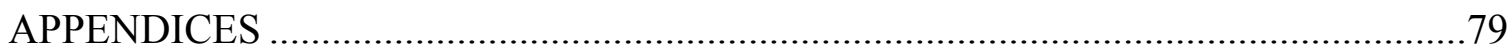

Appendix 1 Contents and key features of reproductive health curriculum

Appendix 2 Description of five adolescent reproductive health leaflets 


\section{LIST OF TABLES, FIGURES AND BOXES}

\section{Tables}

Table1 Distribution of adolescent boys aged 10-19 by site, age group and school status during the enumeration survey in 2000

Table 2 Distribution of adolescents girls aged 10-19 by site, age group and school status during the enumeration survey in 2000

Table 3 Adolescents and parents interviewed in baseline and endline surveys

Table 4 Distribution of RH curriculum

Table 5 Distribution of BCC materials

Table $6 \quad$ Formal and informal sensitization meetings conducted among gatekeepers at community and schools.

Table 7 Training on RH curriculum and adolescent-friendly services (AFS)....

Table 8 RH sessions in community and schools

Table 9 RH sessions conducted and events organized by peer educators.

Table 10 Background characteristics of boys by site and time of interview

Table 11 Background characteristics of girls by site and time of interview.....

Table 12 Parents/guardians' occupation as reported by adolescents

Table 13 Adolescents' exposure to intervention by background characteristics

Table 14 Sources of RH information by site, sex and time of interview ......

Table 15 Knowledge of HIV/AIDS by site, age group, sex and time of interview

Table 16 Knowledge of contraceptive methods by site, age group, sex and time of interviews .

Table 17 Knowledge of potential health risks of early pregnancy by site, age group, sex and time of interview

Table 18 Adolescent boys' attitudes regarding introducing RH education in school and utilizing health facility or pharmacy for contraceptives and STI services by site and age group.

Table 19 Adolescent girls' attitudes regarding introducing RH education in school and utilizing health facility or pharmacy for contraceptives and STI services by site and age group 
Table 20 Adolescent boys' attitude regarding use of contraceptives by site and age group

Table 21 Adolescent girls' attitude regarding use of contraceptives by site and age group

Table 22 Sexual exposure of unmarried adolescent boys by site, school status, age group and time of interviews

Table 23 Use of condom by unmarried and sexually active male adolescents by site, age group and time of interview

Table 24 Substance use by site, age group, sex and time of interview

Table 25 Models, variables, and analytic categories.

Table 26 Adjusted and unadjusted odds ratios (OR) of respondents' knowledge of $\mathrm{RH}$ issues and condom use at last sex by time of interview and site (models I to IV, and model XV).

Table 27 Adjusted and unadjusted odds ratios (OR) associated with the interaction term of time by experimental groups regarding respondents' knowledge of $\mathrm{RH}$ issues and condom use at last sex (models I to IV, and model XV) .

Table 28 Adjusted odds ratios of respondents' knowledge and behavior by selected covariates

Table 29 Adjusted and unadjusted odds ratios (OR) associated with RH intervention exposure regarding attitude of respondents on different $\mathrm{RH}$ issues for each intervention site.

Table 30 Adjusted and unadjusted odds ratios (OR) associated with intervention sites regarding attitude of exposed respondents on different $\mathrm{RH}$ issues

Table 31 Adjusted odds ratios for selected covariates tested for association with each of ten reproductive health issues by intervention site.

Table 32 Incremental costs of interventions by sites in constant 2002 Taka. 


\section{Figures}

Figure 1 Location of the study sites

Figure 2 Parents' survey at baseline: Support for RH education in schools (percent).....

Figure 3 Linkages with school, community and health facility

Figure 4 Study population by site, school status and sex

Figure 5 Adolescents' knowledge of fertile period by site, sex and time of interview (percent)

Figure 6 Six month averages of RH service utilization by adolescents

\section{Boxes}

Box 1 FGD Findings: Gatekeepers recognize the need for RH education

Box 2 In-depth findings: Following the footsteps of elders

Box 3 In-depth findings: Multiple partners

Box $4 \quad$ In-depth findings: Accompanying a pal.

Box 5 In-depth findings: Peer motivation

Box 6 In-depth findings: Path to addiction

Box 7 In-depth findings: Peer pressure. 


\section{ABBREVIATIONS}

\begin{tabular}{|c|c|}
\hline AIDS & Acquired Immune Deficiency Syndrome \\
\hline AFS & Adolescent Friendly Services \\
\hline $\mathrm{ANC}$ & Antenatal Care \\
\hline ASKS & Ananya Samaj Kallyan Sangostha \\
\hline ACPR & Associates for Community and Population Research \\
\hline $\mathrm{BCC}$ & Behavior Change Communication \\
\hline BANBEIS & Bangladesh Bureau of Educational Information and Statistics \\
\hline BRAC & Bangladesh Rural Advancement Committee \\
\hline CSW & Commercial Sex Worker \\
\hline ESP & Essential Service Package \\
\hline FGD & Focus Group Discussion \\
\hline FHI & Family Health International \\
\hline GFATM & Global Fund to Fight AIDS, Tuberculosis and Malaria \\
\hline HIV & Human Immunodeficiency Virus \\
\hline ICDDR, B & International Center for Diarrhoeal Disease Research, Bangladesh \\
\hline $\mathrm{KaS}$ & Kanchan Samity \\
\hline MIS & Management Information System \\
\hline $\mathrm{M} \& \mathrm{E}$ & Monitoring and Evaluation \\
\hline $\mathrm{NGO}$ & Non Governmental Organization \\
\hline NIPORT & National Institute of Population Research and Training \\
\hline NSDP & NGO Service Delivery Program \\
\hline NASROB & $\begin{array}{l}\text { National Assessment of Situation and Response to Opioid/Opiate use in } \\
\text { Bangladesh }\end{array}$ \\
\hline NCTB & National Curriculum and Textbook Board \\
\hline $\mathrm{PC}$ & Population Council \\
\hline PSTC & Population Services and Training Center \\
\hline $\mathrm{PNC}$ & Postnatal Care \\
\hline RH & Reproductive Health \\
\hline RTI & Reproductive Tract Infection \\
\hline STD & Sexually Transmitted Disease \\
\hline STI & Sexually Transmitted Infection \\
\hline SD & Standard Deviation \\
\hline $\mathrm{TT}$ & Tetanus Toxoid \\
\hline TREE & Theatre for Research Education and Empowerment \\
\hline UPGMS & Unnata Paribar Gathan Mohila Sangostha \\
\hline UFHP & Urban Family Health Partnership \\
\hline USAID & United States Agency for International Development \\
\hline UNICEF & United Nations Children's Fund \\
\hline UNFPA & United Nations Population Fund \\
\hline USA & United States of America \\
\hline UK & United Kingdom \\
\hline
\end{tabular}




\section{ACKNOWLEDGEMENTS}

This report is the product of an operations research project conducted over a three-year period. As such, it involves a large number of individuals and organizations who helped at different stages of the project.

Firstly, we express our gratitude to the sponsor of the project, the United States Agency for International Development (USAID). Without their financial support and understanding on the emerging issue of adolescent reproductive health the study would not have become a reality.

We would like to express appreciation to our project partners, the Urban Family Health Partnership, Kanchan Samity, Ananya Samaj Kallyan Sangostha and Unnata Paribar Gathan Mohila Sangostha. Their support and cooperation have been crucial in carrying out the research project. The twenty-four schoolteachers along with facilitators and peer educators as well as adolescents, parents and community leaders from the project areas deserve our sincere thanks. We also would like to offer our thanks to Theatre for Research Education and Empowerment for helping the adolescents in performing the theatrical show, Population Services and Training Center for conducting training of teachers and facilitators, and Associates for Community and Population Research for conducting surveys. We are grateful to Dr. Mazharul Islam and Mr. Nitai Chakrabarty of Dhaka University for their technical assistance at different stages of the project. The field interviewers who so skillfully collected sensitive data from assuredly benefited the report.

For making valuable recommendations and suggestions in our dissemination seminars, we are especially grateful to Dr. Khandaker Mosharraf Hossain, the honorable Minister, Ministry of Health and Family Welfare, Government of the People's Republic of Bangladesh, Prof. Mohammad Junaid, Director General, Directorate of Secondary and Higher Education, Ministry of Education, Mr. Waliur Rahman, Director General, Department of Youth Development, Ministry of Youth and Sports, Professor Gulnahar Zaman, member, National Curriculum and Textbook Board, Dr. Mizanur Rahman, MIS/M\&E Advisor, NGO Service Delivery Program, Mr. Faruque Ahmed, Director Health and Nutrition Program, BRAC and all the participants from different bilateral agencies, research organizations and national NGOs.

We are highly indebted to Dr. Nancy Williamson, former coordinator of Global Operations Research who helped the project staff a great deal by giving inputs in the initial stage of the project, Dr. Zareen Khair, Program Management Specialist, USAID, Dhaka for her help in launching the project, Dr. Sarah Harbison, CTO, USAID Washington DC, USA for her valuable suggestions while visiting the project site, and $D r$. Emelita Wong of Family Health International, North Carolina, for helping in data analysis. Last but not the least, we are grateful to all Population Council staff for their technical and logistic support. 


\section{BACKGROUND}

A multi-country operations research study investigating the combined effectiveness of a set of interventions designed to improve adolescent reproductive health (RH) knowledge, attitude and practices was launched in 1999. This study was conducted concurrently in Bangladesh, Kenya, Mexico and Senegal. The principal elements of the project were established through a consultative process that included several of the principal agencies, donors, research organizations and individuals working in the field of adolescent health care internationally. Because of the study's multi-country nature, there was a degree of standardization built into its design. However, the overall design of the interventions also conformed to local conditions, and was most relevant to adolescents living in the communities where the studies were conducted.

In Bangladesh the Urban Family Health Partnership (UFHP), a USAID funded activity, and its three NGO partners working in urban sites in Dinajpur, Pabna and Rangpur implemented the project in collaboration with Population Council. This report presents the findings of the project carried out in Bangladesh.

\section{STATEMENT OF THE PROBLEM}

Adolescents constitute one-fourth of the total population (133 million) of Bangladesh. The overall adult literacy rate is 41 percent (Mahbub ul Haq Human Development Centre 2002). For secondary school the net enrollment ratio of girls is 51 percent while it is 49 percent for boys (Bangladesh Bureau of Educational Information and Statistics 2001). Early marriage, especially among females, is highly prevalent in Bangladesh. There are more than 2.5 million married adolescents in Bangladesh (NIPORT, Mitra Associates and 
ORC Macro 2001). Seventy-eight percent of adolescent girls marry before reaching age 18 (NIPORT, Mitra Associates and ORC Macro 2001). Adolescent fertility is 144 births per 1000 women below age 20 and one-fifth of adolescent mothers have little knowledge about life-threatening conditions during pregnancy; 60 percent receive no antenatal care (NIPORT, Mitra Associates and ORC Macro 2001). Ninety-two percent of mothers aged less than 20 years deliver at home and the unmet need for contraception among this group is 27 percent (NIPORT, Mitra Associates and ORC Macro 2001).

A large majority of adolescents (both married and unmarried) do not have information on sexuality, contraception, or STIs and HIV/AIDS (Barkat et al. 2000; Nahar et al. 1999; Haider et al. 1997). Nevertheless, RH education has not been a part of the education curriculum, and the existing service delivery system is not catering to the needs of unmarried adolescents. The family structure in Bangladesh is still very strong and plays a major role in the lives of adolescents providing support, love and care, but fails to respond to the need for reproductive health of adolescents. Hence, adolescents typically have unmet needs for reproductive health information and services but their reproductive health needs (especially for the unmarried ones) do not draw the attention of parents, schools or the existing health care systems.

Bangladesh continues to have low HIV prevalence combined with the highest documented risk behaviors in Asia: low condom use, high turnover of clients of sex workers, low knowledge regarding HIV/AIDS, and extensive needle and syringe sharing by injecting drug users (National AIDS/STD Programme, Bangladesh 2003). As a result, sexually transmitted infection (STI) prevalence rates among commercial sex workers 
(National AIDS/STD Programme, Bangladesh 2003) and hepatitis C prevalence rates in injecting drug users (Azim et al. 2002) are high.

Pre-marital sex is traditionally taboo in Bangladesh for variety of social, religious and cultural reasons. In the past little attention has been given to the sexual behavior of unmarried adolescents in Bangladesh, but the shift towards the HIV/AIDS arena makes it important to explore the risks associated with all sexual behavior. Rising trends in risk behavior are seen among adolescents, including those engaging in sex, suffering from STIs, and having sex with commercial sex workers, in addition to having limited knowledge regarding HIV/AIDS and limited access to RH services (Barkat et al. 2000; Nahar et al. 1999; Haider et al. 1997). Furthermore, some adolescents are also involved in the sex trade (National AIDS/STD Programme, Bangladesh 2003), taking drugs (Panda et al. 2002), and migrating to other countries where they are exposed to risky situations (Chowdhury, Choudhury, and Lazzari 1995). In the 2002 HIV sentinel surveillance, more than 55 percent of STI patients sampled were below 24 years of age (National AIDS/STD Programme, Bangladesh 2002).

The effects of globalization, rising age at marriage, rapid urbanization and greater opportunities for socialization in Bangladesh have heightened the risk of STIs, HIV/AIDS, and unwanted pregnancy. Therefore, to avoid the social consequences of unplanned pregnancy, transmission of STIs and HIV/AIDS, adolescents need to be aware of their reproductive health. However, cultural and programmatic barriers inhibit the provision of $\mathrm{RH}$ information and services to adolescents. Considering the vulnerable situation of adolescents as a part of the multi-country study, an operations research 
project was launched in northwestern part of Bangladesh with an aim to prevent adverse outcomes and promote a positive lifestyle.

\section{OBJECTIVES AND HYPOTHESES}

\section{Objectives}

The overall objective of this study was to determine the feasibility and effectiveness of a systematic intervention to foster a supportive environment to address the problems faced by adolescents aged 13-19 years by making existing health services more accessible to them and providing them with $\mathrm{RH}$ education that will enable them to manage their reproductive health.

The specific objectives of the operations research were to:

- Improve RH of adolescents by providing information and adolescent-friendly services to out-of-school and in-school adolescents

- Improve RH knowledge and attitudes, reduce risky sexual behavior among sexually active adolescents, and increase utilization of RH services for both married and unmarried adolescents

- Assess the effect of an adolescent RH education intervention on adolescent RH knowledge, attitudes and behavior including utilization of RH services

- Determine whether there is an additional contribution from a school-based intervention on adolescent $\mathrm{RH}$ knowledge and attitudes, and utilization of $\mathrm{RH}$ services

- Determine the incremental cost of the intervention for replication in other areas

\section{Hypotheses}

- Study Sites A and B will show greater improvement in the environment for adolescent RH programs than Site C.

- Study Sites A and B will show greater improvement in adolescent-friendly services than Site $\mathrm{C}$ and greater utilization of services by adolescents.

- Study Site B will show greater improvement in school-based RH education than Site $\mathrm{A}$ and $\mathrm{C}$, and greater improvement in $\mathrm{RH}$ knowledge, attitudes and behaviors by adolescents.

- Overall, Site B will show the most improvement in RH knowledge, attitudes and behavior of adolescents with Site A next and Site C last. 


\section{METHODOLOGY}

\section{Study design}

A quasi-experimental design with two experimental strategies and a control site using pre- and post-intervention measurements was used to test the hypotheses.

$\begin{array}{llllll}\text { Experimental strategy I } & \text { Pabna } & \text { (Site A) } & \mathbf{O}_{1} & \mathbf{X}_{1} & \mathbf{O}_{2} \\ \text { Experimental strategy II } & \text { Dinajpur } & \text { (Site B) } & \mathbf{O}_{3} & \mathbf{X}_{2} & \mathbf{O}_{4} \\ \text { Comparison strategy } & \text { Rangpur } & \text { (Site C) } & \mathbf{O}_{5} & & \mathbf{O}_{6}\end{array}$

Where: $\mathrm{X}_{1}$ is the strategy to provide $\mathrm{RH}$ education to out-of-school adolescents along with community support activities and adolescent-friendly health care facilities and providers. $\mathrm{X}_{2}$ is the strategy to provide $\mathrm{RH}$ education to out-of-school adolescents along with community support activities and adolescent-friendly health facilities and providers, as well as school-based reproductive health education. $\mathrm{O}_{1}, \mathrm{O}_{3}$ and $\mathrm{O}_{5}$ are pre-intervention measurements of the key variables while $\mathrm{O}_{2}, \mathrm{O}_{4}$ and $\mathrm{O}_{6}$ are post-intervention measurements. The pre- and post-tests include population-based surveys of approximately 6,000 adolescents, one from each eligible household, and one-half of their parents to measure changes in key outcome indicators.

The interventions were implemented in three urban sites where the partner NGOs of UFHP were delivering health services, and in three phases for a period of three years. Phase I was a diagnostic period to understand the prevailing adolescent reproductive health issues in the local socio-economic and cultural context for designing appropriate interventions. For this purpose Focus Group Discussions (FGDs) among gatekeepers and population-based baseline surveys among adolescents and parents were carried out. The second phase consisted of implementing the intervention strategies, and the third phase 
comprised a post-intervention qualitative study and endline population-based surveys among both adolescents and parents.

\section{Selection of the study sites}

The criteria for selecting three study sites were developed by considering categories of clinics functioning in communities: Category A (municipality clinics), Category B (district headquarter clinics) and Category $\mathrm{C}$ (other urban clinics). For this study, category B clinics were chosen from three different districts in the same geographic region, so that the socio-cultural characteristics of the study population would be similar. The staff structure of a B type clinic includes one clinic manager (medical doctor) for overall management, one to two medical doctors who deliver services, two to three paramedics and one counselor. One paramedic by rotation serves at the static clinic while others go to satellite units in the community. The three UFHP participating NGOs were Ananya Samaj Kallyan Sangostha (ASKS) in Pabna, Kanchan Samity (KaS) in Dinajpur and Unnata Paribar Gathan Mohila Sangostha (UPGMS) in Rangpur. Depending on the population size served by these clinics, either part or all of the clinic catchment area with populations of approximately 60,000 were study sites. The intervention areas were noncontiguous and largely urban.

\section{Map and description of the study sites}

\section{Site $A$}

Pabna was selected to be Site A and received community RH education along with community support activities and adolescent-friendly services at the clinic. Site A is 300 $\mathrm{km}$ away from Dhaka and from Site B, and $200 \mathrm{~km}$ from Site C. 
Figure 1 Location of the study sites

This site is located in the transit route of illegal drugs that come from India.

\section{Site B}

Dinajpur was selected to be Site B and received the community $\mathrm{RH}$ education program along with community support activities, the school-based RH education

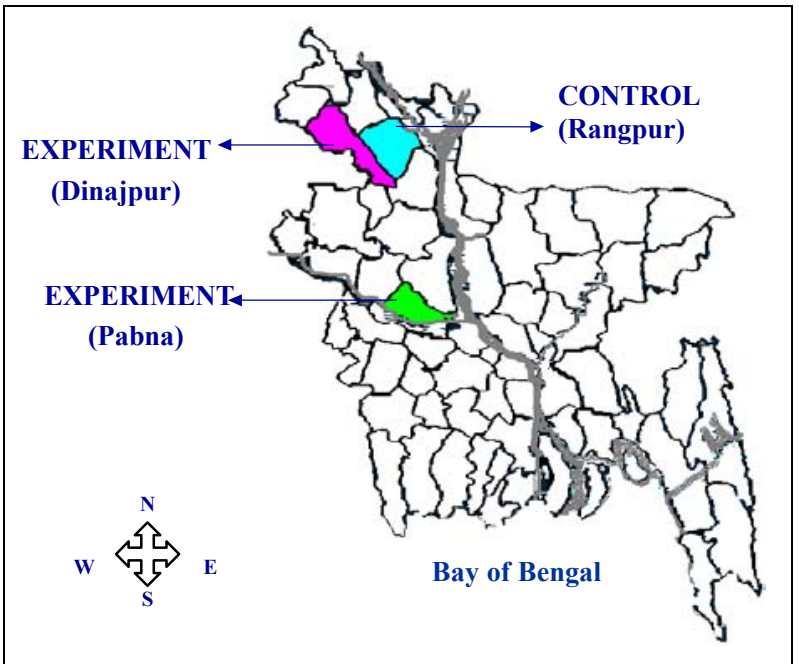
program, and adolescent-friendly services at the clinic. Site B is situated in the extreme northwest of Bangladesh and is roughly $600 \mathrm{~km}$ away from the capital city, and nearly $300 \mathrm{~km}$ from Site A. Although it appears contiguous, Site B is also $100 \mathrm{~km}$ from the control site. Site $\mathrm{B}$ is a closed community with a proportionately smaller migrant population in comparison to Site $\mathrm{C}$ and Site $\mathrm{A}$.

\section{Site C}

Rangpur, selected as Site $\mathrm{C}$, served as the control area and received no special intervention. Site C is situated closer to Site B than Site A.

\section{Household enumeration survey}

A household enumeration survey was conducted to collect information from the households needed to prepare the sampling frame for conducting surveys as well as for subsequent interventions (Table 1). 
Table 1 Distribution of adolescent boys aged 10-19 year by site, age group and school status during the enumeration survey in 2000

\begin{tabular}{|c|c|c|c|c|c|c|}
\hline \multirow[t]{2}{*}{$\begin{array}{l}\text { Site/ Age } \\
\text { group }\end{array}$} & \multicolumn{3}{|c|}{$\begin{array}{l}\text { Total eligible adolescents excluding } \\
\text { domestic help/temporary residents }\end{array}$} & \multicolumn{3}{|c|}{$\begin{array}{l}\text { Total eligible adolescents who are } \\
\text { domestic help/temporary residents }\end{array}$} \\
\hline & In-school & $\begin{array}{l}\text { Out-of- } \\
\text { school }\end{array}$ & Total & In-school & $\begin{array}{l}\text { Out-of- } \\
\text { school }\end{array}$ & Total \\
\hline \multicolumn{7}{|l|}{ Site A } \\
\hline 10 & 791 & 158 & 949 & 6 & 9 & 15 \\
\hline $11-12$ & 1,211 & 399 & 1,610 & 6 & 17 & 23 \\
\hline $13-17$ & 2,211 & 1,681 & 3,892 & 35 & 57 & 92 \\
\hline $18-19$ & 734 & 813 & 1,547 & 44 & 38 & 82 \\
\hline Subtotal & 4,947 & 3,051 & 7,998 & 91 & 121 & 212 \\
\hline \multicolumn{7}{|l|}{ Site B } \\
\hline 10 & 722 & 167 & 889 & 7 & 15 & 22 \\
\hline $11-12$ & 1,125 & 324 & 1,449 & 21 & 39 & 60 \\
\hline $13-17$ & 2,188 & 1,144 & 3,332 & 50 & 79 & 129 \\
\hline $18-19$ & 694 & 494 & 1,188 & 37 & 27 & 64 \\
\hline Subtotal & 4,729 & 2,129 & 6,858 & 115 & 160 & 275 \\
\hline \multicolumn{7}{|l|}{ Site C } \\
\hline 10 & 835 & 181 & 1,016 & 6 & 41 & 47 \\
\hline $11-12$ & 1,341 & 410 & 1,751 & 17 & 93 & 110 \\
\hline $13-17$ & 2,483 & 1,388 & 3,871 & 50 & 197 & 247 \\
\hline $18-19$ & 767 & 651 & 1,418 & 39 & 62 & 101 \\
\hline $\begin{array}{l}\text { Subtotal } \\
\text { Total }\end{array}$ & $\begin{array}{r}5,426 \\
15,102 \\
\end{array}$ & $\begin{array}{l}2,630 \\
7,810\end{array}$ & $\begin{array}{r}8,056 \\
22,912 \\
\end{array}$ & $\begin{array}{l}112 \\
318\end{array}$ & $\begin{array}{l}393 \\
674\end{array}$ & $\begin{array}{l}505 \\
992\end{array}$ \\
\hline
\end{tabular}

Complete counts of the households were done and socio-demographic characteristics of household members were recorded. The survey identified a total of 42,760 dwelling units: 14,784 in Site A, 12,886 in Site B and 15,090 in Site C. Of the identified households, 9,485 in Site A, 8,088 in Site B, and 9,709 in Site C had at least one adolescent aged 10-19 years (not shown). The total number of adolescents aged 10-19 years of both sexes in the study areas was 49,956 , including 11 percent domestic help and temporary residents. The total comprised 48 percent boys and 52 percent girls; 66 percent were in school and 34 percent were not (Tables 1 and 2). 
Table 2 Distribution of adolescent girls aged 10-19 by site, age group and school status during enumeration survey in 2000

\begin{tabular}{|c|c|c|c|c|c|c|}
\hline \multirow[t]{2}{*}{$\begin{array}{l}\text { Site/ Age } \\
\text { group }\end{array}$} & \multicolumn{3}{|c|}{$\begin{array}{l}\text { Total eligible adolescents excluding } \\
\text { domestic help/temporary residents }\end{array}$} & \multicolumn{3}{|c|}{$\begin{array}{l}\text { Total eligible adolescents who are } \\
\text { domestic help/temporary residents }\end{array}$} \\
\hline & In-school & $\begin{array}{l}\text { Out-of- } \\
\text { school }\end{array}$ & Total & In-school & $\begin{array}{l}\text { Out-of- } \\
\text { school }\end{array}$ & Total \\
\hline \multicolumn{7}{|l|}{ Site A } \\
\hline 10 & 853 & 68 & 921 & 9 & 90 & 99 \\
\hline $11-12$ & 1,445 & 140 & 1,585 & 16 & 180 & 196 \\
\hline $13-17$ & 2,866 & 867 & 3,733 & 47 & 407 & 454 \\
\hline $18-19$ & 758 & 563 & 1,321 & 33 & 411 & 444 \\
\hline Subtotal & 5,922 & 1,638 & 7,560 & 105 & 1,088 & 1,193 \\
\hline \multicolumn{7}{|l|}{ Site B } \\
\hline 10 & 724 & 124 & 848 & 9 & 146 & 155 \\
\hline $11-12$ & 1,194 & 166 & 1,360 & 29 & 211 & 240 \\
\hline $13-17$ & 2,446 & 627 & 3,073 & 63 & 451 & 514 \\
\hline $18-19$ & 708 & 370 & 1,078 & 40 & 310 & 350 \\
\hline Subtotal & 5,072 & 1,287 & 6,359 & 141 & 1118 & 1,259 \\
\hline \multicolumn{7}{|l|}{ Site C } \\
\hline 10 & 846 & 80 & 926 & 32 & 283 & 315 \\
\hline $11-12$ & 1,423 & 164 & 1,587 & 39 & 465 & 504 \\
\hline $13-17$ & 3,164 & 614 & 3,778 & 92 & 720 & 812 \\
\hline $18-19$ & 872 & 384 & 1,256 & 59 & 444 & 503 \\
\hline Subtotal & 6,305 & 1,242 & 7,547 & 222 & 1,912 & 2,134 \\
\hline Total & 17,299 & 4,167 & 21,466 & 468 & 4,118 & 4,586 \\
\hline
\end{tabular}

\section{Sampling design}

The sample size needed was estimated to be nearly 3,000 adolescents aged 13-19 years for each of the surveys. The total study sample was equally distributed by site, i.e., 1,000 respondents per site, and by sex (male or female) and school status (in-school or out-ofschool) for a sub-total of 250 respondents per subgroup.

As depicted in Table 3, during the baseline survey a total of 3,959 adolescents aged 13-19 years were selected for interviews anticipating a 30 percent non-response rate, and 2,971 were successfully interviewed. The response rate was 75 percent. The non-response rate was higher among out-of-school adolescents (Table 3). The reasons for non-response 
were migration ( 8 percent), refusal to give an interview ( 7 percent), age misreporting (6 percent) and non-availability of subjects after three attempts (4 percent) (not shown). Simultaneously parents of every second adolescent who was successfully interviewed were also interviewed. The fathers of male adolescents and mothers of female adolescent respondents were interviewed. A total of 1,612 parents were selected for the survey and 1,531 were successfully interviewed. The response rate was 95 percent (Table 3). The reasons for non-response were migration ( 3 percent) and refusal to give an interview ( 2 percent) (not shown).

During the endline survey the same sample size allocation was used. The sample selection in the endline survey was designed to cover 25 percent of the adolescents from the baseline survey on the basis of the same sampling frame prepared during the baseline. As the sampling frame was two years old, an operational frame for the target group (1319 years) was prepared by excluding those aged 18-19 years during the baseline survey. Similarly, adolescents who were 11-12 years old during the baseline survey were included in the sample frame. Sampling in the endline survey was designed assuming a non-response rate of 30 percent for the in-school adolescents and 40 percent for out-ofschool adolescents. 
Table 3 Adolescents and parents interviewed in baseline and endline surveys

\begin{tabular}{|c|c|c|c|c|c|c|}
\hline & \multicolumn{2}{|c|}{ Selected } & \multicolumn{2}{|c|}{ Successfully interviewed } & \multicolumn{2}{|c|}{ Non-response rate } \\
\hline & $\begin{array}{l}\text { Baseline } \\
\text { Number }\end{array}$ & $\begin{array}{l}\text { Endline } \\
\text { Number }\end{array}$ & $\begin{array}{l}\text { Baseline } \\
\text { Number }\end{array}$ & $\begin{array}{l}\text { Endline } \\
\text { Number }\end{array}$ & $\begin{array}{l}\text { Baseline } \\
\text { Percent }\end{array}$ & $\begin{array}{l}\text { Endline } \\
\text { Percent }\end{array}$ \\
\hline \multicolumn{7}{|c|}{ ADOLESCENTS } \\
\hline Site A & & & & & & \\
\hline $\begin{array}{l}\text { In-school } \\
\text { Boy } \\
\text { Girl }\end{array}$ & $\begin{array}{l}317 \\
300\end{array}$ & $\begin{array}{l}342 \\
350\end{array}$ & $\begin{array}{l}242 \\
240\end{array}$ & $\begin{array}{l}258 \\
259\end{array}$ & $\begin{array}{l}23.7 \\
20.0\end{array}$ & $\begin{array}{l}24.6 \\
26.0\end{array}$ \\
\hline $\begin{array}{l}\text { Out-of scho } \\
\text { Boy } \\
\text { Girl }\end{array}$ & $\begin{array}{l}324 \\
314\end{array}$ & $\begin{array}{l}372 \\
377\end{array}$ & $\begin{array}{l}244 \\
247\end{array}$ & $\begin{array}{l}256 \\
243\end{array}$ & $\begin{array}{l}24.7 \\
21.3\end{array}$ & $\begin{array}{l}31.2 \\
35.5\end{array}$ \\
\hline $\begin{array}{l}\text { Sub-total } \\
\text { Site B }\end{array}$ & 1,255 & 1,441 & 973 & 1,016 & 22.5 & 29.5 \\
\hline $\begin{array}{l}\text { In-school } \\
\text { Boy } \\
\text { Girl }\end{array}$ & $\begin{array}{l}322 \\
318\end{array}$ & $\begin{array}{l}394 \\
375\end{array}$ & $\begin{array}{l}236 \\
254\end{array}$ & $\begin{array}{l}259 \\
264\end{array}$ & $\begin{array}{l}26.7 \\
20.1\end{array}$ & $\begin{array}{l}34.3 \\
29.6\end{array}$ \\
\hline $\begin{array}{l}\text { Out-of scho } \\
\text { Boy } \\
\text { Girl }\end{array}$ & $\begin{array}{l}381 \\
358\end{array}$ & $\begin{array}{l}414 \\
444\end{array}$ & $\begin{array}{l}251 \\
251\end{array}$ & $\begin{array}{l}261 \\
260\end{array}$ & $\begin{array}{l}34.1 \\
29.9\end{array}$ & $\begin{array}{l}37.0 \\
41.4\end{array}$ \\
\hline $\begin{array}{l}\text { Sub-total } \\
\text { Site C }\end{array}$ & 1,379 & 1,627 & 992 & 1,044 & 28.1 & 36.0 \\
\hline $\begin{array}{l}\text { In-school } \\
\text { Boy } \\
\text { Girl }\end{array}$ & $\begin{array}{l}329 \\
321\end{array}$ & $\begin{array}{l}358 \\
418\end{array}$ & $\begin{array}{l}255 \\
258\end{array}$ & $\begin{array}{l}260 \\
262\end{array}$ & $\begin{array}{l}22.5 \\
19.6\end{array}$ & $\begin{array}{l}27.4 \\
37.3\end{array}$ \\
\hline $\begin{array}{l}\text { Out-of scho } \\
\text { Boy } \\
\text { Girl }\end{array}$ & $\begin{array}{l}331 \\
344\end{array}$ & $\begin{array}{l}413 \\
452\end{array}$ & $\begin{array}{l}248 \\
245\end{array}$ & $\begin{array}{l}261 \\
259\end{array}$ & $\begin{array}{l}25.1 \\
28.8\end{array}$ & $\begin{array}{l}36.8 \\
42.7\end{array}$ \\
\hline Sub-total & 1,325 & 1,641 & 1,006 & 1,042 & 24.1 & 36.5 \\
\hline Grand total & 3,959 & 4,709 & 2,971 & 3,102 & 25.0 & 34.1 \\
\hline $\begin{array}{l}\text { PARENTS } \\
\text { Father } \\
\text { Mother }\end{array}$ & $\begin{array}{l}813 \\
799\end{array}$ & $\begin{array}{r}1002 \\
925\end{array}$ & $\begin{array}{l}766 \\
765\end{array}$ & $\begin{array}{l}792 \\
786\end{array}$ & $\begin{array}{l}5.8 \\
4.3\end{array}$ & $\begin{array}{l}21.0 \\
15.0\end{array}$ \\
\hline Total & 1,612 & 1,927 & 1,531 & 1,578 & 5.0 & 18.1 \\
\hline
\end{tabular}

However, for both subgroups the non-response rate was found to be higher largely due to migration (20 percent), which includes marriage-related migration among adolescent girls, education and job-related migration among male adolescents, and other migration (not shown). As a result, an additional sample was drawn from the same frame excluding 
those who had been selected for interview previously. A total of 4,709 adolescents were selected for the endline survey; of them 3,102 were successfully interviewed giving a response rate of 66 percent. A parents' survey was conducted using the same methodology as the baseline survey. A total of 1,927 parents were selected for the survey, and 1,578 were successfully interviewed (response rate of 82 percent) (Table 3). The higher non-response rate was due to migration (11 percent) (not shown).

\section{Independent variables}

Site, time and site by time interactions are the main independent variables used in the analysis. The characteristics of study participants, i.e. age, sex, years of schooling, marital status and ever worked for pay specified as covariates in the multivariate analyses were also independent variables.

\section{Dependent variables}

The dependent variables included exposure to intervention; knowledge, attitude and behavior change on RH issues; and utilization of clinical services. Specific knowledge, attitudes and behaviors that comprise the set of dependent variables include:

\section{Knowledge}

- Has correct knowledge of at least three modes of transmission of HIV/AIDS

- Knows at least two modern contraceptive methods

- Has correct knowledge of fertile period

- Knows at least three potential health risks of early pregnancy

\section{Attitude}

- Agrees with use of contraceptives by unmarried adolescents

- Agrees with use of contraceptives by married adolescents

- Agrees with use of condom by unmarried sexually active adolescents for preventing pregnancy 
- Agrees with use of condom by unmarried sexually active adolescents to prevent infections

- Supports RH education in school

- Has favorable view towards contraceptive services from a health/ family planning clinic

- Suggests condom as a good method for adolescents

- Has favorable view towards contraceptive services from a pharmacy

- Has favorable view towards STI services from a health/ family planning clinic

- Has favorable view towards STI services from a pharmacy

\section{Behavior}

- Unmarried male adolescents used condom in last sexual intercourse

As the 'intervention' was not directly applied to the study participants but rather to the geographic areas where the target audiences reside, it is important that exposure to the intervention be measured among the young adults, and hence in some analysis, exposure to the intervention is a dependent variable. Because not all of the target audience may have been exposed to the intervention, it is also important to assess levels of outcomes by self-report of exposure. Thus, in some analyses of Sites A and B, self-report of exposure to RH education is an independent variable.

\section{Data collection}

As the study is a multi-country effort, similar questionnaires were used for data collection with some local modifications. The questionnaires were designed so that changes in the key outcome indicators can be measured by comparing data collected in the baseline with the endline survey. In Bangladesh, questionnaires were first developed in Bangla, pretested and finalized, and administered in Bangla to study participants. The final version was translated into English. 
Three, nine-member data collection teams carried out the data collection in both the baseline and endline surveys. Data collection teams consisted of one male supervisor, one female field editor, three male interviewers, three female interviewers and a local facilitator for household identification. One team was assigned to data collection in each study site. Prior to deploying the teams, two weeks of extensive theoretical and practical training were undertaken. To check the quality of the data collection, the Population Council posted one Research Assistant in each site. In addition, a team composed of two senior personnel from Population Council, the local survey firm, and Dhaka University closely monitored the process and visited the data collection sites several times. Prior to interviewing adolescents and parents, informed consent was obtained from the respondents. The baseline data collection was done during the period of February to April 2000, while the endline data collection was done during April to June 2002.

\section{Data analysis}

Data weighting was done by site and weighted analyses are reported taking into account the different sampling probabilities and different response rates by sex, age groups, and in-school status within each site. Both bivariate and multivariate quantitative analyses were done. The first set of bivariate analyses compares the characteristics of study participants by site and survey period (Tables 10 to 12). The second set of bivariate analyses compares baseline and endline levels of self-report of exposure to intervention, knowledge, attitudes and practices within sites, and between the intervention and control sites. The multivariate analyses were conducted in four sets: the first set of models compares the level of outcomes by survey period within each site while adjusting for the following background characteristics: number of years of schooling, sex, age, marital 
status, and experience working for pay. The second set of models compares the changes in outcomes over time in the intervention sites (Pabna and Dinajpur) with the changes in outcomes over time in the control site (Rangpur), while controlling for the background characteristics of study participants enumerated above. The third set of multivariate analyses compare attitudes of study participants at endline by self-report of exposure to RH education, separately in the intervention sites (Pabna and Dinajpur) but not in the control site, while controlling for the above background characteristics. The fourth set of models compares the attitudes of study participants by the experimental sites (Dinajpur compared to Pabna) among those who self-reported exposure to RH education.

For the first two sets of multivariate models, unadjusted estimates were also obtained. In the unadjusted comparison of outcomes by time period, only time was included as an explanatory variable while in the unadjusted comparison of changes over time in the intervention sites compared to changes over time in the control group, site, time and site by time interactions were the explanatory variables. In the adjusted models, the covariates listed above were included in the models in addition to time, site or time by site interaction variables.

Qualitative data were collected through focus group discussions (FGDs) and in-depth interviews. A total of 12 FGDs, each consisting of eight to ten participants were conducted separately with parents, teachers, religious leaders and community leaders in Sites A and B before the interventions began. The major topics covered in the FGDs included RH information needs, introducing RH topics in a school curriculum and adolescent RH service needs. Thematic analysis was done and the findings used in 
conducting sensitization meetings. Thirty-one in-depth interviews were carried out among adolescents (16 boys and 15 girls) across the intervention and control areas to obtain insights about sensitive topics such as sexual exposure, condom use, and drug use in order to complement the quantitative survey.

\section{Limitations of the study}

The study targeted adolescents aged 13-19 years from three pre-selected urban areas located in the northwestern region of the country. Therefore, the findings cannot be generalized as indicative of the overall situation of Bangladesh. Moreover, due to the sensitivity of the issue, some respondents may not have revealed their true sexual behavior, resulting in an incomplete picture. However, we feel comfortable that the levels reported are of a relative magnitude that can be trusted.

In relation to intervention exposure, there are three major limitations. First, considering the school intervention, 20 to 25 percent of adolescents usually attend schools located outside the study area, while similar proportions of adolescents living outside the study area attend the schools within the study area. Thus, some adolescents who may have been exposed to the intervention may live outside the survey catchment area, and may not have been interviewed; some of those interviewed may attend school some distance away and may not have been exposed to the interventions. In addition, though the target age was 13-19 years for the community intervention, in the case of the school intervention it was not feasible to address adolescents of similar age. Adolescents aged 13-16 attend high schools while those aged 17-19 years attend colleges. The institutions have different settings, and it was not possible to cover both within the available study time frame. 
Emphasis was placed on adolescents 13-16 years old in classes VII-X. Subsequently, school management committees disallowed the inclusion of students of class VII aged 13 for fear of negative repercussions from parents, and those in class $\mathrm{X}$ aged 16 due to the approach of final examinations. Therefore, only students aged 14 years in class VIII and those aged 15 years in class IX received the intervention. Of the 10 schools located in Site B, two did not participate in the project. The total number of students in the targeted age group from non-participating schools was approximately 500. Thus, a large proportion of in-school adolescents who constituted the survey population were not exposed to the interventions at school. Conversely, three percent of school students who were exposed to intervention but were not usual residents in the intervention sites were excluded from the survey.

Second, the total number of out-of-school adolescents aged 13-19 years in the intervention areas (Site A and Site B) is 8339 , of which 1780 were excluded from the survey since they were domestic help and temporary residents (Tables 1 and 2). However, through the community interventions, a large proportion of these adolescents received $\mathrm{RH}$ education.

Third, the endline survey, which took place after an interval of two years, excluded adolescents who were 18-19 years old at the time of the baseline survey (29 percent of the sample) but who may have been exposed to the intervention, particularly in the community. Adolescents who were 11-12 during the baseline survey were included in the sample frame of endline survey. This group constituted 21 percent of the sample, but was not reached by the intervention program because at that time they were not part of 
the target group. For these reasons, exposure to RH education was found to be very low (8 percent for Site A and 30 percent for Site B) in the endline survey.

Moreover, the overall design of the project was meant to measure the impact of the diffusion of RH messages in the community at large. However, the 20-month time period of the intervention may not have been adequate to effectively diffuse the RH information. Finally, the control site could not be kept as a control in a true sense, due to other NGO activities creating further difficulties in measuring the effects of the intervention.

\section{DESCRIPTION OF INTERVENTIONS}

\section{Development and distribution of RH curriculum}

An adolescent reproductive health curriculum was developed with the active participation of teachers, program managers and adolescents. The topics of the curriculum were identified on the basis of findings of the FGDs and the baseline survey (Appendix 1). FGDs were conducted among teachers, religious leaders, community leaders and parents, while the baseline survey was carried out among adolescents and their parents. Once topics were selected, the five existing curricula available in Bangladesh were reviewed and a draft curriculum was developed that incorporated the following features:

- Making the curriculum socially acceptable: Bearing in mind the social and cultural perspective of Bangladesh society, day-to-day adolescent life events, risky behavior and the need for appropriate health care were explained in relation to the local context and values. The inclusion of neutral topics along with topics on consequences of STIs/HIV/AIDS and risky behavior further renders the curriculum socially acceptable.

- Making the curriculum lively: To maintain the attention of adolescents while providing sensitive information, the curriculum was enhanced with poems, stories, riddles and quizzes. The curriculum was designed so that every session begins with a poem, which portrayed the theme of the whole session. Adolescents normally recite 
or sing the words of the poem. This helps them remember highlights of the issues later. The text is intended to capture the interest of the students and stimulate further reading and learning. It is written in simple easy-to-read language. The whole text is narrated in story fashion, based on four main characters and their relation to friends and families. At the end of each session, a box shows an excerpt of a conversation between the main characters. Usually, the nature of the conversation follows two of the characters' reluctance to accept what they had been taught, while the other two comment on the benefits of what they have learned. This serves to reiterate and clarify important issues.

- Addressing the RH needs of both male and female adolescents: Research findings suggest that boys are more disadvantaged than girls in accessing reproductive health information. While girls obtain some basic information from their mothers, boys typically get no information from either parent. Findings indicate boys are also involved in risk taking behaviors. It was strongly felt that boys' RH concerns are equally as important as girls. Hence, the curriculum addresses issues relevant to both girls and boys.

- Enhancing the curriculum with didactic and participatory learning techniques: A didactic and participatory teaching technique was introduced in every session to help teachers make the sessions participatory and lively. Techniques included brainstorming, skits, question-answers, conversation and using note-slips. To save teachers' time every session included a session plan with time, process, methods and materials mentioned. In addition, at the beginning of the curriculum there are two chapters, one for teachers and one for adolescents, which instruct them on how to effectively use the curriculum.

- Introducing topics of priority: Changes during adolescence, sexual relations and sexual abuse, RTI/STI and HIV/AIDS, childbirth and family planning, prenatal and postnatal care, along with other equally important subjects like gender issues and drug abuse were selected to include in the curriculum.

Education experts, adolescents,

\begin{tabular}{|c|c|c|c|}
\hline \multirow{2}{*}{ program managers and health } & \multicolumn{3}{|c|}{ Table 4 Distribution of RH curriculum } \\
\hline & Recipients & Site A & Site B \\
\hline reviewed the & Teachers & - & 24 \\
\hline & Facilitators & 14 & 15 \\
\hline Adolescents & Peer educators (Community) & 39 & 40 \\
\hline \multirow{4}{*}{$\begin{array}{l}\text { teachers also provided input in } \\
\text { participatory workshops and group }\end{array}$} & Peer educators (School) & - & 44 \\
\hline & Service providers & 25 & 20 \\
\hline & School library & - & 80 \\
\hline & Total & 78 & 223 \\
\hline
\end{tabular}

meetings, which contributed to

making the curriculum acceptable to all. Twenty-four teachers implemented the curriculum in eight schools in Site B (Dinajpur) after receiving five days of training. For 
fine-tuning the curriculum, experts observed the RH sessions to assess whether teachers were comfortable delivering accurate $\mathrm{RH}$ information and following the sequence of the topics. Teachers then received refresher training to further strengthen their ability to teach sensitive issues. About 300 curricula were distributed in Site A and Site B (Table 4).

\section{Development and distribution of behavior change communication (BCC) materials}

One brochure on project activities and five leaflets, entitled "A few words on menstruation," "A few words on ejaculation/wet dreams," "A few words on RTI/STI," "Parents' responsibility towards adolescents," and "Availability of adolescent-friendly services" were developed by the project (Appendix 2). In addition to the brochure and leaflets, a poster

on adolescent- Table 5 Distribution of BCC materials

\begin{tabular}{|c|c|c|c|c|c|}
\hline friendly services & Recipients & Flip & nart & $\begin{array}{l}\text { Brochu } \\
\text { types o }\end{array}$ & $\begin{array}{l}\text { and } 5 \\
\text { eaflets }\end{array}$ \\
\hline \multirow{2}{*}{ and a flipchart on } & & Site A & Site B & Site A & Site B \\
\hline & Teachers & - & 24 & - & 144 \\
\hline \multirow{2}{*}{ adolescent } & Facilitators & 14 & 15 & 84 & 90 \\
\hline & Peer educators (community) & - & - & 195 & 200 \\
\hline \multirow[t]{2}{*}{ issues were also } & Peer educators (school) & - & - & - & 220 \\
\hline & Service providers & 6 & 6 & 150 & 120 \\
\hline \multirow[t]{2}{*}{ developed. About } & School library & - & - & - & 40 \\
\hline & Adolescents & - & - & - & 11,780 \\
\hline 100 posters were & Parents & - & - & 1200 & 1800 \\
\hline \multirow{2}{*}{ posted in public } & Gatekeepers \& clinic attendees & & & 750 & 1,200 \\
\hline & Total & 20 & 45 & 2,379 & 15,594 \\
\hline
\end{tabular}

places in each

site. The flipchart was distributed among teachers, facilitators and service providers.

They, as well as the peer educators, distributed the leaflets to parents and adolescents. 
Leaflets were also kept in the waiting spaces of the clinics for clients to take. Table 5 presents the distribution of $\mathrm{BCC}$ materials.

\section{Conducting sensitization meetings among gatekeepers}

Formal and informal sensitization meetings were conducted among gatekeepers about the $\mathrm{RH}$ needs of adolescents to foster a supportive environment allowing adolescents to receive RH information and services (Table 6). Gatekeepers included parents, teachers, community leaders, political leaders, religious leaders and service providers.

Meetings were organized formally

and informally, both in groups and

on a one-to-one basis. Before

forming adolescent groups for $\mathrm{RH}$

education, parents were sensitized
Table 6 Formal and informal sensitization meetings conducted among gatekeepers at community and schools

\begin{tabular}{lrrr}
\hline Site & Community & School & Total \\
\hline A & 270 & - & 270 \\
B & 193 & 25 & 218 \\
Total & $\mathbf{4 6 3}$ & $\mathbf{2 5}$ & $\mathbf{4 8 8}$ \\
\hline
\end{tabular}

about the RH needs of adolescents and were informed about the project.

At the school level, sensitization meetings were organized with headmasters, school

Box 1 FGD Findings: Gatekeepers recognize the need for RH education

- Parents approved providing RH information because it is difficult for them to discuss $\mathrm{RH}$ issues with their children.

- Parents opined RH information must be included in school and Madrasah curricula.

- Religious and community leaders believe that risktaking behavior will decrease if adolescents have correct RH information.

- Almost all the gatekeepers believed that RH information should be started from the eighth grade. management committees and teachers to discuss $\mathrm{RH}$ education and service needs of adolescents. The schools took the responsibility of sensitizing parents about the RH courses. Leaflets on “Parents' responsibilities towards adolescents" and "Availability of adolescent-friendly services" depicting 
the needs of adolescent $\mathrm{RH}$ information and services were distributed at the dissemination workshop and meetings. At the clinic level, all clinic staff was oriented on the RH service needs of adolescents and providing services from the existing structure in an adolescent friendly manner.

Sensitization was also done through disseminating the baseline survey and FGD findings, in particular among gatekeepers, with an emphasis on the vulnerable situation of adolescents globally, nationally and locally.

Figure 2 Parents' survey at baseline: FGD findings demonstrated that almost all the gatekeepers recognized the necessity of RH education (Box 1). The survey data confirmed that the majority of parents were supportive of $\mathrm{RH}$ education in schools Support for RH education in schools (\%) (Figure 2).

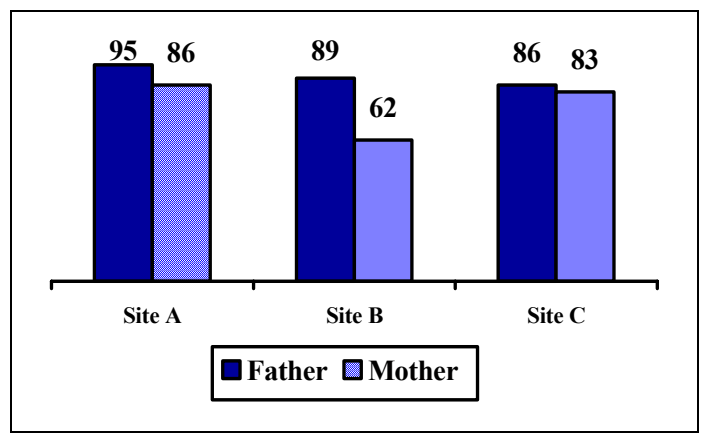

\section{Training on RH curriculum and adolescent friendly services}

Youth between 21 and 28 years with 14 years of schooling were recruited as "facilitators" to educate out-of-school adolescents aged 13-19 years on $\mathrm{RH}$ issues. There were 16 facilitators, four males and four females from each experimental site. Facilitators were trained on the RH curriculum for five days in July 2000 followed by a four-day refresher training five months later (due to high turnover of facilitators, a total of 29 were trained during the project period). Willing and enthusiastic teachers from eight secondary schools were selected and trained using the RH curriculum to conduct RH sessions among inschool adolescents of class VIII and IX. A total of 24 teachers (19 females and 5 males) 
were trained for four days in June 2000 on the RH curriculum followed by refresher training six months later. Peer educators, known as health ambassadors, were also engaged in the community as well as in the schools during the later part of the project period. They were trained in July-August 2001 on RH issues and adolescent friendly services offered by the clinics and were expected to provide RH messages to their peers (in-school and out-of-school adolescents, neighbors and relatives). Clinical service providers were trained in April 2000 on being welcoming, maintaining non-judgmental attitudes, and offering minimal waiting time, privacy, confidentiality and affordable services. At the same time non-clinical service providers of the clinics were oriented on adolescent RH service needs and friendly services. Regarding affordable services, adolescents who attended sessions received a health scheme card from the implementing agency that allowed them to consult a doctor free of charge for one year. Table 7 summarizes the types and number of trainees who received training on $\mathrm{RH}$ and adolescent friendly services.

Table 7 Training on RH curriculum and adolescent friendly services (AFS)

\begin{tabular}{|c|c|c|c|c|c|c|c|c|c|c|}
\hline \multirow{3}{*}{$\begin{array}{l}\text { Training } \\
\text { categories }\end{array}$} & \multicolumn{8}{|c|}{ RH curriculum } & \multirow{2}{*}{\multicolumn{2}{|c|}{$\begin{array}{c}\begin{array}{c}\text { AFS } \\
\text { services }\end{array} \\
\text { Service } \\
\text { providers }\end{array}$}} \\
\hline & \multicolumn{2}{|c|}{ Teachers } & \multicolumn{2}{|c|}{ Facilitators } & \multicolumn{2}{|c|}{$\begin{array}{l}\text { School peer } \\
\text { educators }\end{array}$} & \multicolumn{2}{|c|}{$\begin{array}{l}\text { Community } \\
\text { peer } \\
\text { educators }\end{array}$} & & \\
\hline & $\begin{array}{c}\text { Site } \\
\text { A }\end{array}$ & $\begin{array}{c}\text { Site } \\
\text { B }\end{array}$ & $\begin{array}{c}\text { Site } \\
\text { A }\end{array}$ & $\begin{array}{c}\text { Site } \\
\text { B }\end{array}$ & $\begin{array}{c}\text { Site } \\
\text { A }\end{array}$ & $\begin{array}{c}\text { Site } \\
\text { B }\end{array}$ & $\begin{array}{c}\text { Site } \\
\text { A }\end{array}$ & $\begin{array}{c}\text { Site } \\
\text { B }\end{array}$ & $\begin{array}{c}\text { Site } \\
\text { A }\end{array}$ & $\begin{array}{c}\text { Site } \\
\text { B }\end{array}$ \\
\hline \multirow{2}{*}{ No. of trainees } & - & 24 & 14 & 15 & - & 44 & 39 & 40 & 25 & 20 \\
\hline & \multicolumn{10}{|c|}{ Number of training programs } \\
\hline TOT on RH & - & 1 & 1 & 1 & - & 1 & 1 & 1 & 1 & 1 \\
\hline Refresher & - & 1 & 2 & 2 & - & - & - & - & 3 & 3 \\
\hline Total & & 2 & 3 & 3 & - & 1 & 1 & 1 & 4 & 4 \\
\hline
\end{tabular}




\section{Conducting RH sessions and providing adolescent friendly services}

The 17-session curriculum extended to 20 sessions for out-of-school adolescents while it was condensed to 15 sessions for in-school adolescents. In the community, each facilitator conducted at least one session per day for one hour, completing a total of 20 RH sessions in a month. They were also responsible for conducting sensitization meetings with parents and elders, organizing adolescent groups (10-15 adolescents per group) for the RH sessions and counseling adolescents if needed. Sessions took place over the duration of the project, from July 2000 to January 2002.

At the schools, students attended 15 participatory RH sessions. These sessions were conducted once a week spread over the whole year, allowing for school holidays, examinations, and teachers' strikes. Two rounds of sessions took place; the first round was from July 2000 to December 2000 while the second was from February 2001 to December 2001. To measure the impact of the RH sessions in schools, pre-test and posttest surveys were carried out among the participating students using a self-administered questionnaire. The findings suggest that knowledge of transmission of HIV/AIDS increased from 66 to 84 percent, RTI/STIs from 17 to 61 percent, human fertilization from 20 to 76 percent and FP methods from 3 to 35 percent (Rob et al. 2002).

Table 8 Reproductive Health sessions in community and schools

\begin{tabular}{|c|c|c|c|c|c|c|c|c|c|}
\hline \multirow{3}{*}{ Site } & \multicolumn{5}{|c|}{ Community } & \multicolumn{4}{|c|}{ School } \\
\hline & \multirow[t]{2}{*}{$\begin{array}{l}\text { No. of } \\
\text { groups }\end{array}$} & \multirow[t]{2}{*}{$\begin{array}{l}\text { No. of } \\
\text { sessions }\end{array}$} & \multicolumn{3}{|c|}{$\begin{array}{l}\text { No. of out-of-school } \\
\text { adolescents reached }\end{array}$} & \multirow[t]{2}{*}{$\begin{array}{l}\text { No. of } \\
\text { sessions }\end{array}$} & \multicolumn{3}{|c|}{$\begin{array}{l}\text { No. of in-school } \\
\text { adolescents reached }\end{array}$} \\
\hline & & & Boys & Girls & Total $^{*}$ & & Boys & Girls & Total $^{* *}$ \\
\hline A & 270 & 5,400 & 1,690 & 1,747 & 3,437 & - & - & - & - \\
\hline B & 193 & 3,860 & 975 & 1,590 & 2,565 & 645 & 533 & 1,823 & 2,356 \\
\hline Total & 463 & 9,260 & 2,665 & 3,337 & 6,002 & 645 & 533 & 1,823 & 2,356 \\
\hline
\end{tabular}

*Out-of-school adolescents included domestic helps and temporary residents.

** Total enrolled students in Classes VIII and IX. 
Table 8 presents the number of groups formed with adolescents for RH education, the number of sessions conducted and the number of in-school and out-of-school adolescents reached by the project. In the community, 72 percent of out-of-school adolescents were exposed to the intervention, including domestic help and temporary residents. Over 80 percent of students were exposed in to the school-based intervention. In both cases, not all adolescents were fully exposed, i.e. did not attend every session.

At the clinic level, the range of services provided was based on the government essential service package (ESP) which included family planning, RTI/STI (diagnosis and treatment), TT vaccination, antenatal and postnatal services, Figure 3 Linkages with school, community and health facility

as well as other $\mathrm{RH}$ services

related to pubertal events. These

services were provided to

adolescents from four static

clinics and 26 satellite clinics. In

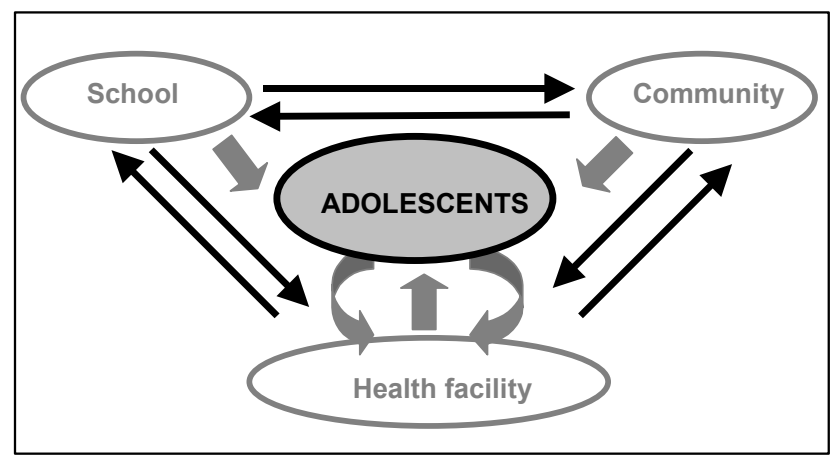

each site, two clinic staff, one male and one female, were assigned to monitor the activities of facilitators, teachers and peer educators (Rob et al. 2002). A linkage was established between clinic, school and community levels after implementing the RH education program both at the community and schools. Facilitators and teachers informed adolescents about the availability of clinical services during their RH sessions. They also referred out-of-school and in-school adolescents from the community and schools to the clinic when needed. The clinic staff visited the community and schools to monitor RH sessions and also informed adolescents about the availability of clinical services. In 
addition, peer educators from the community and school referred adolescents to the clinics. Moreover, the out-of-school adolescents received a physical tour of the clinics by the facilitators during their RH course. All these activities helped establish the linkages between community and clinic, and school and clinic. The linkage between community and schools were established mainly by peer educators' activities. Both the community and school peer educators worked together to organize theatrical shows and other activities to observe Worlds AIDS Day and Population Day. As a result of the education program and linkages, adolescents received support from school, community and clinics that ultimately resulted in creating an overall enabling environment for adolescents for seeking RH services at the clinics. They made a total of 4,729 visits for services. Detailed analysis of the data is given in the utilization of clinical service section.

\section{Provision of bulletin board, post box facility and telephone hotline}

A bulletin board and a post box were provided at each school. Peer educators were responsible for maintaining the bulletin board, where they posted poems, songs and news on RH issues. The students dropped anonymous letters in the post box seeking answers to questions on sensitive and personal RH issues. Either peer educators or teachers answered the questions. In the clinics, besides RH services and counseling, information was provided through a telephone hotline and publication of a question-answer section in local newspapers. Trained counselors managed the hotline at each clinic. A total of 320 phone calls were received in Site A. A post box was placed in front of each clinic, in which adolescents were asked to drop letters if they wanted to know more about any specific RH issue. Over 200 letters were received. These questions and the answers 
provided by counselors were regularly published in local newspapers to reach a wider group of adolescents.

\section{Peer educators' activities}

Forty-four peer educators (19 males and 25 females) were selected from the eight schools in Site B, while 79 (39 males and 40 females) were chosen from the community in Sites $\mathrm{A}$ and $\mathrm{B}$ on the basis of willingness, education and leadership capacity. Peer educators conducted sessions in groups or on a one-to-one basis and reported the number of adolescents reached in monthly meetings. Peer educators from the community and schools in Site B organized a cultural show where both in-school and out-of-school adolescents performed dramas and presented songs and poems on issues covered in their RH curriculum. Their activities also included observation of AIDS day and special days related to population and health issues, organizing drama groups and performing open stage or street drama in community and schools.

Table 9 RH sessions conducted and events organized by peer educators

\begin{tabular}{lccc}
\hline & $\begin{array}{c}\text { Site A } \\
\text { Community }\end{array}$ & Community & Site B \\
\hline Number of RH sessions & & & School \\
Boys & 499 & 128 & 236 \\
Girls & 470 & 624 & 296 \\
Total & $\mathbf{9 6 9}$ & $\mathbf{7 5 2}$ & $\mathbf{5 3 2}$ \\
Number of RH Events & & & \\
Quiz competition & 270 & 193 & 24 \\
Games & 14 & 96 & - \\
Drama & 1 & 1 & 5 \\
Cultural show* & - & 1 & \\
AlDS/Population Day* & 2 & 4 & $\mathbf{2 9}$ \\
Total & $\mathbf{2 8 7}$ & $\mathbf{2 9 5}$ & \\
\hline
\end{tabular}

* Both community and in-school adolescents took part in these occasions together in Site B. 


\section{STUDY AND TARGET POPULATION}

The study population included a total of 29,487 of adolescents aged 13-19 years residing in Site A $(10,493)$, Site B $(8,671)$ and Site C $(10,323)$. They were almost equal

Figure 4 Study population by site, schooling status and sex

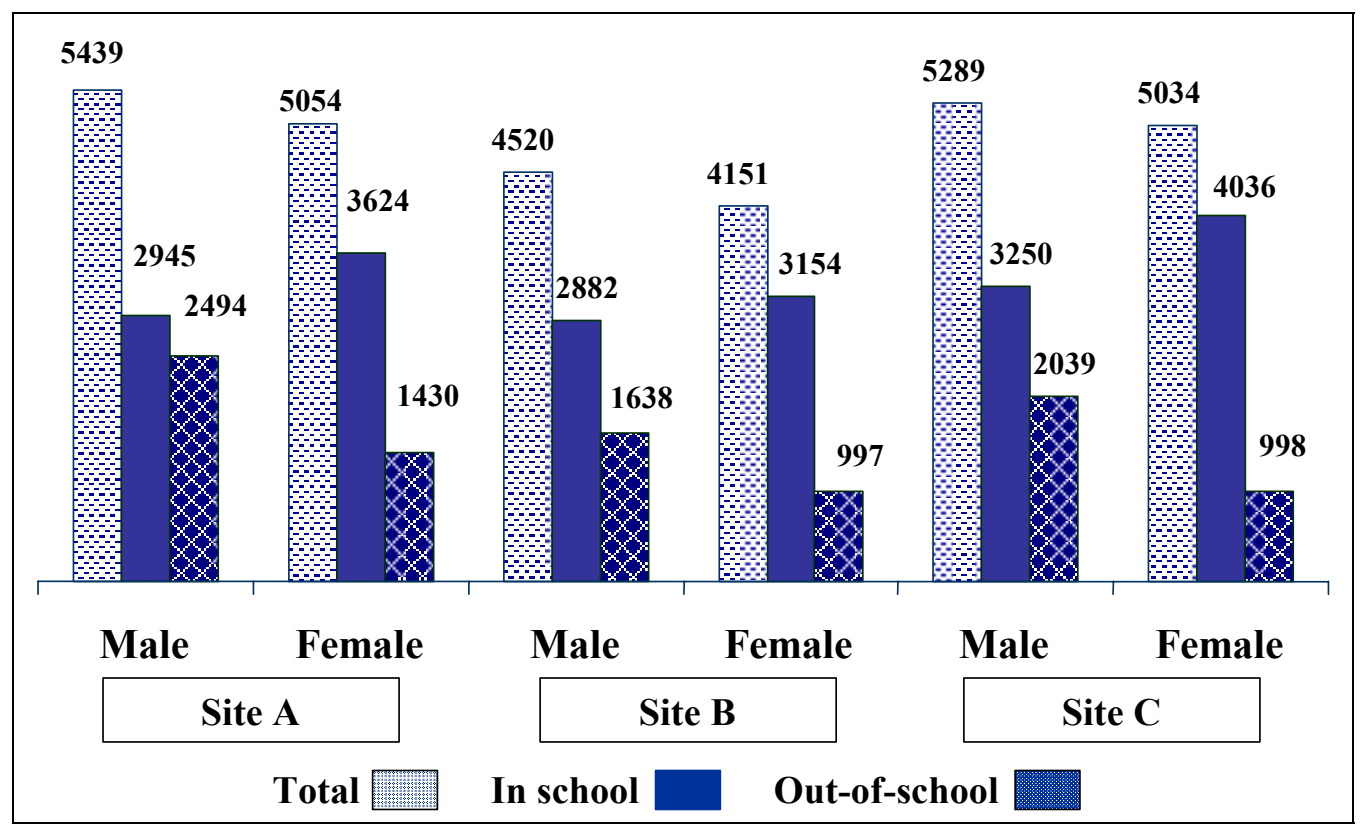

in sex ratio and about 70 percent were in school (Figure 4).

However, the population exposed to the interventions was different by site. For example, adolescents aged 13 and 16-19 years were excluded from the school-based intervention following discussions with teachers, parents and program managers during the design phase. In contrast all adolescents aged 13-19 years irrespective of marital status were included in the community-based intervention. The community-based intervention also included domestic help and temporary residents who constituted 21 percent of the total out-of-school adolescents in the intervention sites (Tables 1 and 2). 


\section{FINDINGS}

\section{Socio-demographic characteristics of the adolescents}

Respondents had similar age distributions in the baseline and endline surveys for both intervention and control sites with almost same mean age (Tables 10 and 11). No significant variation was observed between the younger and older age groups across site and time of interview.

There was no marked variation in current school status between baseline and endline surveys among boys and girls across the sites. In both the baseline and endline more than 90 percent of boys were found to have had at least one year of primary education and over 60 percent had at least one year of secondary education. Site $\mathrm{C}$ had a significantly lower proportion of boys with secondary education during the endline survey than at the baseline survey. The mean number of years in school for boys was nearly the same both in baseline and endline surveys with a slight, but significant, decline in the control site (Table 10). Current school attendance rates among the girls varied between 66 percent to 77 percent in the baseline and 69 percent to 73 percent in the endline survey, with Site C having somewhat higher, but not significant, attendance rates (Table 11). Over 79 percent of girls had at least one year of secondary education both in the baseline and endline surveys compared to over 61 percent among boys. During the endline survey, the number of years in school among girls was significantly higher than that of boys within each site $(p<01)$, but the between-site differences between girls and boys did not differ significantly. 
Table 10 Background characteristics of boys by site and time of interviews

\begin{tabular}{|c|c|c|c|c|c|c|}
\hline & \multicolumn{2}{|c|}{ Site A } & \multicolumn{2}{|c|}{ Site B } & \multicolumn{2}{|c|}{ Site C } \\
\hline & $\begin{array}{l}\text { Baseline } \\
\text { Percent/ } \\
\text { mean }\end{array}$ & $\begin{array}{l}\text { Endline } \\
\text { Percent/ } \\
\text { mean }\end{array}$ & $\begin{array}{l}\text { Baseline } \\
\text { Percent/ } \\
\text { mean }\end{array}$ & $\begin{array}{l}\text { Endline } \\
\text { Percent/ } \\
\text { mean }\end{array}$ & $\begin{array}{l}\text { Baseline } \\
\text { Percent/ } \\
\text { mean }\end{array}$ & $\begin{array}{l}\text { Endline } \\
\text { Percent/ } \\
\text { mean }\end{array}$ \\
\hline Age group & & & & & & \\
\hline $13-14$ & 26.9 & 29.3 & 30.0 & 30.3 & 29.5 & 31.1 \\
\hline $15-16$ & 32.1 & 26.6 & 31.8 & 28.4 & 32.0 & 27.8 \\
\hline $17-19$ & 41.0 & 44.2 & 38.2 & 41.3 & 38.6 & 41.1 \\
\hline $\begin{array}{l}\text { Mean age in years } \\
\text { (sd) }\end{array}$ & $\begin{array}{l}16.0 \\
(1.8)\end{array}$ & $\begin{array}{l}16.0 \\
(2.1)\end{array}$ & $\begin{array}{l}15.8 \\
(1.9)\end{array}$ & $\begin{array}{l}16.0 \\
(2.0)\end{array}$ & $\begin{array}{l}15.8 \\
(1.8)\end{array}$ & $\begin{array}{l}15.9 \\
(2.0)\end{array}$ \\
\hline $\begin{array}{l}\text { School status } \\
\text { Currently attending school }\end{array}$ & 51.1 & 48.6 & 56.3 & 56.1 & 58.9 & 53.2 \\
\hline No formal education & 9.1 & 7.2 & 7.7 & 7.7 & 6.2 & 6.4 \\
\hline $\begin{array}{l}\text { At least one year primary } \\
\text { education }\end{array}$ & 90.9 & 92.9 & 92.3 & 92.2 & 93.8 & 93.6 \\
\hline $\begin{array}{l}\text { At least one year } \\
\text { secondary education }\end{array}$ & 66.5 & 65.6 & 68.8 & 68.4 & 71.3 & $61.3^{* *}$ \\
\hline $\begin{array}{l}\text { At least one year of } \\
\text { college education }\end{array}$ & 4.2 & 6.6 & 4.4 & 6.6 & 5.2 & $9.9^{* *}$ \\
\hline $\begin{array}{l}\text { Mean number of years in } \\
\text { school (sd) }\end{array}$ & $\begin{array}{r}6.5 \\
(3.1)\end{array}$ & $\begin{array}{r}6.6 \\
(3.1)\end{array}$ & $\begin{array}{r}6.8 \\
(3.0)\end{array}$ & $\begin{array}{r}6.7 \\
(3.1)\end{array}$ & $\begin{array}{r}7.0 \\
(3.0)\end{array}$ & $\begin{array}{r}6.5^{*} \\
(3.3)\end{array}$ \\
\hline $\begin{array}{l}\text { Marital status } \\
\text { Single }\end{array}$ & 98.8 & $96.1^{* *}$ & 99.6 & 98.7 & 99.4 & 99.2 \\
\hline Married & 1.2 & $3.9^{* *}$ & 0.4 & 1.3 & 0.6 & 0.8 \\
\hline $\begin{array}{l}\text { Religion } \\
\text { Islam } \\
\text { Hindu }\end{array}$ & $\begin{array}{r}93.5 \\
6.3\end{array}$ & $\begin{array}{r}94.6 \\
4.1\end{array}$ & $\begin{array}{r}90.7 \\
8.1\end{array}$ & $\begin{array}{r}89.3 \\
8.9\end{array}$ & $\begin{array}{r}91.7 \\
8.3\end{array}$ & $\begin{array}{r}91.0 \\
8.3\end{array}$ \\
\hline Others & 0.2 & $1.3^{*}$ & 1.2 & 1.8 & 0.0 & 0.7 \\
\hline $\begin{array}{l}\text { Working status } \\
\text { Working } \\
\text { Non working }\end{array}$ & $\begin{array}{l}52.3 \\
47.7\end{array}$ & $\begin{array}{l}48.0 \\
52.0\end{array}$ & $\begin{array}{l}48.4 \\
51.6\end{array}$ & $\begin{array}{l}50.2 \\
49.8\end{array}$ & $\begin{array}{l}42.8 \\
57.2\end{array}$ & $\begin{array}{l}48.6 \\
51.4\end{array}$ \\
\hline $\begin{array}{l}\text { Parents' survival status } \\
\text { Father alive } \\
\text { Mother alive }\end{array}$ & $\begin{array}{l}91.9 \\
986\end{array}$ & 90.7 & 88.6 & 90.2 & 91.3 & $\begin{array}{l}88.0 \\
979\end{array}$ \\
\hline $\mathrm{N}$ & 504 & 517 & 517 & 542 & 515 & 533 \\
\hline
\end{tabular}

${ }^{*}$ Significant at $p<0.05 ;{ }^{* *} p<0.01$

The endline survey included more married adolescents than the baseline survey. Marriage in this group is generally low for males, only reaching four percent among Site A at the endline. Between 13 and 21 percent of the girls were married at the endline. 
Table 11 Background characteristics of girls by site and time of interviews

\begin{tabular}{|c|c|c|c|c|c|c|}
\hline & \multicolumn{2}{|c|}{ Site A } & \multicolumn{2}{|c|}{ Site B } & \multicolumn{2}{|c|}{ Site C } \\
\hline & $\begin{array}{l}\text { Baseline } \\
\text { Percent/ } \\
\text { mean }\end{array}$ & $\begin{array}{l}\text { Endline } \\
\text { Percent/ } \\
\text { mean }\end{array}$ & $\begin{array}{l}\text { Baseline } \\
\text { Percent/ } \\
\text { mean }\end{array}$ & $\begin{array}{l}\text { Endline } \\
\text { Percent/ } \\
\text { mean }\end{array}$ & $\begin{array}{l}\text { Baseline } \\
\text { Percent/ } \\
\text { mean }\end{array}$ & $\begin{array}{l}\text { Endline } \\
\text { Percent/ } \\
\text { mean }\end{array}$ \\
\hline Age group & & & & & & \\
\hline $13-14$ & 30.6 & 29.8 & 32.6 & 30.7 & 34.0 & 29.7 \\
\hline $15-16$ & 32.5 & 29.0 & 30.3 & 30.5 & 29.3 & 31.8 \\
\hline $17-19$ & 37.0 & 41.2 & 37.1 & 38.8 & 36.7 & 38.5 \\
\hline $\begin{array}{l}\text { Mean age in years } \\
\text { (sd) }\end{array}$ & $\begin{array}{r}15.8 \\
(1.8)\end{array}$ & $\begin{array}{l}15.9 \\
(1.9)\end{array}$ & $\begin{array}{l}15.7 \\
(1.8)\end{array}$ & $\begin{array}{l}15.8 \\
(1.9)\end{array}$ & $\begin{array}{l}15.6 \\
(1.8)\end{array}$ & $\begin{array}{l}15.8 \\
(1.8)\end{array}$ \\
\hline $\begin{array}{l}\text { School status } \\
\text { Currently attending school }\end{array}$ & 65.9 & 69.0 & 73.1 & 72.7 & 77.3 & 73.3 \\
\hline No formal education & 3.8 & 2.8 & 4.2 & 4.4 & 3.3 & 3.5 \\
\hline $\begin{array}{l}\text { At least one year primary } \\
\text { education }\end{array}$ & 96.2 & 97.1 & 95.8 & 95.6 & 96.7 & 96.5 \\
\hline $\begin{array}{l}\text { At least one year } \\
\text { secondary education }\end{array}$ & 80.4 & 79.1 & 80.6 & 80.3 & 82.8 & 84.3 \\
\hline $\begin{array}{l}\text { At least one year of } \\
\text { college education }\end{array}$ & 6.0 & 7.6 & 6.3 & 8.5 & 6.1 & $12.8^{* *}$ \\
\hline $\begin{array}{l}\text { Mean number of years } \\
\text { in school (sd) }\end{array}$ & $\begin{array}{r}7.6 \\
(2.6)\end{array}$ & $\begin{array}{r}7.5 \\
(2.6)\end{array}$ & $\begin{array}{r}7.7 \\
(2.7)\end{array}$ & $\begin{array}{r}7.6 \\
(2.8)\end{array}$ & $\begin{array}{r}7.7 \\
(2.6)\end{array}$ & $\begin{array}{r}7.8 \\
(2.6)\end{array}$ \\
\hline $\begin{array}{l}\text { Marital status } \\
\text { Sinqle }\end{array}$ & 808 & 792 & 893 & 871 & 892 & 854 \\
\hline Married & 19.2 & 20.8 & 10.7 & 12.9 & 10.8 & 14.6 \\
\hline Religion & & & & & & \\
\hline Islam & $\begin{array}{r}94.7 \\
5.1\end{array}$ & $\begin{array}{r}95.4 \\
46\end{array}$ & $\begin{array}{r}91.8 \\
72\end{array}$ & $\begin{array}{r}93.4 \\
6.0\end{array}$ & $\begin{array}{r}91.4 \\
86\end{array}$ & $\begin{array}{r}91.7 \\
8.3\end{array}$ \\
\hline $\begin{array}{l}\text { Hindu } \\
\text { Others }\end{array}$ & 5.1 & 4.6 & & 6.0 & & 8.3 \\
\hline Uners & 0.2 & 0.0 & 1.0 & 0.6 & 0.0 & 0.0 \\
\hline $\begin{array}{l}\text { Working status } \\
\text { Working } \\
\text { Non-working }\end{array}$ & $\begin{array}{l}11.9 \\
88.1\end{array}$ & $\begin{array}{r}21.0^{* *} \\
79.0\end{array}$ & $\begin{array}{l}15.4 \\
84.6\end{array}$ & $\begin{array}{l}16.7 \\
83.3\end{array}$ & $\begin{array}{l}12.4 \\
87.6\end{array}$ & $\begin{array}{l}14.5 \\
85.5\end{array}$ \\
\hline $\begin{array}{l}\text { Parents' survival status } \\
\text { Father alive } \\
\text { Mother alive }\end{array}$ & $\begin{array}{l}89.8 \\
98.5\end{array}$ & $\begin{array}{l}91.6 \\
97.8\end{array}$ & $\begin{array}{l}90.1 \\
97.5\end{array}$ & $\begin{array}{l}84.7 \\
99.0\end{array}$ & $\begin{array}{l}87.8 \\
98.8\end{array}$ & $\begin{array}{l}90.8 \\
98.4\end{array}$ \\
\hline$N$ & 469 & 499 & 475 & 502 & 491 & 509 \\
\hline
\end{tabular}

** Significant at $p<0.01$

Bangladesh is predominantly a Muslim country, and over 90 percent of the respondents in the study sites reported their religion to be Islam (Tables 10 and 11). 
Over 43 percent of boys and 12 percent of girls were engaged in income earning activities across the sites. The endline survey found significantly more working females in Site A compared to the baseline. As would be expected, a higher proportion of out-ofschool adolescents were involved in wage earning activities than their in-school counterparts (not shown), indicating that paid employment begins at early ages, possibly depriving them of education. Though there were no significant differences among the sites over time, adolescents were found to be orphaned more by fathers than by mothers.

Findings presented in Table 12 suggest that the most common occupation of the respondents' father or male guardian was business, followed by service and skilled labor. Significant increases were seen in all three sites in fathers reported to be skilled laborers, and slight increases were also seen in Sites A and B among those reported to be day laborers. Most respondents' mothers or female guardians were housewives both in the baseline and endline, with small but significant declines in all three sites at the time of the endline survey. Site $\mathrm{C}$ had a higher proportion of adolescents whose mothers' occupation was in service compared to Site A $(p<0.01)$ and Site B during baseline and endline. 
Table 12 Parents/guardians' occupation as reported by adolescents

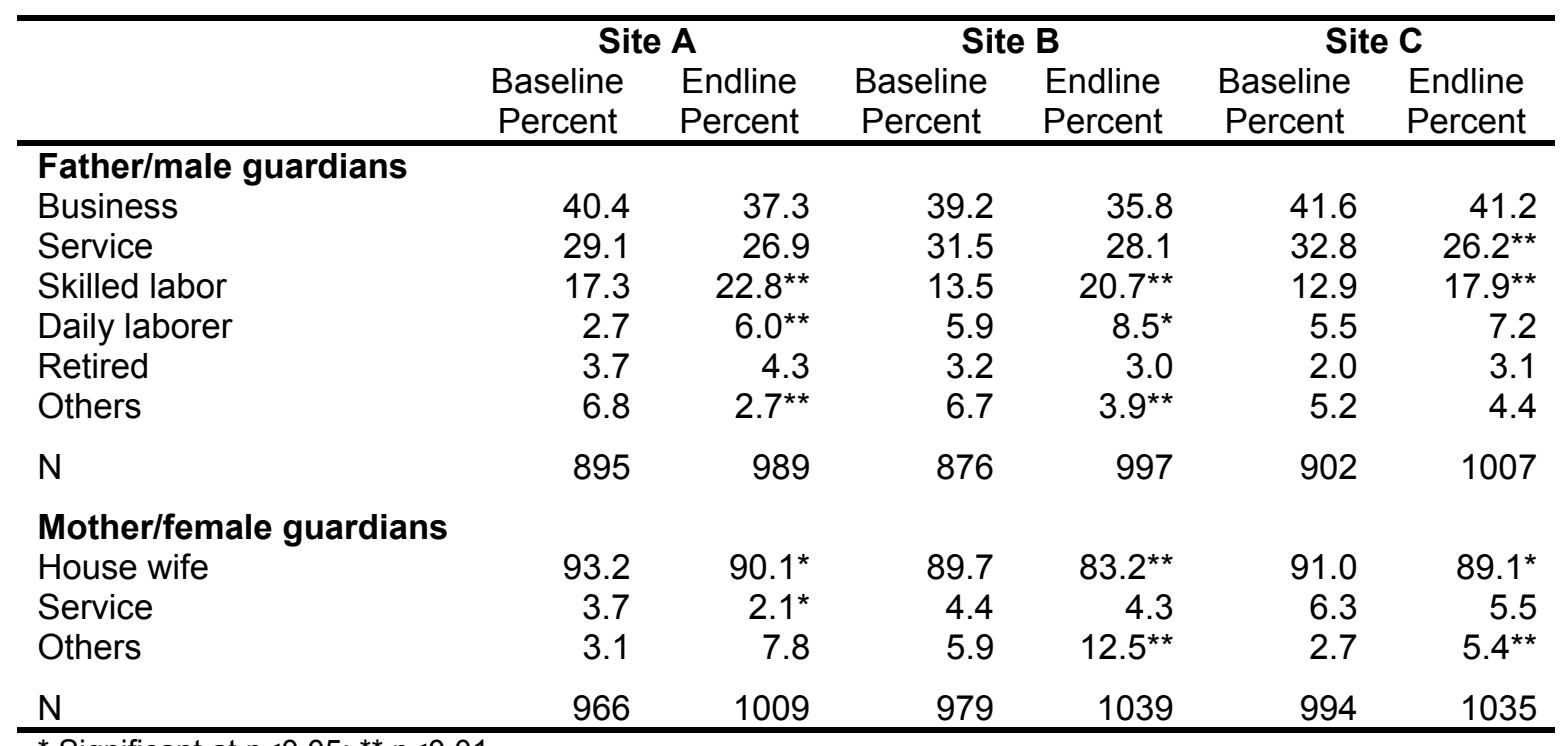

\section{Exposure to RH education}

In order to evaluate the effectiveness of the interventions, it is essential to know what percentage of adolescents in the intervention sites received $\mathrm{RH}$ education provided by the project. Table 13 presents the percentage of adolescents who received RH education from teachers in schools, from facilitators in the community and from peer educators both in schools and in the community in the intervention sites. The results should be interpreted with caution as they are based on a random sample of adolescents from households rather than from the schools providing $\mathrm{RH}$ education or the community facilitators conducting RH sessions in the community. It should be recalled that peer educators were introduced in the later part of the project to complement the teachers and facilitators' work.

The findings indicate a limited exposure to the RH education interventions in Site A (8.4 percent), but in virtually all cases in study Site B, exposure to the intervention is 
significantly higher than $\mathrm{RH}$ education from any source (30 percent). In Site B, nine percent of the adolescents received $\mathrm{RH}$ education from teachers while 20 percent of the adolescents received $\mathrm{RH}$ education from facilitators and six percent received $\mathrm{RH}$ education and took part in activities organized by peer educators. In study Site A, only eight percent of the adolescents reported receiving the community intervention, while adolescents of Site B had significantly higher exposure than Site A. Adding the schoolbased intervention to the community-based intervention increased coverage.

Table 13 Adolescents' exposure to the intervention by background characteristics

\begin{tabular}{|c|c|c|c|c|c|c|c|}
\hline \multirow[t]{2}{*}{$\begin{array}{l}\text { Background } \\
\text { Characteristics }\end{array}$} & \multirow{2}{*}{$\begin{array}{l}\text { RH education } \\
\text { from teachers } \\
\text { Site B } \\
\text { Percent }\end{array}$} & \multicolumn{2}{|c|}{$\begin{array}{l}\text { RH education } \\
\text { from facilitators } \\
\text { (youth) }\end{array}$} & \multicolumn{2}{|c|}{$\begin{array}{l}\text { RH education/ } \\
\text { activities from } \\
\text { peers }\end{array}$} & \multicolumn{2}{|c|}{$\begin{array}{l}\mathrm{RH} \text { information } \\
\text { from any sources }\end{array}$} \\
\hline & & $\begin{array}{l}\text { Site A } \\
\text { Percent }\end{array}$ & $\begin{array}{l}\text { Site B } \\
\text { Percent }\end{array}$ & $\begin{array}{c}\text { Site A } \\
\text { Percent }\end{array}$ & $\begin{array}{l}\text { Site B } \\
\text { Percent }\end{array}$ & $\begin{array}{l}\text { Site A } \\
\text { Percent }\end{array}$ & $\begin{array}{l}\text { Site B } \\
\text { Percent }\end{array}$ \\
\hline $\begin{array}{l}\text { BOYS } \\
13-14 \\
15-19\end{array}$ & $\begin{array}{r}11.0 \\
4.0\end{array}$ & $\begin{array}{l}4.0 \\
8.8\end{array}$ & $\begin{array}{r}7.9 \\
16.4^{* *}\end{array}$ & $\begin{array}{l}2.0 \\
5.2\end{array}$ & $\begin{array}{l}4.8 \\
6.9\end{array}$ & $\begin{array}{l}4.0 \\
9.9\end{array}$ & $\begin{array}{l}20.6^{* *} \\
21.4^{* *}\end{array}$ \\
\hline $\begin{array}{l}\text { In-school } \\
\text { Out-of-school }\end{array}$ & $\begin{array}{l}8.8 \\
0.0\end{array}$ & $\begin{array}{l}7.5 \\
7.7\end{array}$ & $\begin{array}{r}11.7 \\
18.7^{\star *}\end{array}$ & $\begin{array}{l}5.0 \\
3.6\end{array}$ & $\begin{array}{l}6.7 \\
4.8\end{array}$ & $\begin{array}{l}8.4 \\
7.7\end{array}$ & $\begin{array}{l}21.9^{* *} \\
19.3^{* *}\end{array}$ \\
\hline $\begin{array}{l}\text { All boys } \\
\mathrm{N}\end{array}$ & $\begin{array}{r}6.1 \\
542\end{array}$ & $\begin{array}{r}7.4 \\
517\end{array}$ & $\begin{array}{r}14.0^{* *} \\
542\end{array}$ & $\begin{array}{r}4.4 \\
517\end{array}$ & $\begin{array}{r}6.3 \\
542\end{array}$ & $\begin{array}{r}8.3 \\
517\end{array}$ & $\begin{array}{r}21.0^{* *} \\
542\end{array}$ \\
\hline $\begin{array}{l}\text { GIRLS } \\
13-14 \\
15-19\end{array}$ & $\begin{array}{r}20.8 \\
8.9\end{array}$ & $\begin{array}{l}4.7 \\
8.8\end{array}$ & $\begin{array}{l}19.5^{\star *} \\
28.4^{* *}\end{array}$ & $\begin{array}{l}2.0 \\
2.3\end{array}$ & $\begin{array}{r}5.8 \\
6.3^{* *}\end{array}$ & $\begin{array}{r}4.7 \\
10.0\end{array}$ & $\begin{array}{l}41.6^{* *} \\
39.1^{* *}\end{array}$ \\
\hline $\begin{array}{l}\text { In-school } \\
\text { Out-of-school }\end{array}$ & $\begin{array}{r}14.8 \\
2.2\end{array}$ & $\begin{array}{r}6.9 \\
10.5\end{array}$ & $\begin{array}{l}24.0^{* *} \\
33.7^{* *}\end{array}$ & $\begin{array}{l}2.2 \\
2.1\end{array}$ & $\begin{array}{r}5.1^{*} \\
10.0^{*}\end{array}$ & $\begin{array}{r}7.7 \\
11.7\end{array}$ & $\begin{array}{l}40.0^{* *} \\
38.9^{* *}\end{array}$ \\
\hline All girls & 12.5 & 7.6 & $25.6^{* *}$ & 2.2 & $6.2^{* *}$ & 8.4 & $39.8^{* *}$ \\
\hline $\mathrm{N}$ & 502 & 499 & 502 & 499 & 502 & 499 & 502 \\
\hline $\begin{array}{l}\text { ALL } \\
\text { Boys and Girls }\end{array}$ & 9.2 & 7.5 & $19.5^{\star *}$ & 3.3 & $6.1^{* *}$ & 8.4 & $30.1^{* *}$ \\
\hline $\mathrm{N}$ & 1044 & 1016 & 1044 & 1016 & 1044 & 1016 & 1044 \\
\hline
\end{tabular}

* Significant at $p<0.05 ;{ }^{* *} p<0.01$

Female adolescents in Site B were more likely to report attending the RH education sessions in all contexts than those in Site A. Not surprisingly, given the grade levels targeted, the younger age group reported more exposure to teachers while the older 
adolescents reported more exposure to facilitators and peers. This is evident at both the intervention sites. Exposure-related questions were not asked to the respondents in Site C.

\section{Knowledge of reproductive health issues}

\section{Sources of information}

As shown in Table 14, friends remained a major source of information for boys and family members for girls in both surveys, however these proportions declined significantly in Sites B and C at the endline, and increased in Site A. Boys in Site A reported significant increases in media, relatives and facilitators as sources, and boys in Site B were significantly more likely to report facilitators or peers at the endline than at baseline. Teachers, facilitators and peer educators emerged as new RH sources at the intervention sites. However, the change was more dominant in Site B. For example, more than 11 percent of girls and six percent of boys mentioned teachers as a source of RH information in Site B while the corresponding figures were below one percent for Site A. Significantly more boys and girls in both Sites A and C reported the media as a source at endline, compared with the baseline. This may indicate a more progressive direction among local media conveying RH and HIV/AIDS information. However, it should be kept in mind that the number of adolescents reporting this as an important source does not exceed 12 percent, indicating a still very limited role for media outlets in adolescent RH education.

A significantly larger proportion of boys (12 percent) and girls (18 percent) in Site B (boys: $\mathrm{p}<0.01$; girls: $\mathrm{p}<0.01$ ) also mentioned facilitators as a source compared to four percent and three percent of boys and girls respectively in Site A. Peer educators as a RH source was only mentioned in Site B (Table 14). 
Table 14 Sources $^{1}$ of RH information by site, sex and time of interview

\begin{tabular}{|c|c|c|c|c|c|c|}
\hline \multirow[b]{2}{*}{ Sources } & \multicolumn{2}{|c|}{ Site A } & \multicolumn{2}{|c|}{ Site B } & \multicolumn{2}{|c|}{ Site C } \\
\hline & $\begin{array}{r}\text { Baseline } \\
\text { Percent } \\
\end{array}$ & $\begin{array}{l}\text { Endline } \\
\text { Percent } \\
\end{array}$ & $\begin{array}{r}\text { Baseline } \\
\text { Percent } \\
\end{array}$ & $\begin{array}{l}\text { Endline } \\
\text { Percent } \\
\end{array}$ & $\begin{array}{r}\text { Baseline } \\
\text { Percent } \\
\end{array}$ & $\begin{array}{l}\text { Endline } \\
\text { Percent } \\
\end{array}$ \\
\hline \multicolumn{7}{|l|}{ BOYS } \\
\hline Teachers & 0.0 & 0.0 & 0.2 & $6.1^{* *}$ & 0.0 & 0.3 \\
\hline Family members & 3.0 & 2.6 & 1.7 & 1.6 & 3.5 & 4.0 \\
\hline Friends & 48.5 & $62.8^{* *}$ & 45.9 & $38.9^{*}$ & 70.6 & $30.2^{* *}$ \\
\hline Health providers & 2.1 & 1.1 & 1.1 & $0.1^{*}$ & 0.6 & 1.9 \\
\hline Media & 1.4 & $11.7^{* *}$ & 7.1 & 10.4 & 4.1 & $8.4^{* *}$ \\
\hline Relatives & 4.3 & $16.5^{\star *}$ & 3.3 & 5.4 & 3.7 & 6.1 \\
\hline Facilitators & 0.0 & $4.2^{* *}$ & 0.0 & $12.3^{* *}$ & na & na \\
\hline $\begin{array}{l}\text { Health ambassadors (peers) } \\
\mathbf{N}\end{array}$ & $\begin{array}{r}0.0 \\
504\end{array}$ & $\begin{array}{r}0.3 \\
517\end{array}$ & $\begin{array}{r}0.0 \\
517\end{array}$ & $\begin{array}{r}2.1^{* *} \\
542\end{array}$ & $\begin{array}{r}\text { na } \\
515\end{array}$ & $\begin{array}{r}\text { na } \\
533\end{array}$ \\
\hline \multicolumn{7}{|l|}{ GIRLS } \\
\hline Teachers & 0.4 & 0.0 & 0.3 & $11.1^{* *}$ & 0.3 & 0.4 \\
\hline Family members & 59.3 & 58.4 & 60.9 & $52.1^{* *}$ & 56.2 & $65.4^{* *}$ \\
\hline Friends & 18.1 & $32.3^{* *}$ & 25.9 & $16.8^{* *}$ & 21.8 & 23.4 \\
\hline Health providers & 0.2 & $2.7^{* *}$ & 1.1 & $0.1^{*}$ & 0.1 & $2.4^{* *}$ \\
\hline Media & 1.8 & $8.1^{* *}$ & 2.1 & 0.8 & 2.3 & $4.7^{*}$ \\
\hline Relatives & 32.2 & $42.0^{* *}$ & 40.9 & $25.2^{\star *}$ & 30.2 & $46.7^{* *}$ \\
\hline Facilitators & 0.0 & $3.1^{* *}$ & 0.0 & $18.2^{\star *}$ & na & na \\
\hline Health ambassadors (peers) & 0.0 & 0.1 & 0.0 & $4.8^{* *}$ & na & na \\
\hline $\mathbf{N}$ & 469 & 499 & 475 & 502 & 491 & 509 \\
\hline
\end{tabular}

\section{Knowledge of HIV/AIDS}

Adolescents were asked whether they had heard about HIV/AIDS. Findings presented in Table 15 show that significant increases in awareness took place in all study sites among boys and girls in both age groups. Increases were greatest in Site B followed by Site C and Site A; all attained nearly universal awareness by the time of the endline survey. The increase in awareness was greater among younger adolescents than their older counterparts, as older youth had higher levels of knowledge at the baseline. However, while comparing the changes between sites, Site B showed a significantly higher increase 
in knowledge about HIV/AIDS among boys compared to Site A $(\mathrm{p}<0.01)$ and Site C $(\mathrm{p}<0.05)$, though for girls this was not significant.

Table 15 Knowledge of HIVIAIDS by site, age group, sex and time of interview

\begin{tabular}{|c|c|c|c|c|c|c|}
\hline & \multicolumn{2}{|c|}{ Site A } & \multicolumn{2}{|c|}{ Site B } & \multicolumn{2}{|c|}{ Site C } \\
\hline & $\begin{array}{c}\text { Baseline } \\
\text { Percent } \\
\end{array}$ & $\begin{array}{l}\text { Endline } \\
\text { Percent }\end{array}$ & $\begin{array}{c}\text { Baseline } \\
\text { Percent }\end{array}$ & $\begin{array}{l}\text { Endline } \\
\text { Percent } \\
\end{array}$ & $\begin{array}{c}\text { Baseline } \\
\text { Percent } \\
\end{array}$ & $\begin{array}{l}\text { Endline } \\
\text { Percent }\end{array}$ \\
\hline \multicolumn{7}{|c|}{ BOYS } \\
\hline \multicolumn{7}{|c|}{ Heard about HIVIAIDS } \\
\hline $13-14$ & 86.8 & $94.1^{*}$ & 71.0 & $98.2^{* *}$ & 82.2 & $96.4^{* *}$ \\
\hline $15-19$ & 94.0 & $99.7^{* *}$ & 87.3 & $98.7^{* *}$ & 90.4 & $99.2^{* *}$ \\
\hline All & 92.1 & $98.3^{* *}$ & 82.2 & $98.5^{* *}$ & 88.0 & $98.3^{* *}$ \\
\hline \multicolumn{7}{|c|}{ Know at least three routes of transmission of HIVIAIDS } \\
\hline $13-14$ & 9.6 & $50.3^{* *}$ & 5.2 & $54.9^{* *}$ & 15.8 & $43.4^{* *}$ \\
\hline $15-19$ & 13.6 & $57.8^{* *}$ & 17.7 & $64.8^{* *}$ & 22.0 & $55.9^{* *}$ \\
\hline All & 12.7 & $55.6^{\star *}$ & 13.9 & $61.8^{* *}$ & 20.2 & $51.8^{* *}$ \\
\hline $\mathbf{N}$ & 504 & 517 & 517 & 542 & 515 & 533 \\
\hline \multicolumn{7}{|c|}{ GIRLS } \\
\hline \multicolumn{7}{|c|}{ Heard about HIVIAIDS } \\
\hline $13-14$ & 74.8 & $98.0^{\star *}$ & 73.5 & $97.4^{* *}$ & 74.9 & $97.4^{* *}$ \\
\hline $15-19$ & 90.8 & $99.1^{* *}$ & 82.8 & $97.4^{* *}$ & 87.0 & $98.9^{* *}$ \\
\hline All & 85.9 & $98.8^{* *}$ & 79.8 & $97.4^{* *}$ & 83.1 & $98.4^{* *}$ \\
\hline \multicolumn{7}{|c|}{ Know at least three routes of transmission of HIVIAIDS } \\
\hline $13-14$ & 6.3 & $31.5^{* *}$ & 10.3 & $43.5^{* *}$ & 8.4 & $29.1^{* *}$ \\
\hline $15-19$ & 12.3 & $48.7^{* *}$ & 16.5 & $50.9^{* *}$ & 16.0 & $43.6^{* *}$ \\
\hline All & 10.4 & $43.5^{\star *}$ & 14.3 & $48.5^{* *}$ & 13.5 & $39.3^{* *}$ \\
\hline $\mathbf{N}$ & 469 & 499 & 475 & 502 & 491 & 509 \\
\hline
\end{tabular}

* Significant at $p<0.05 ;{ }^{* *} p<0.01$.

When respondents were asked about routes of transmission of HIV, it was found that the level of knowledge about at least three routes of transmission was significantly higher in the endline survey than the baseline (Table 15). This is true for all the sites for both boys and girls. The routes of transmission of HIV mentioned by the adolescents included unprotected sex with occasional partners, use of a non-sterile syringe, blood transfusion, mother to child transmission and sexual contact with an infected person. The increase in knowledge about at least three routes of transmission among boys was significantly 
higher both in Site A $(\mathrm{p}<0.01)$ and Site B $(\mathrm{p}<0.01)$ compared to that of Site C. As for girls, the change in Site B $(p<0.05)$ was significantly higher than that of Site C. The results indicate that Site B showed more significant improvement in knowledge regarding routes of transmission of HIV/AIDS than Site $\mathrm{C}$ for both boys $(\mathrm{p}<0.01)$ and girls $(\mathrm{p}<0.05)$ while Site A showed significantly more improvement than Site C only for boys $(\mathrm{p}<0.01)$. The absolute change in Site A was greater than that in Site C for girls. A national HIV/AIDS program implemented by nearly $200 \mathrm{NGOs}$ and government BCC activities in the mass media along with $\mathrm{RH}$ interventions likely also contributed to the increased knowledge levels seen. While knowledge improved, large proportions of young people, particularly girls, are still unable to name three transmission routes.

\section{Awareness of contraceptives}

Over three-fourth of the adolescent population had heard about contraceptive methods in both the baseline and endline surveys. The change in awareness between the surveys was more pronounced among adolescents of the younger age group. The contraceptive awareness was found to be significantly higher in the endline compared to the baseline survey across study sites and gender. While comparing the changes between study sites, it was found that boys in Site B demonstrated significantly greater improvement in knowledge compared to both Site A $(\mathrm{p}<0.01)$ and Site $\mathrm{C}(\mathrm{p}<0.01)$; for girls, those in Site A $(\mathrm{p}<0.01)$ showed significantly greater improvement than those in Site B. However, a significant increase in awareness was also observed among girls in Site C compared to other sites, which may be due to interventions implemented by other agencies (Table 16).

Regarding method specific awareness, a wide variation was found for at least two modern contraceptive methods. It can be seen that the increase in awareness among boys within 
the study sites was significant across the age groups, with higher increases among younger age groups in intervention Site B (Table 16). As for girls, the change in awareness was higher in Site A and Site C compared to Site B.

Table 16 Knowledge of contraceptive methods by site, age group, sex and time of interview

\begin{tabular}{|c|c|c|c|c|c|c|}
\hline & \multicolumn{2}{|c|}{ Site A } & \multicolumn{2}{|c|}{ Site B } & \multicolumn{2}{|c|}{ Site C } \\
\hline & $\begin{array}{l}\text { Baseline } \\
\text { Percent }\end{array}$ & $\begin{array}{l}\text { Endline } \\
\text { Percent }\end{array}$ & $\begin{array}{l}\text { Baseline } \\
\text { Percent }\end{array}$ & $\begin{array}{l}\text { Endline } \\
\text { Percent }\end{array}$ & $\begin{array}{l}\text { Baseline } \\
\text { Percent }\end{array}$ & $\begin{array}{l}\text { Endline } \\
\text { Percent }\end{array}$ \\
\hline \multicolumn{7}{|l|}{ BOYS } \\
\hline \multicolumn{7}{|c|}{ Heard about contraceptive methods } \\
\hline $13-14$ & 66.7 & $78.8^{*}$ & 45.8 & $93.9^{* *}$ & 63.2 & $82.0^{* *}$ \\
\hline $15-19$ & 94.3 & $99.2^{* *}$ & 90.3 & $98.7^{* *}$ & 88.4 & $98.6^{* *}$ \\
\hline All & 86.9 & $93.2^{* *}$ & 77.0 & $97.2^{* *}$ & 81.0 & $93.4^{* *}$ \\
\hline \multicolumn{7}{|c|}{ Know at least two modern contraceptive methods (spontaneous responses) } \\
\hline $13-14$ & 33.8 & $53.0^{* *}$ & 31.0 & $60.6^{* *}$ & 25.0 & 31.9 \\
\hline $15-19$ & 76.1 & $96.7^{* *}$ & 82.0 & $87.8^{*}$ & 69.0 & $76.3^{*}$ \\
\hline All & 64.7 & $83.9^{* *}$ & 66.8 & $79.5^{* *}$ & 56.0 & $62.5^{*}$ \\
\hline $\mathbf{N}$ & 504 & 517 & 517 & 542 & 515 & 533 \\
\hline \multicolumn{7}{|c|}{ GIRLS } \\
\hline \multicolumn{7}{|c|}{ Heard about contraceptive methods } \\
\hline $13-14$ & 76.2 & $99.3^{* *}$ & 83.2 & $90.9^{*}$ & 60.5 & $98.0^{* *}$ \\
\hline $15-19$ & 95.4 & $99.4^{* *}$ & 97.2 & 99.1 & 89.8 & $99.7^{* *}$ \\
\hline All & 89.6 & $99.4^{* *}$ & 92.6 & $96.4^{* *}$ & 80.0 & $99.2^{* *}$ \\
\hline \multicolumn{7}{|c|}{ Know at least two modern contraceptive methods (spontaneous responses) } \\
\hline $13-14$ & 28.0 & $65.8^{* *}$ & 37.7 & 37.7 & 14.5 & $43.7^{* *}$ \\
\hline $15-19$ & 64.3 & $87.2^{* *}$ & 60.3 & $69.8^{* *}$ & 48.5 & $66.2^{* *}$ \\
\hline All & 53.3 & $81.0^{* *}$ & 53.1 & $60.0^{*}$ & 37.1 & $59.5^{\star *}$ \\
\hline $\mathbf{N}$ & 469 & 499 & 475 & 502 & 491 & 509 \\
\hline
\end{tabular}


Figure 5 Adolescents' knowledge of fertile period by site, sex and time of interview (\%)

Knowledge of fertile period

Before assessing knowledge

about the fertile period,

adolescents were asked whether

they know about sexual

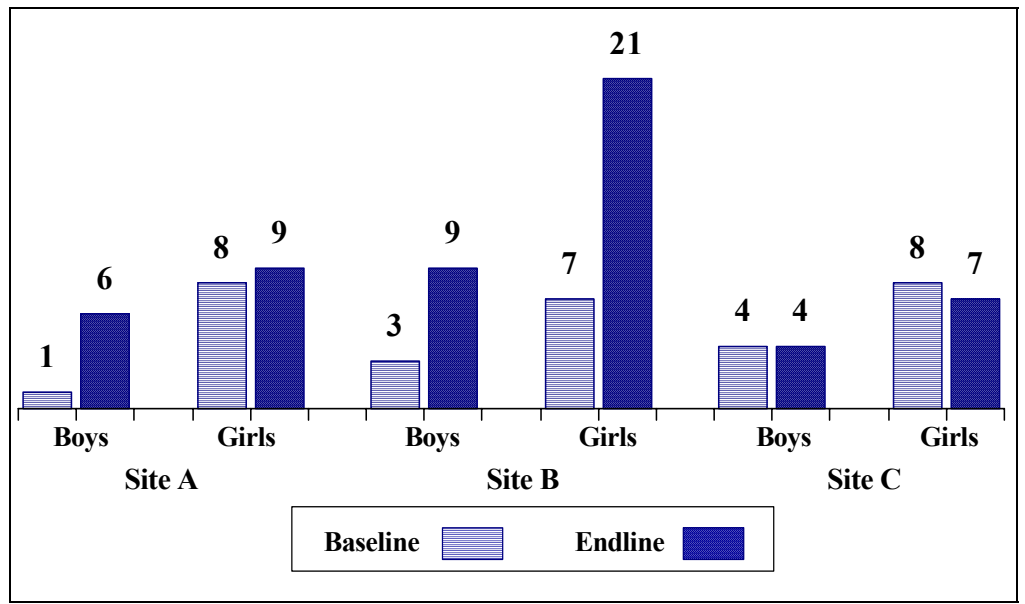

intercourse. A large proportion

(75 percent to 97 percent) of adolescents of both age groups responded affirmatively.

Significant improvement in correct knowledge of the fertile period (2 weeks after starting menstruation) occurred since the baseline survey in both the experimental sites (boys, Sites $\mathrm{A}$ and $\mathrm{B}, \mathrm{p}<0.01$; girls, Site $\mathrm{B} \mathrm{p}<0.01$ ) except for girls in Site A (Figure 5). Similarly, comparing sites, the intervention sites showed significant improvement in knowledge of the fertile period compared to the control except for girls in Site A. Overall, Site B showed greater improvement in knowledge compared to Site A (girls, $\mathrm{p}<0.01$ ) and Site $\mathrm{C}$ (boys, $\mathrm{p}<0.01$; girls, $\mathrm{p}<0.01$ ). Although these results supported the study hypothesis, knowledge is very low. With the exception of girls in Site B, 10 percent or fewer knew the fertile period.

\section{Knowledge of potential health risks of early pregnancy}

This essential reproductive health knowledge was measured by two variables: awareness of any potential health risks of early pregnancy; and adolescents' ability to cite at least three potential health risks related to early pregnancy. During the endline survey 90-99 percent of boys and girls at three sites were aware of potential health risks of early pregnancy compared to 67-94 percent at the baseline survey. The increase in awareness over the period is significant for boys of Site B and both boys and girls of Site C. Boys of 
Site B showed greater increases in awareness than Site C and Site A $(\mathrm{p}<0.01)$ while Site C showed a significantly $(\mathrm{p}<0.01)$ higher increase in awareness than Site A. For girls, Site $\mathrm{C}$ showed a significantly greater $(\mathrm{p}<0.01)$ increase in awareness than did Sites A and B.

Table 17 Knowledge of potential health risks of early pregnancy by site, age group, sex and time of interview

\begin{tabular}{|c|c|c|c|c|c|c|}
\hline & \multicolumn{2}{|c|}{ Site A } & \multicolumn{2}{|c|}{ Site B } & \multicolumn{2}{|c|}{ Site C } \\
\hline & $\begin{array}{c}\text { Baseline } \\
\text { Percent }\end{array}$ & $\begin{array}{l}\text { Endline } \\
\text { Percent }\end{array}$ & $\begin{array}{c}\text { Baseline } \\
\text { Percent }\end{array}$ & $\begin{array}{l}\text { Endline } \\
\text { Percent }\end{array}$ & $\begin{array}{c}\text { Baseline } \\
\text { Percent }\end{array}$ & $\begin{array}{l}\text { Endline } \\
\text { Percent }\end{array}$ \\
\hline \multicolumn{7}{|l|}{ BOYS } \\
\hline \multicolumn{7}{|c|}{ Aware of any health risks to a young pregnant girl and her child } \\
\hline $13-14$ & 73.5 & 76.3 & 51.9 & $96.4^{* *}$ & 82.9 & $95.8^{* *}$ \\
\hline $15-19$ & 92.7 & 95.3 & 73.8 & $99.2^{* *}$ & 91.5 & $98.4^{* *}$ \\
\hline All & 87.5 & 89.7 & 67.3 & $98.5^{* *}$ & 89.0 & $97.6^{* *}$ \\
\hline \multicolumn{7}{|c|}{ Knows at least 3 potential health risks of early pregnancy } \\
\hline $13-14$ & 13.2 & $31.1^{* *}$ & 11.6 & $52.1^{* *}$ & 40.8 & $18.1^{* *}$ \\
\hline $15-19$ & 23.4 & $59.3^{* *}$ & 16.0 & $67.6^{* *}$ & 48.8 & $32.2^{* *}$ \\
\hline All & 20.8 & $51.1^{* *}$ & 14.7 & $62.9^{* *}$ & 46.3 & $27.7^{* *}$ \\
\hline $\mathbf{N}$ & 504 & 517 & 517 & 542 & 515 & 533 \\
\hline \multicolumn{7}{|c|}{ GIRLS } \\
\hline \multicolumn{7}{|c|}{ Aware of any health risks to a young pregnant girl and her child } \\
\hline $13-14$ & 87.4 & 88.5 & 77.4 & 85.1 & 61.4 & $94.7^{* *}$ \\
\hline $15-19$ & 96.9 & 98.0 & 90.6 & 92.2 & 84.0 & $98.3^{* *}$ \\
\hline All & 94.0 & 95.2 & 86.3 & 90.0 & 76.3 & $97.2^{* *}$ \\
\hline \multicolumn{7}{|c|}{ Knows at least 3 potential health risks of early pregnancy } \\
\hline $13-14$ & 14.7 & 11.4 & 16.2 & 14.3 & 18.6 & 25.3 \\
\hline $15-19$ & 20.0 & $37.0^{* *}$ & 25.2 & 24.1 & 24.3 & $36.3^{* *}$ \\
\hline All & 18.6 & $29.4^{* *}$ & 22.3 & 21.1 & 22.2 & $33.0^{* *}$ \\
\hline $\mathbf{N}$ & 469 & 499 & 475 & 502 & 491 & 509 \\
\hline
\end{tabular}

* Significant at $p<0.05 ;{ }^{* *} p<0.01$.

When adolescents were asked to cite the health risks related to early pregnancy, it was found that a significantly higher proportion $(\mathrm{p}<0.01)$ of boys and girls of Site A could cite the risks associated with early pregnancy since the baseline survey period (Table 17). In Site $B$, the level of knowledge among boys was significantly $(p<0.01)$ changed since the baseline while hardly any change was observed for girls. Interestingly, in Site C girls' 
knowledge increased significantly $(\mathrm{p}<0.01)$ while for boys it decreased significantly $(\mathrm{p}<0.01)$. Comparing between the intervention sites over the period, it was observed that the level of knowledge of at least three potential health risks among boys in Site B $(\mathrm{p}<0.01)$ significantly increased compared to Site A, while girls in Site A and Site C showed significant $(\mathrm{p}<0.05)$ increases compared to Site B. The Bangladesh government has a safe motherhood program and is implementing it through its large health and family planning infrastructure. Findings suggest that though 90 percent or more of adolescents are aware of risks associated with early pregnancy but only a small proportion of adolescents knew what the risk factors are.

\section{Attitude towards reproductive health issues}

In this section, current attitudes of adolescents toward introducing RH education in school, contraceptives and STI services delivered by health facilities and pharmacies, and contraceptive use by married and unmarried adolescents are explored using endline data.

\section{Attitudes towards RH education and services}

Tables 18 and 19 shows that over 90 percent of adolescents supported the introduction of RH education in schools irrespective of sex or site. There were no significant differences among boys; older girls in Site A were significantly less likely to support RH education in schools than those in Sites B or C, though in absolute terms their support was also high. Respondents were asked whether they thought they would be treated in a respectful manner if they sought contraceptives and/or STI services from a health facility or pharmacy. Boys from Site A and the control site were more likely to have a favorable view of the service providers' attitude towards them than boys in Site B. Boys in Sites A and $\mathrm{C}$ were also more likely than girls to have favorable attitudes toward the services 
offered by these facilities. Girls in Site B were more favorable toward services in health facilities those in the other sites.

Table 18 Adolescent boys' attitudes regarding introducing RH education in school and utilizing health facility or pharmacy for contraceptive and STI services by site and age group

\begin{tabular}{|c|c|c|c|c|c|c|}
\hline & Site A & Site B & Site C & $\begin{array}{c}\text { Absolute } \\
\text { difference } \\
\text { between } \\
\text { site A \& C }\end{array}$ & $\begin{array}{c}\text { Absolute } \\
\text { difference } \\
\text { between } \\
\text { site B \& C }\end{array}$ & $\begin{array}{c}\text { Absolute } \\
\text { difference } \\
\text { between site A } \\
\text { \& B }\end{array}$ \\
\hline \multicolumn{7}{|c|}{ Support RH education in school } \\
\hline $13-14$ & 87.5 & 91.5 & 84.9 & 2.6 & 6.6 & 4.0 \\
\hline $15-19$ & 97.5 & 98.1 & 98.6 & 1.1 & 0.5 & 0.6 \\
\hline All & 94.6 & 96.3 & 94.4 & 0.2 & 1.9 & 1.7 \\
\hline \multicolumn{7}{|c|}{ Favorable attitude toward contraceptive services from a health facility } \\
\hline $13-14$ & 31.6 & 2.4 & 35.3 & 3.7 & $32.9^{* *}$ & $29.2^{* *}$ \\
\hline $15-19$ & 35.2 & 6.9 & 58.6 & $23.4^{\star *}$ & $51.7^{* *}$ & $28.3^{* *}$ \\
\hline All & 34.0 & 5.5 & 51.4 & $17.4^{* *}$ & $45.9^{* *}$ & $28.5^{* *}$ \\
\hline \multicolumn{7}{|c|}{ Favorable attitude toward contraceptive services from a pharmacy } \\
\hline $13-14$ & 9.3 & 1.2 & 15.7 & 6.4 & $14.5^{* *}$ & $8.1^{* *}$ \\
\hline $15-19$ & 12.1 & 5.3 & 22.6 & $10.5^{\star *}$ & $17.3^{* *}$ & $6.8^{* *}$ \\
\hline All & 11.2 & 4.1 & 20.3 & $9.1^{* *}$ & $16.2^{* *}$ & $7.1^{* *}$ \\
\hline \multicolumn{7}{|c|}{ Favorable attitude toward STI services from a health facility } \\
\hline $13-14$ & 50.7 & 41.8 & 48.2 & 2.5 & 6.4 & 8.9 \\
\hline $15-19$ & 59.5 & 44.7 & 75.8 & $16.3^{* *}$ & $31.1^{* *}$ & $14.8^{* *}$ \\
\hline All & 56.8 & 43.8 & 67.4 & $10.6^{* *}$ & $23.6^{* *}$ & $13.0^{* *}$ \\
\hline \multicolumn{7}{|c|}{ Favorable attitude toward STI services from a pharmacy } \\
\hline $13-14$ & 24.3 & 43.3 & 34.3 & 10.0 & 9.0 & $19.0^{* *}$ \\
\hline $15-19$ & 29.5 & 43.9 & 50.7 & $21.2^{* *}$ & 6.8 & $14.4^{* *}$ \\
\hline All & 27.9 & 43.9 & 45.6 & $17.7^{* *}$ & 1.7 & $16.0^{* *}$ \\
\hline $\mathbf{N}$ & 517 & 542 & 533 & & & \\
\hline
\end{tabular}

* Significant at $p<0.05 ;{ }^{* *} p<0.01$.

Few significant differences emerged among the girls' attitudes. Significantly more of the younger girls at Site B were favorably disposed toward health facility services, but overall the perception about receiving respectful contraceptive services does not exceed 12 percent for any site or age group. This may indicate very conservative attitudes about obtaining these services, or possibly, a realistic assessment and an awareness of the strong cultural taboos against unmarried young women seeking services. Interestingly, 
attitudes among females seem slightly better if seeking STI care. Those in Site B, perhaps because they were exposed to the RH intervention, were significantly more likely than those in either Site A or C to anticipate good service at a health center, while those in Site $\mathrm{C}$ were more likely to express positive attitudes about care from pharmacies.

Table 19 Adolescent girls' attitudes regarding introducing RH education in school and utilizing health facility or pharmacy for contraceptive and STI services by site and age group

\begin{tabular}{|c|c|c|c|c|c|c|}
\hline & Site A & Site B & Site C & $\begin{array}{c}\text { Absolute } \\
\text { difference } \\
\text { between } \\
\text { site A \& C } \\
\end{array}$ & $\begin{array}{c}\text { Absolute } \\
\text { difference } \\
\text { between } \\
\text { site B \& C } \\
\end{array}$ & $\begin{array}{c}\text { Absolute } \\
\text { difference } \\
\text { between site A } \\
\text { \& B } \\
\end{array}$ \\
\hline \multicolumn{7}{|c|}{ Support RH education in school } \\
\hline $13-14$ & 96.7 & 96.1 & 97.4 & 0.7 & 1.3 & 0.6 \\
\hline $15-19$ & 93.7 & 97.4 & 98.3 & $4.6^{* *}$ & 0.9 & $3.7^{*}$ \\
\hline All & 94.6 & 96.8 & 98.2 & $3.6^{* *}$ & 1.4 & 2.2 \\
\hline \multicolumn{7}{|c|}{ Favorable attitude toward contraceptive services from a health facility } \\
\hline $13-14$ & 3.4 & 9.1 & 8.6 & 5.2 & 0.5 & $5.7^{*}$ \\
\hline $15-19$ & 8.0 & 11.2 & 9.2 & 1.2 & 2.0 & 3.2 \\
\hline All & 6.6 & 10.5 & 9.0 & 2.4 & 1.5 & $3.9^{*}$ \\
\hline \multicolumn{7}{|c|}{ Favorable attitude toward contraceptive services from a pharmacy } \\
\hline $13-14$ & 4.7 & 5.2 & 7.3 & 2.6 & 2.1 & 0.5 \\
\hline $15-19$ & 7.4 & 7.5 & 8.1 & 0.7 & 0.6 & 0.1 \\
\hline All & 6.4 & 6.8 & 7.9 & 1.5 & 1.1 & 0.4 \\
\hline \multicolumn{7}{|c|}{ Favorable attitude toward STI services from a health facility } \\
\hline $13-14$ & 25.5 & 37.0 & 34.4 & 8.9 & 2.6 & $11.5^{*}$ \\
\hline $15-19$ & 31.7 & 47.4 & 36.2 & 4.5 & $11.2^{* *}$ & $15.7^{* *}$ \\
\hline All & 29.9 & 44.3 & 35.8 & $5.9^{* *}$ & $8.5^{* *}$ & $14.4^{* *}$ \\
\hline \multicolumn{7}{|c|}{ Favorable attitude toward STI services from a pharmacy } \\
\hline $13-14$ & 18.1 & 11.6 & 25.8 & 7.7 & $14.2^{* *}$ & 6.5 \\
\hline $15-19$ & 22.9 & 17.2 & 35.5 & $12.6^{* *}$ & $18.3^{* *}$ & 5.7 \\
\hline All & 21.4 & 15.5 & 32.7 & $11.3^{* *}$ & $17.2^{* *}$ & $5.9^{*}$ \\
\hline $\mathbf{N}$ & 499 & 502 & 509 & & & \\
\hline
\end{tabular}

* Significant at $p<0.05 ;{ }^{* *} p<0.01$.

\section{Attitude towards use of contraceptive methods}

Adolescents were asked their opinion about contraceptive use by married as well as unmarried adolescents. Among all boys and all girls, more than 89 percent agreed that married adolescents should use contraceptives (Tables 20 and 21). 
Table 20 Adolescent boys' attitude regarding use of contraceptives by site and age group

\begin{tabular}{|c|c|c|c|c|c|c|}
\hline & Site A & Site B & Site C & $\begin{array}{c}\text { Absolute } \\
\text { difference } \\
\text { between } \\
\text { Site A \& C }\end{array}$ & $\begin{array}{c}\text { Absolute } \\
\text { difference } \\
\text { between } \\
\text { Site B \& C }\end{array}$ & $\begin{array}{c}\text { Absolute } \\
\text { difference } \\
\text { between Site A } \\
\& \text { B } \\
\end{array}$ \\
\hline \multicolumn{7}{|c|}{ Agreed on use of contraceptives by married adolescents } \\
\hline $13-14$ & 76.2 & 82.3 & 72.5 & 3.7 & $9.8^{*}$ & 6.1 \\
\hline $15-19$ & 98.6 & 97.1 & 96.5 & 2.1 & 0.6 & 1.5 \\
\hline All & 91.9 & 92.6 & 89.0 & 2.9 & $3.6^{*}$ & 0.7 \\
\hline \multicolumn{7}{|c|}{ Agreed on use of contraceptives by unmarried adolescents } \\
\hline $13-14$ & 58.9 & 63.2 & 63.3 & 4.4 & 0.1 & 4.3 \\
\hline $15-19$ & 86.3 & 74.9 & 86.4 & 0.1 & $11.5^{\star *}$ & $11.4^{\star *}$ \\
\hline All & 78.3 & 71.4 & 79.2 & 0.9 & $7.8^{* *}$ & $6.9^{* *}$ \\
\hline \multicolumn{7}{|c|}{ Approved condom as a good method for adolescents } \\
\hline $13-14$ & 57.0 & 48.2 & 36.1 & $20.9^{* *}$ & $12.1^{*}$ & 8.8 \\
\hline $15-19$ & 90.4 & 78.5 & 74.4 & $16.0^{* *}$ & 4.1 & $11.9^{* *}$ \\
\hline All & 80.7 & 69.3 & 62.5 & $18.2^{* *}$ & $6.8^{*}$ & $11.4^{* *}$ \\
\hline \multicolumn{7}{|c|}{$\begin{array}{l}\text { Agreed on use of condom by unmarried sexually active adolescents for preventing } \\
\text { pregnancy }\end{array}$} \\
\hline $13-14$ & 70.2 & 80.6 & 67.7 & 2.5 & $12.9^{* *}$ & $10.4^{*}$ \\
\hline $15-19$ & 98.1 & 96.8 & 97.0 & 1.1 & 0.2 & 1.3 \\
\hline All & 89.9 & 91.9 & 88.2 & 1.7 & $3.7^{*}$ & 2.0 \\
\hline \multicolumn{7}{|c|}{$\begin{array}{l}\text { Agreed on use of condom by unmarried sexually active adolescents for preventing } \\
\text { infections }\end{array}$} \\
\hline $13-14$ & 70.2 & 79.4 & 67.7 & 2.5 & $11.7^{*}$ & 9.2 \\
\hline $15-19$ & 97.0 & 97.1 & 96.7 & 0.3 & 0.4 & 0.1 \\
\hline All & 89.2 & 91.9 & 88.0 & 1.2 & $3.9^{*}$ & 2.7 \\
\hline $\mathbf{N}$ & 517 & 542 & 533 & & & \\
\hline
\end{tabular}

* Significant at $p<0.05 ;{ }^{* *} p<0.01$.

Boys at Site B had significantly more positive attitudes than the boys at Site C $(p<0.05)$, while girls of Site A had significantly more favorable attitudes compared to Site B $(\mathrm{p}<0.01)$. Regarding contraceptive use by unmarried adolescents, over 70 percent of boys and 56 percent of girls approved of unmarried adolescents' use of contraceptives. Girls in the control site had significantly $(\mathrm{p}<0.01)$ more positive attitudes than those in the intervention areas. Similar proportions of boys at Sites A and C were supportive of unmarried adolescents' use of contraceptives, with significant differences among older 
boys and all boys, compared with those in Site B. While it is not possible to know exactly how teachers presented this topic in the curriculum, it is possible that personal bias may have influenced their coverage.

Table 21 Adolescent girls' attitudes regarding use of contraceptives by site and age group

\begin{tabular}{|c|c|c|c|c|c|c|}
\hline & Site A & Site B & Site C & $\begin{array}{c}\text { Absolute } \\
\text { difference } \\
\text { between } \\
\text { Site A \& C }\end{array}$ & $\begin{array}{c}\text { Absolute } \\
\text { difference } \\
\text { between } \\
\text { Site B \& C } \\
\end{array}$ & $\begin{array}{c}\text { Absolute } \\
\text { difference } \\
\text { between Site A } \\
\& B \\
\end{array}$ \\
\hline \multicolumn{7}{|c|}{ Agreed on use of contraceptive methods by married adolescents } \\
\hline $13-14$ & 96.6 & 82.5 & 96.0 & 0.6 & $13.5^{\star *}$ & $14.1^{*}$ \\
\hline $15-19$ & 96.9 & 96.6 & 96.9 & 0.0 & 0.3 & 0.3 \\
\hline All & 96.4 & 92.0 & 96.7 & 0.3 & $4.7^{* *}$ & $4.4^{* *}$ \\
\hline \multicolumn{7}{|c|}{ Agreed on use of contraceptive methods by unmarried adolescents } \\
\hline $13-14$ & 34.9 & 47.4 & 73.3 & $38.4^{* *}$ & $25.9^{* *}$ & $12.5^{\star}$ \\
\hline $15-19$ & 64.5 & 67.0 & 81.1 & $16.6^{* *}$ & $14.1^{* *}$ & 2.5 \\
\hline All & 55.7 & 60.8 & 78.6 & $22.9^{* *}$ & $17.8^{* *}$ & 5.1 \\
\hline \multicolumn{7}{|c|}{ Approved condom as a good method for adolescents } \\
\hline $13-14$ & 29.5 & 16.2 & 13.3 & $16.2^{* *}$ & 2.9 & $13.3^{* *}$ \\
\hline $15-19$ & 56.6 & 24.6 & 37.3 & $19.3^{* *}$ & $12.7^{\star *}$ & $32.0^{* *}$ \\
\hline All & 48.5 & 22.1 & 30.3 & $18.2^{* *}$ & $8.2^{* *}$ & $26.4^{* *}$ \\
\hline \multicolumn{7}{|c|}{$\begin{array}{l}\text { Agreed on use of condom by unmarried sexually active adolescents for preventing } \\
\text { pregnancy }\end{array}$} \\
\hline $13-14$ & 68.5 & 59.1 & 70.9 & 2.4 & $11.8^{*}$ & 9.4 \\
\hline $15-19$ & 92.9 & 80.2 & 86.9 & $6.0^{* *}$ & $6.7^{*}$ & $12.7^{* *}$ \\
\hline All & 86.0 & 73.9 & 82.3 & 3.7 & $8.4^{* *}$ & $12.1^{* *}$ \\
\hline \multicolumn{7}{|c|}{$\begin{array}{l}\text { Agreed on use of condom by unmarried sexually active adolescents for preventing } \\
\text { infections }\end{array}$} \\
\hline $13-14$ & 63.1 & 59.1 & 66.2 & 3.1 & 7.1 & 4.0 \\
\hline $15-19$ & 91.1 & 79.5 & 85.2 & $5.9^{*}$ & $5.7^{*}$ & $11.6^{* *}$ \\
\hline All & 83.0 & 73.3 & 79.6 & 3.4 & $6.3^{*}$ & $9.7^{* *}$ \\
\hline $\mathbf{N}$ & 499 & 502 & 509 & & & \\
\hline
\end{tabular}

* Significant at $p<0.05 ;{ }^{* *} p<0.01$.

Significantly more boys in the older age group in Site A were favorably disposed toward unmarried adolescents' use of contraceptives compared to those in Site B $(\mathrm{p}<0.01)$. Respondents were asked to suggest suitable contraceptive methods for adolescents. Attitudes regarding the condom were significantly higher in Site A $(\mathrm{p}<0.01)$ compared to 
Site $\mathrm{C}$ as well as Site B among all boys and older boys, and among all girls (Tables 20 and 21).

When asked whether unmarried sexually active adolescents should use the condom to prevent pregnancy or infection, 88 to 92 percent of boys and 73 to 86 percent of girls agreed. Younger boys at Site B had significantly more favorable attitudes than those in Sites A and C, while older girls of Site A had significantly more positive attitudes than those in Sites B and C.

\section{Reproductive health behavior}

\section{Sexual behavior of unmarried adolescents}

Findings indicate that less than one percent of unmarried girls and eight percent of unmarried boys had experienced sex at the time of baseline survey. For boys, the rate increased very slightly to 10 percent at the time of the endline survey while it remained the same for girls. As the total number of unmarried sexually active girls was small, they were excluded

\section{Box 2 In-depth findings: Following the footsteps of elders}

"One night at the age of 15 when I was returning home I saw a man offering money to a CSW at the railway station. I followed them and saw everything. After watching the same thing for a week I saved money, gathered courage and finally started doing it" ...A 19 years unmarried out-of-school working boy from the analysis.

\section{Sexual behavior of unmarried boys}

Sexual exposure (ever had sex) showed small but statistically significant increases among younger boys in Site A and older boys in Site C (Table 22). 
Table 22 Sexual exposure of unmarried adolescent boys by site, school status, age group and time of interview

\begin{tabular}{|c|c|c|c|c|c|c|}
\hline & \multicolumn{2}{|c|}{ Site A } & \multicolumn{2}{|c|}{ Site B } & \multicolumn{2}{|c|}{ Site C } \\
\hline & $\begin{array}{c}\text { Baseline } \\
\text { Percent/ } \\
\text { mean }\end{array}$ & $\begin{array}{c}\text { Endline } \\
\text { Percent/ } \\
\text { mean }\end{array}$ & $\begin{array}{c}\text { Baseline } \\
\text { Percent/ } \\
\text { mean }\end{array}$ & $\begin{array}{c}\text { Endline } \\
\text { Percent/ } \\
\text { mean }\end{array}$ & $\begin{array}{c}\text { Baseline } \\
\text { Percent/ } \\
\text { mean }\end{array}$ & $\begin{array}{c}\text { Endline } \\
\text { Percent/ } \\
\text { mean }\end{array}$ \\
\hline \multicolumn{7}{|l|}{ Ever had sex } \\
\hline $13-14$ & 0.0 & $6.6^{* *}$ & 0.0 & 1.2 & 0.0 & 2.4 \\
\hline $15-19$ & 13.8 & 16.5 & 12.0 & 11.1 & 6.7 & $11.0^{*}$ \\
\hline In-school & 4.0 & $8.8^{*}$ & 5.2 & 4.5 & 2.2 & 4.1 \\
\hline Out-of-school & 17.3 & 22.0 & 14.1 & 16.3 & 9.2 & $17.5^{*}$ \\
\hline All & 10.0 & 13.5 & 8.3 & 8.0 & 4.7 & $8.3^{*}$ \\
\hline $\mathbf{N}$ & 499 & 497 & 515 & 535 & 512 & 528 \\
\hline \multicolumn{7}{|c|}{ Had sex in last six months (among those who ever had sex) } \\
\hline $13-14$ & - & 30.0 & - & 0.0 & - & 0.0 \\
\hline $15-19$ & 40.8 & 56.1 & 47.7 & 34.1 & 45.8 & 39.0 \\
\hline In-school & 27.3 & 42.9 & 41.2 & 23.5 & 57.1 & 26.7 \\
\hline Out-of-school & 43.6 & 56.4 & 51.9 & 38.5 & 38.9 & 41.4 \\
\hline All & 40.8 & 51.5 & 47.7 & 32.6 & 45.8 & 35.6 \\
\hline $\mathbf{N}$ & 49 & 66 & 44 & 43 & 24 & 45 \\
\hline \multicolumn{7}{|c|}{ Mean age at first sex (years) } \\
\hline $13-14$ & - & 11.1 & - & 12.0 & - & 11.3 \\
\hline $15-19$ & 14.9 & 15.0 & 15.0 & 15.5 & 14.9 & 14.9 \\
\hline In-school & 15.5 & 14.6 & 15.1 & 15.6 & 15.6 & 14.9 \\
\hline Out-of-school & 14.7 & 14.3 & 14.9 & 15.1 & 14.7 & 14.5 \\
\hline All & 14.9 & 14.4 & 15.0 & 15.3 & 14.9 & 14.6 \\
\hline $\mathbf{N}$ & 50 & 67 & 43 & 43 & 24 & 44 \\
\hline \multicolumn{7}{|c|}{ Mean number of sexual partners in last six months } \\
\hline $13-14$ & - & 2.0 & - & - & - & - \\
\hline $15-19$ & 1.5 & 1.6 & 2.0 & 2.0 & 1.5 & 2.5 \\
\hline In-school & 2.3 & 1.3 & 1.2 & 1.4 & 1.4 & 4.8 \\
\hline Out-of-school & 1.3 & 1.8 & 2.4 & 2.2 & 1.6 & 1.7 \\
\hline All & 1.5 & 1.6 & 2.0 & 2.0 & 1.5 & 2.5 \\
\hline $\mathbf{N}$ & 20 & 34 & 21 & 14 & 11 & 16 \\
\hline
\end{tabular}

* Significant at $p<0.05 ;{ }^{* *} p<0.01$. Note: Care should be taken in interpreting results with small n's.

Out-of-school boys in Site C showed the greatest absolute increase, but there was also a slight increase among in-school boys in Site A. No significant differences emerged over time when sexually active unmarried boys were asked about their sexual experience in the prior six months. The proportion of sexually active adolescents was substantially 
higher among out-of-school boys $(\mathrm{p}<0.01)$ compared to in-school boys during the

\section{Box 3 In-depth findings: Multiple partners}

"In my life I had sex with about 50 partners, one of them was my girlfriend, four were neighborhood girls, three were male friends and the rest were CSWs"...A 19 year old unmarried out-of-school working boy baseline and endline surveys. It was found that the first and the most recent sexual experiences were almost universally consensual (about 95\% in two surveys)

(not shown).

The mean age at first sexual exposure was around 15 years. There was no marked

Box 4 In-depth findings: Accompanying a pal

"Five months ago, my friend brought a CSW to the nearby river embankment and asked me to join him. It was my first time. We did the same thing two more times. The first time was out of interest, but the last time I went to accompany him"... A 15 year old unmarried in-school boy variation in mean age at first sex across site, time of interview or school status.

\section{Box 5 In-depth findings: Peer motivation}

"My friends advised me to use condom during having sex with a CSW. So, last time when I had sex I used condom. I bought it from a grocery store."... A 19 year old unmarried out-of-school working boy
Most adolescent boys experienced their first sexual intercourse with neighbors followed by commercial sex workers, relatives and girl friends.

\section{Condom use by unmarried adolescents}

Condom use increased among sexually active unmarried boys since the baseline survey but the changes were not significant. Use of condoms with commercial sex workers also increased over the period in Sites A and B, but the number of cases is small and the change is not significant (Table 23). 
Table 23 Use of condom by unmarried, sexually active male adolescents by site, age group and time of interview

\begin{tabular}{lcrrrrr}
\hline & \multicolumn{2}{c}{ Site A } & \multicolumn{2}{c}{ Site B } & \multicolumn{2}{c}{ Site C } \\
& Baseline & Endline & Baseline & Endline & Baseline & Endline \\
& Percent & Percent & Percent & Percent & Percent & Percent \\
\hline Used condom in last intercourse & & & & & \\
$13-14$ & 0.0 & 0.0 & 0.0 & 0.0 & 0.0 & 25.0 \\
$15-19$ & 30.6 & 49.1 & 27.3 & 48.8 & 20.0 & 25.0 \\
All & 30.6 & 42.4 & 27.3 & 46.5 & 20.0 & 25.0 \\
N & $\mathbf{4 9}$ & $\mathbf{6 6}$ & $\mathbf{4 4}$ & $\mathbf{4 3}$ & $\mathbf{2 4}$ & $\mathbf{4 5}$ \\
Used condom during sex with commercial sex workers & & & \\
$13-14$ & 0.0 & 0.0 & 0.0 & 0.0 & 0.0 & 0.0 \\
$15-19$ & 46.2 & 72.0 & 42.8 & 69.2 & 57.2 & 57.7 \\
All & 46.2 & 64.3 & 42.8 & 69.2 & 57.2 & 57.7 \\
N & $\mathbf{1 3}$ & $\mathbf{2 8}$ & $\mathbf{2 1}$ & $\mathbf{2 6}$ & $\mathbf{7}$ & $\mathbf{2 6}$ \\
\hline
\end{tabular}

\section{Substance abuse}

Cigarette smoking occurred among boys and girls across the study sites, but was most prevalent among older boys. Smoking increased significantly among both older boys and girls in Site A, and among all girls in Site C, but generally a very small proportion of girls have ever tried smoking (Table 24). The mean and median age of first smoking was 14 for both boys and girls (not shown).

Fewer than 14 percent of adolescent boys across sites reported ever consuming alcohol or cough syrup containing codeine; virtually no girls reported doing so. 
Table 24 Substance use by sex, age group, site and time of interview

\begin{tabular}{|c|c|c|c|c|c|c|}
\hline & \multicolumn{2}{|c|}{ Site A } & \multicolumn{2}{|c|}{ Site B } & \multicolumn{2}{|c|}{ Site C } \\
\hline & $\begin{array}{l}\text { Baseline } \\
\text { Percent }\end{array}$ & $\begin{array}{l}\text { Endline } \\
\text { Percent }\end{array}$ & $\begin{array}{c}\text { Baseline } \\
\text { Percent }\end{array}$ & $\begin{array}{l}\text { Endline } \\
\text { Percent }\end{array}$ & $\begin{array}{r}\text { Baseline } \\
\text { Percent }\end{array}$ & $\begin{array}{l}\text { Endline } \\
\text { Percent }\end{array}$ \\
\hline \multicolumn{7}{|l|}{ BOYS } \\
\hline \multicolumn{7}{|c|}{ Ever smoked cigarette } \\
\hline $13-14$ & 22.1 & 29.8 & 10.3 & 11.6 & 19.7 & 22.9 \\
\hline $15-19$ & 62.1 & $70.7^{*}$ & 50.7 & 46.2 & 59.2 & 60.2 \\
\hline All & 51.4 & $58.8^{*}$ & 38.7 & 36.2 & 47.6 & 48.5 \\
\hline \multicolumn{7}{|c|}{ Ever consumed alcoholic drink } \\
\hline $13-14$ & 0.7 & 2.0 & 0.0 & 0.0 & 0.0 & 0.0 \\
\hline $15-19$ & 7.6 & $18.4^{* *}$ & 8.6 & 9.0 & 3.0 & $7.6^{* *}$ \\
\hline All & 5.8 & $13.6^{* *}$ & 6.0 & 6.3 & 2.1 & $5.3^{* *}$ \\
\hline \multicolumn{7}{|c|}{ Ever used drugs } \\
\hline $13-14$ & 0.0 & $5.9^{* *}$ & 0.6 & 3.6 & 0.0 & 1.2 \\
\hline $15-19$ & 12.2 & $22.5^{\star *}$ & 9.1 & 13.0 & 3.3 & $8.2^{* *}$ \\
\hline All & 8.9 & $17.6^{* *}$ & 6.6 & $10.1^{*}$ & 2.3 & $6.0^{* *}$ \\
\hline $\mathbf{N}$ & 504 & 517 & 517 & 542 & 515 & 533 \\
\hline \multicolumn{7}{|c|}{ GIRLS } \\
\hline \multicolumn{7}{|c|}{ Ever smoked cigarette } \\
\hline $13-14$ & 5.6 & 6.7 & 4.5 & 2.6 & 3.0 & $9.3^{*}$ \\
\hline $15-19$ & 5.2 & $12.0^{\star *}$ & 8.1 & 5.2 & 7.1 & $11.5^{*}$ \\
\hline All & 5.3 & $10.4^{* *}$ & 6.9 & 4.6 & 5.5 & $10.8^{* *}$ \\
\hline \multicolumn{7}{|c|}{ Ever consumed alcoholic drink } \\
\hline $13-14$ & 0.0 & 0.0 & 0.0 & 0.0 & 0.0 & 0.0 \\
\hline $15-19$ & 0.0 & 0.9 & 1.3 & 0.0 * & 0.3 & 0.3 \\
\hline All & 0.0 & 0.6 & 0.8 & 0.0 & 0.2 & 0.2 \\
\hline \multicolumn{7}{|c|}{ Ever used drugs } \\
\hline $13-14$ & 2.1 & 0.0 & 0.0 & 0.0 & 1.8 & 2.7 \\
\hline $15-19$ & 2.5 & 0.9 & 0.6 & 0.0 & 0.3 & 2.0 \\
\hline All & 2.6 & $0.6^{*}$ & 0.4 & 0.0 & 0.8 & 2.2 \\
\hline $\mathbf{N}$ & 469 & 499 & 475 & 502 & 491 & 509 \\
\hline
\end{tabular}

* Significant at $\mathrm{p}<0.05 ; * * \mathrm{p}<0.01$.

Drinking increased over the period and the

Box 6 In-depth findings: Path to addiction

change was significant among boys of Site

$\mathrm{A}$, and to a lesser degree, among those in

Site C though proportions remained small.

The mean age at which boys started using

"In the first year of college I drank phensydil (codeine containing cough syrup) for the first time with my friends. The drink was great! I used to look after the family business when I had time- so money was no problem. No one in my family also noticed it. I continued drinking and became addicted." ...A 19 year old unmarried in-school boy 
alcohol or cough syrup for the first time was around 16 years.

Fewer than 18 percent of boys across sites ever consumed drugs. Adolescents mostly used marijuana. In a pattern similar to alcohol consumption, drug use increased among older boys in Sites A and C, and among younger boys in Site A alone. Drug use had a

Box 7 In-depth findings: Peer pressure "After my father died I started spending more time with friends. At the age of 16, with my peers I first tried marijuana for free. It helped me in forgetting the pain of loss of my father. Now, I've been taking it regularly as it is not costly at all." ...A 19 year unmarried out-of-school working boy strong positive association with non-schooling

$(\mathrm{p}<0.01)$ and working status $(\mathrm{p}<0.01)$ of

adolescents (data not shown).

\section{Multivariate results}

In addition to the bivariate analyses described, multivariate analyses were carried out to test the study hypotheses on knowledge, attitudes and behavior. The models and their key dependent variables are listed in Table 25.

Table 25 Models, variables, and analytic categories

\begin{tabular}{|c|c|c|}
\hline Models & Dependent variables & Categories \\
\hline \multicolumn{3}{|c|}{ Knowledge } \\
\hline Model I & $\begin{array}{l}\text { Has correct knowledge of at least three modes of transmission } \\
\text { of HIVIAIDS }\end{array}$ & Yes/No \\
\hline Model II & $\begin{array}{l}\text { Knows at least two modern contraceptive methods } \\
\text { (spontaneous response) }\end{array}$ & Yes/No \\
\hline Model III & $\begin{array}{l}\text { Has correct knowledge of fertile period (two weeks after starting } \\
\text { period) }\end{array}$ & Yes/No \\
\hline Model IV & Knows at least three potential health risks of early pregnancy & Yes/No \\
\hline \multicolumn{3}{|l|}{ Attitude } \\
\hline Model V & Agrees with use of contraceptives by unmarried adolescents & Yes/No \\
\hline Model VI & Agrees with use of contraceptives by married adolescents & Yes/No \\
\hline Model VII & $\begin{array}{l}\text { Agrees with use of condom by unmarried sexually active } \\
\text { adolescents for preventing pregnancy }\end{array}$ & Yes/No \\
\hline Model VIII & Agrees with use of condom by unmarried sexually active & Yes/No \\
\hline
\end{tabular}


adolescents to prevent infections

Model IX

Model X

Model XI

Model XII

Model XIII

Model XIV

Behavior

Model XV
Suggests condom as a good method for adolescents

Support RH education in school

Has favorable view towards contraceptive services from a health/ family planning clinic

Has favorable view towards contraceptive services from a pharmacy

Has favorable view towards STI services from a health/ family planning clinic

Has favorable views towards STI services from a pharmacy
Yes/No

Yes/No

Yes/No

Yes/No

Yes/No

Yes/No

Unmarried male adolescents used condom in last sexual

Yes/No

\section{Reproductive health knowledge}

In intervention Sites A and B, the unadjusted and adjusted estimates of effects of time on each of the four outcome knowledge variables had odd ratios greater than 1, with the adjusted estimates larger than the unadjusted estimates (Table 26). Thus, for each of the four outcomes, respondents at endline reported higher levels of knowledge than did respondents at baseline. In the control site (Site C), the increase in knowledge at the endline from the baseline occurred in two knowledge outcomes: knew at least three modes of HIV transmission and knew at least two modern contraceptive methods. 
Table 26 Adjusted and unadjusted odds ratios (OR) of respondents' knowledge of RH issues and condom use at last sex by time of interview and site (models I to IV, and model XV)

\begin{tabular}{|c|c|c|c|c|c|c|}
\hline \multirow[t]{2}{*}{ Variable } & \multicolumn{2}{|c|}{ Site A } & \multicolumn{2}{|c|}{ Site B } & \multicolumn{2}{|c|}{ Site C } \\
\hline & $\begin{array}{l}\text { Adjusted } \\
\text { OR }\end{array}$ & $\begin{array}{l}\text { Unadjus- } \\
\text { ted OR }\end{array}$ & $\begin{array}{l}\text { Adjus- } \\
\text { ted OR }\end{array}$ & $\begin{array}{l}\text { Unadjus- } \\
\text { ted OR }\end{array}$ & $\begin{array}{c}\text { Adjus- } \\
\text { ted } \\
\text { OR } \\
\end{array}$ & $\begin{array}{c}\text { Unadjus- } \\
\text { ted OR }\end{array}$ \\
\hline \multicolumn{7}{|c|}{ Knowledge of at least 3 modes of transmission of HIVIAIDS } \\
\hline \multicolumn{7}{|l|}{ Baseline(r) } \\
\hline Endline & $9.19^{* * *}$ & $7.56^{\star * \star}$ & $10.19^{* * *}$ & $7.54^{\star * *}$ & $5.64^{* * *}$ & $4.13^{* * *}$ \\
\hline \multicolumn{7}{|c|}{ Knowledge of at least 2 modern contraceptive methods } \\
\hline \multicolumn{7}{|c|}{ Time of interview } \\
\hline Endline & $4.5^{\star * *}$ & $3.23^{* * *}$ & $1.61^{* * *}$ & $1.55^{\star * *}$ & $1.94^{* * *}$ & $1.78^{* * *}$ \\
\hline \multicolumn{7}{|c|}{ Knowledge of fertile period } \\
\hline \multicolumn{7}{|c|}{ Time of interview } \\
\hline Endline & $1.65^{* *}$ & $1.79^{* * *}$ & $3.29^{* * *}$ & $3.20^{* * *}$ & 0.84 & 0.92 \\
\hline \multicolumn{7}{|c|}{ Knowledge of at least 3 potential health risks of early pregnancy } \\
\hline \multicolumn{7}{|l|}{ Time of interview } \\
\hline Endline & $3.0^{* * *}$ & $2.77^{* \star *}$ & $3.72^{* * *}$ & $3.33^{* * *}$ & $0.84^{*}$ & $0.82^{* *}$ \\
\hline \multicolumn{7}{|l|}{$\begin{array}{l}\text { Time of interview } \\
\text { Baseline }(r)\end{array}$} \\
\hline Endline & $2.31^{*}$ & 1.67 & $2.41^{*}$ & $2.32^{*}$ & 2.0 & 1.56 \\
\hline
\end{tabular}

${ }^{*}$ Significant at $p<0.10 ;{ }^{* *} p<0.05 ;{ }^{* * *} p<0.01 . \quad(r)=$ Reference category.

The changes, in particular, increases in the level of reproductive health knowledge from baseline to endline, are larger in the intervention sites than in the control site, except for the change in knowledge of at least two modern contraceptive methods in Site B being statistically equal to change over time in the control site (Table 27). 
Table 27 Adjusted and unadjusted odds ratios (OR) associated with the interaction term of time by experimental groups regarding respondents' knowledge of RH issues and condom use at last sex (models I to IV, and model XV)

\begin{tabular}{lcc}
\hline Variable & Adjusted OR & Unadjusted OR \\
\hline Knowledge of at least 3 modes of transmission of HIVIAIDS & \\
In Site B at endline survey & $1.84^{* * *}$ & $1.83^{* * *}$ \\
In Site A at endline survey & $1.80^{* * *}$ & $1.83^{* * *}$ \\
Knowledge of at least 2 modern contraceptive methods & \\
In Site B at endline survey & 0.83 & 0.87 \\
In Site A at endline survey & $2.13^{* * *}$ & $1.81^{* * *}$ \\
Knowledge of fertile period & & \\
In Site B at endline survey & $3.91^{* * *}$ & $3.47^{* * *}$ \\
In Site A at endline survey & $1.97^{* *}$ & $1.94^{* *}$ \\
Knowledge of at least 3 potential health risks of early pregnancy & \\
In Site B at endline survey & $4.41^{* * *}$ & $4.06^{* * *}$ \\
In Site A at endline survey & $3.57^{* * *}$ & $3.38^{* * *}$ \\
Unmarried male adolescents used condom in last sex & \\
In Site B at endline survey & 1.24 & 1.48 \\
In Site A at endline survey & 1.03 & 1.07 \\
\hline
\end{tabular}

*Significant at $p<0.10 ;{ }^{* *} p<0.05 ;{ }^{* * *} p<0.01$. ( $\left.r\right)=$ Reference category.

Overall, the adjusted estimates of effects of time on levels of knowledge were higher than the unadjusted estimates. Such shift in unadjusted and adjusted estimates may be accounted for by some of the effects of the covariates included in the logistic models for knowledge outcomes. The effects of such covariates in level of knowledge scores are described as follows. An increase in the number of years of schooling and an increase in age were both associated with an increase in level of reproductive health knowledge (Table 28). Girls, however, were less likely than boys to be knowledgeable of the reproductive health outcomes, except knowledge of a girl's fertile period. The married study participants were more likely than the unmarried to know of all of the reproductive health outcomes, although the married adolescents were as likely as the unmarried to know of at least three modes of HIV/AIDS transmission. Those who ever worked for pay 
were about as likely as those who did not work for pay to know of the fertile period or health risks of early pregnancy. Those who ever worked for pay were more likely than those who did not work for pay to know of at least two modern contraceptive methods. In contrast, ever working for pay had a negative association with knowing at least three modes of HIV/AIDS transmission.

Table 28 Adjusted odds ratios of respondents' knowledge and behavior by selected covariates ${ }^{1}$

\begin{tabular}{|c|c|c|c|c|c|}
\hline Outcome & $\begin{array}{l}\text { Years of } \\
\text { schooling }\end{array}$ & Girl $^{2}$ & Age & Married $^{3}$ & $\begin{array}{l}\text { Worked } \\
\text { for pay }\end{array}$ \\
\hline \multicolumn{6}{|l|}{ Knowledge } \\
\hline $\begin{array}{l}\text { Knowledge of at least } 3 \text { modes } \\
\text { of transmission of HIVIAIDS }\end{array}$ & $1.34^{\star \star *}$ & $0.45^{\star * \star}$ & 0.997 & 0.9 & $0.84^{* *}$ \\
\hline $\begin{array}{l}\text { Knowledge of at least } 2 \\
\text { modern contraceptive methods }\end{array}$ & $1.16^{\star \star *}$ & $0.43^{* * *}$ & $1.45^{\star \star *}$ & $7.07^{* * *}$ & $1.27^{\star \star *}$ \\
\hline Knowledge of fertile period & $1.17^{* * *}$ & $1.67^{* * *}$ & $1.22^{\star \star *}$ & $4.71^{* * *}$ & 1.12 \\
\hline $\begin{array}{l}\text { Knowledge of at least } 3 \\
\text { potential health risks of early } \\
\text { pregnancy }\end{array}$ & $1.21^{* * *}$ & $0.41^{* * *}$ & $1.06^{\star \star *}$ & $1.46^{* * *}$ & 1.03 \\
\hline \multicolumn{6}{|l|}{ Behavior } \\
\hline $\begin{array}{l}\text { Use of condom by unmarried } \\
\text { male adolescents in last sex }\end{array}$ & 1.05 & $\mathrm{~N} / \mathrm{A}$ & $1.29^{\star *}$ & $\mathrm{~N} / \mathrm{A}$ & $2.15^{\star *}$ \\
\hline
\end{tabular}

* Significant at $p<0.10 ;{ }^{* *} p<0.05 ;{ }^{* *} p<0.01 . \quad \mathrm{N} / \mathrm{A}-$ Not applicable

\section{Attitudes towards reproductive health issues}

Table 29 shows the adjusted and unadjusted estimates of the odds of favorable attitudes to each of ten reproductive health issues among those who were exposed to the reproductive health $(\mathrm{RH})$ intervention compared to those who were not exposed to the RH intervention, separately for intervention Sites A and B. In both sites, respondents at

\footnotetext{
${ }^{1}$ Odd ratios were from multivariable model for each outcome where these covariates together with site, time of interview and site by time interactions were the explanatory variables.

${ }^{2}$ Reference category is 'Boy'.

${ }^{3}$ Reference category is 'Unmarried'.

${ }^{4}$ Reference category is 'Never worked for pay'.
} 
the endline who were exposed to the intervention were more likely than those not exposed to report favorable attitudes towards: a) use of condoms among unmarried sexually active adolescents to prevent pregnancy; b) use of condoms among unmarried sexually active adolescents to prevent sexually transmitted infections; c) condoms as a good contraceptive method for adolescents; d) health clinics as a source of contraceptives; and e) pharmacies as a source of contraceptives. In Site B, those who were exposed to the RH intervention were as likely as those not exposed to report support for introducing $\mathrm{RH}$ education in schools. In Site A, respondents exposed to the RH intervention were about as likely as those unexposed to agree to use of contraceptive methods by either married or unmarried adolescents while in Site B, respondents exposed to the RH intervention were more likely than those unexposed to agree with contraceptive use.

Table 29 Adjusted and unadjusted odds ratios (OR) associated with RH intervention exposure regarding attitude of respondents on different $\mathrm{RH}$ issues for each intervention site

\begin{tabular}{|c|c|c|c|c|}
\hline \multirow[t]{2}{*}{ Variables } & \multicolumn{2}{|c|}{ Site A } & \multicolumn{2}{|c|}{ Site B } \\
\hline & $\begin{array}{c}\text { Adjusted. } \\
\text { OR }\end{array}$ & $\begin{array}{c}\text { Unadjusted } \\
\text { OR }\end{array}$ & $\begin{array}{c}\text { Adjusted } \\
\text { OR }\end{array}$ & $\begin{array}{c}\text { Unadjuste } \\
\text { dOR }\end{array}$ \\
\hline \multicolumn{5}{|c|}{ Agreed with use of contraceptives by unmarried adolescents } \\
\hline \multicolumn{5}{|c|}{ RH Intervention exposure } \\
\hline \multicolumn{5}{|c|}{ No $(r)$} \\
\hline Yes & 1.21 & 1.33 & $1.67^{* \star *}$ & $1.36^{\star *}$ \\
\hline \multicolumn{5}{|c|}{ Agreed with use of contraceptives by married adolescents } \\
\hline \multicolumn{5}{|c|}{ RH Intervention exposure } \\
\hline \multicolumn{5}{|l|}{ No $(r)$} \\
\hline Yes & 0.59 & 1.13 & $4.81^{* * *}$ & $4.20^{\star * *}$ \\
\hline
\end{tabular}

Agreed with use of condom to prevent pregnancy by unmarried sexually active adolescents

RH Intervention exposure

No $(r)$

Yes $4.53^{* *} \quad 6.33^{* *} \quad 3.4^{* * *} \quad 1.82^{* * *}$

Agreed with use of condom to prevent infections by unmarried sexually active adolescents 
RH Intervention exposure

No $(r)$

Yes

$5.94^{* *}$

$7.48^{* * *}$

$3.39^{* \star *}$

$1.79^{* * *}$

Agreed condom is a good method for adolescents

RH Intervention exposure

No $(r)$

Yes

$1.93^{* *}$

$1.94^{* *}$

$2.02^{* * *}$

0.99

Supported RH education in school

RH Intervention exposure

No $(r)$

Yes

1.84

1.94

0.91

1.09

Favorable attitude towards health/family planning clinic for contraceptives

RH Intervention exposure

No $(r)$

Yes

$2.16^{\star * *}$

$1.98^{* * *}$

$1.53^{*}$

$1.6^{* *}$

Favorable attitude towards pharmacy for contraceptives

$\mathrm{RH}$ Intervention exposure

No $(r)$

Yes

$3.06^{* * *}$

$3.21^{* * *}$

$1.69^{*}$

$1.7^{*}$

Favorable attitude towards health/family planning clinic for STI

RH Intervention exposure

No $(r)$

Yes

$2.84^{* * *}$

$2.6^{* * *}$

1.23

1.21

Favorable attitude towards pharmacy for STI

RH Intervention exposure

No $(r)$

Yes

$1.58^{*}$

$1.66^{\star \star}$

$1.54^{* * *}$

1.06

* Significant at $p<0.10 ;{ }^{* *} p<0.05 ;{ }^{* * *} p<0.01 . \quad(r)=$ Reference category.

For three RH issues (use of contraceptive methods by unmarried adolescents, support for

RH education in schools and pharmacy as a source of STI information), respondents

exposed in Site B were as likely as exposed respondents in Site A to report favorable attitudes. Those in Site B were more likely to report favorable attitudes toward use of contraceptive methods by married adolescents compared to their Site A counterparts. For the remaining $\mathrm{RH}$ issues, those in Site B were less likely than those in Site A to report favorable attitudes. 
Table 30 Adjusted and unadjusted odds ratios (OR) associated with intervention sites regarding attitude of exposed respondents on different $\mathrm{RH}$ issues

\begin{tabular}{|c|c|c|}
\hline Variables & Adjusted OR & Unadjusted OR \\
\hline \multicolumn{3}{|c|}{ Agreed with use of contraceptives by unmarried adolescents } \\
\hline \multicolumn{3}{|c|}{ Intervention sites } \\
\hline \multicolumn{3}{|l|}{ Site A ( $r)$} \\
\hline Site B & 1.09 & 0.92 \\
\hline \multicolumn{3}{|c|}{ Agreed with use of contraceptives by married adolescents } \\
\hline \multicolumn{3}{|c|}{ Intervention sites } \\
\hline \multicolumn{3}{|l|}{ Site A (r) } \\
\hline Site B & $3.04^{*}$ & 2.07 \\
\hline \multicolumn{3}{|c|}{$\begin{array}{l}\text { Agreed with use of condom to prevent pregnancy by unmarried sexually active } \\
\text { adolescents }\end{array}$} \\
\hline \multicolumn{3}{|c|}{ Intervention sites } \\
\hline \multicolumn{3}{|l|}{ Site A (r) } \\
\hline Site B & $0.23^{*}$ & $0.18^{* *}$ \\
\hline \multicolumn{3}{|c|}{$\begin{array}{l}\text { Agreed with use of condom to prevent infections by unmarried sexually active } \\
\text { adolescents }\end{array}$} \\
\hline \multicolumn{3}{|c|}{ Intervention sites } \\
\hline \multicolumn{3}{|l|}{ Site A (r) } \\
\hline Site B & $0.22^{*}$ & $0.18^{* *}$ \\
\hline \multicolumn{3}{|c|}{ Agreed condom is a good method for adolescents } \\
\hline \multicolumn{3}{|c|}{ Intervention sites } \\
\hline \multicolumn{3}{|l|}{ Site A (r) } \\
\hline Site B & $0.29 * * *$ & $0.25^{* * *}$ \\
\hline \multicolumn{3}{|c|}{ Supported RH education in school } \\
\hline \multicolumn{3}{|c|}{ Intervention sites } \\
\hline \multicolumn{3}{|l|}{ Site A (r) } \\
\hline Site B & 0.86 & 0.9 \\
\hline \multicolumn{3}{|c|}{ Favorable attitude towards health/family planning clinic for contraceptives } \\
\hline \multicolumn{3}{|c|}{ Intervention sites } \\
\hline \multicolumn{3}{|l|}{ Site A (r) } \\
\hline Site B & $0.34^{* * *}$ & $0.25^{\star * *}$ \\
\hline
\end{tabular}

Favorable attitude towards pharmacy for contraceptives

Intervention sites

Site $A(r)$

Site B $0.36^{\star * *} \quad 0.3^{\star * *}$

Favorable attitude towards health/family planning clinic for STI

Intervention sites

Site $A(r)$

Site $B$

$0.57^{* *} \quad 0.49^{* * *}$

Favorable attitude towards pharmacy for STI 


\section{Intervention sites}

Site $A(r)$

Site B

1.11

0.87

${ }^{*}$ Significant at $p<0.10 ;{ }^{* *} p<0.05 ;{ }^{* * *} p<0.01 .(r)=$ Reference category.

In both Sites $\mathrm{A}$ and $\mathrm{B}$ an increase in the number of years of schooling was associated with favorable RH attitudes as indicated by odd ratios greater than 1 in Table 31 . Statistically significant effects $(p<0.01)$ of years of schooling were found for seven $\mathrm{RH}$ attitudes in both Sites A and B. For the majority of the RH issues, girls were less likely than boys to report positive attitudes, especially in Site A. The older study participants were more likely to report positive $\mathrm{RH}$ attitudes with statistically significant $(\mathrm{p}<0.01)$ results for six RH issues in Site B and five $\mathrm{RH}$ issues in Site A. Married respondents were more likely to report favorable RH attitudes with a statistically significant association $(\mathrm{p}<0.1, \mathrm{p}<0.05, \mathrm{p}<0.01)$ for four $\mathrm{RH}$ issues in both Sites A and B. The association of ever having worked for pay with favorable attitudes towards different $\mathrm{RH}$ issues was mostly positive but this association was significant $(\mathrm{p}<0.1, \mathrm{p}<0.05, \mathrm{p}<0.01)$ for only one $\mathrm{RH}$ issue in Site A and four RH issues in Site B.

\section{Table 31 Adjusted odds ratios for selected covariates tested for association with each of ten reproductive health issues by intervention site}

\begin{tabular}{|c|c|c|c|c|c|}
\hline Site and Outcome & $\begin{array}{c}\text { Years of } \\
\text { schooling }\end{array}$ & Girl1 ${ }^{1}$ & Age & Married $^{2}$ & $\begin{array}{l}\text { Worked } \\
\text { for pay }{ }^{3}\end{array}$ \\
\hline \multicolumn{6}{|l|}{ Site A } \\
\hline $\begin{array}{l}\text { Agreed with use of } \\
\text { contraceptives by unmarried } \\
\text { adolescents }\end{array}$ & $1.13^{* * *}$ & $0.27^{* * *}$ & $1.37^{* * *}$ & 1.14 & 1.01 \\
\hline $\begin{array}{l}\text { Agreed with use of } \\
\text { contraceptives by married } \\
\text { adolescents }\end{array}$ & $1.22^{* * *}$ & $1.92^{* *}$ & $1.78^{* * *}$ & 3.45 & 0.89 \\
\hline $\begin{array}{l}\text { Agreed with use of condom to } \\
\text { prevent pregnancy by } \\
\text { unmarried sexually active } \\
\text { adolescents }\end{array}$ & $1.16^{* * *}$ & $0.44^{* * *}$ & $1.93^{* * *}$ & $2.83^{*}$ & 0.71 \\
\hline
\end{tabular}


Agreed with use of condom to prevent infections by unmarried sexually active adolescents

Agreed condom is a good method for adolescents

Supported $\mathrm{RH}$ education in school

Favorable attitude toward health/family planning clinic for contraceptives

Favorable attitude toward pharmacy for contraceptives

Favorable attitude toward health/family planning clinic for STI

Favorable attitude toward pharmacy for STI

\section{Site B}

Agreed with use of contraceptives by unmarried adolescents

Agreed with use of contraceptives by married adolescents

Agreed with use of condom for preventing pregnancy by unmarried sexually active adolescents

Agreed with use of condom to prevent infection by unmarried sexually active adolescents

Agreed condom is a good method for adolescents

Supported RH education in school

Favorable attitude toward health/family planning clinic for contraceptives

Favorable attitude toward pharmacy for contraceptives

Favorable attitude toward health/family planning clinic for STI

Favorable attitude towards pharmacy for STI
$1.17^{* * *} \quad 0.38^{* * *} \quad 1.75^{* * *} \quad 2.76^{* *}$

0.85

$1.10^{* * *} \quad 0.15^{\star * *} \quad 1.36^{* * *} \quad 3.5^{* * *} \quad 1.33$

$\begin{array}{lllll}1.15^{* * *} & 0.92 & 1.1 & 0.84 & 1.14\end{array}$

$1.004 \quad 0.12^{* * *} \quad 1.06 \quad 2.41^{* * *} \quad 1.25$

$\begin{array}{lllll}1.01 & 0.56^{* *} & 1.08 & 1.14 & 1.22\end{array}$

$\begin{array}{lllll}1.09^{* * *} & 0.3^{* * *} & 1.01 & 1.22 & 1.28\end{array}$

$\begin{array}{lllll}1.06^{*} & 0.73^{* *} & 1.03 & 0.99 & 1.36^{*}\end{array}$

$1.15^{* * *} \quad 0.58^{* * *} \quad 1.14^{* * *} \quad 0.9 \quad 1.53^{* *}$

$\begin{array}{lllll}1.24^{* * *} & 0.68 & 1.74^{* * *} & 1.76 & 1.47\end{array}$

$1.25^{* * *} \quad 0.14^{* * *} \quad 1.49^{* * *} \quad 2.59^{* *} \quad 1.59^{*}$

$1.25^{* * *} \quad 0.14^{* * *} \quad 1.49^{* * *} \quad 2.53^{* *} \quad 1.72^{* *}$

$1.13^{* * *} \quad 0.09^{* * *} \quad 1.20^{* * *} \quad 2.31^{* * *} \quad 1.47^{* *}$

$\begin{array}{lllll}1.28^{* * *} & 0.92 & 1.46^{* * *} & 1.31 & 0.90\end{array}$

$\begin{array}{lllll}1.07 & 1.55 & 1.14^{*} & 2.31^{* *} & 0.89\end{array}$

$\begin{array}{lllll}1.08 & 1.41 & 1.14 & 0.96 & 0.81\end{array}$

$\begin{array}{lllll}1.09^{* * *} & 0.91 & 1.02 & 1.29 & 1.11\end{array}$

$\begin{array}{lllll}1.06^{*} & 0.21^{* \star *} & 0.99 & 1.42 & 1.31\end{array}$ 
* Significant at $p<0.10 ;{ }^{* *} p<0.05 ;{ }^{* * *} p<0.01$.

${ }^{1}$ Reference category is 'Boy'.

${ }^{2}$ Reference category is 'Unmarried'.

${ }^{3}$ Reference category is 'Never Worked for Pay'.

\section{Sexual behavior}

The use of condoms in the last coital act among unmarried male adolescents increased from baseline to endline (last row of Table 26) in adjusted models for Site A and B but the relative increase over time in condom use did not differ from the relative increase in the control site. Older age and having worked for pay were positively associated with use of condoms in the last act.

\section{Service statistics analysis}

Service statistics were collected six months prior to the introduction of the interventions and throughout the intervention period at participating health centers. Approximately one-fourth $(4,729)$ of the adolescent population in the intervention catchment areas visited the adolescent friendly health facilities, including repeat visits. Eighty-seven percent, mostly girls, obtained reproductive health services. Half of the girls who received reproductive health services were unmarried, and about one-third were in school. Girls sought mainly tetanus toxoid vaccines. Other services provided included antenatal and postnatal care (22 percent), family planning (14 percent), RTI/STI services (15 percent), and menstrual regulation related problems. As depicted in Figure 6, the utilization of RH services increased over time in the intervention sites, increasing two times in Site A and 10 times in Site B compared to Site C. Between the two intervention sites, Site B experienced 6 times the utilization of services compared with Site A. This may reflect the benefits of adding the school component to community based intervention 
and the linkage established with the school-based intervention and adolescent-friendly services.

Figure 6 Six month averages of RH service utilization by adolescents

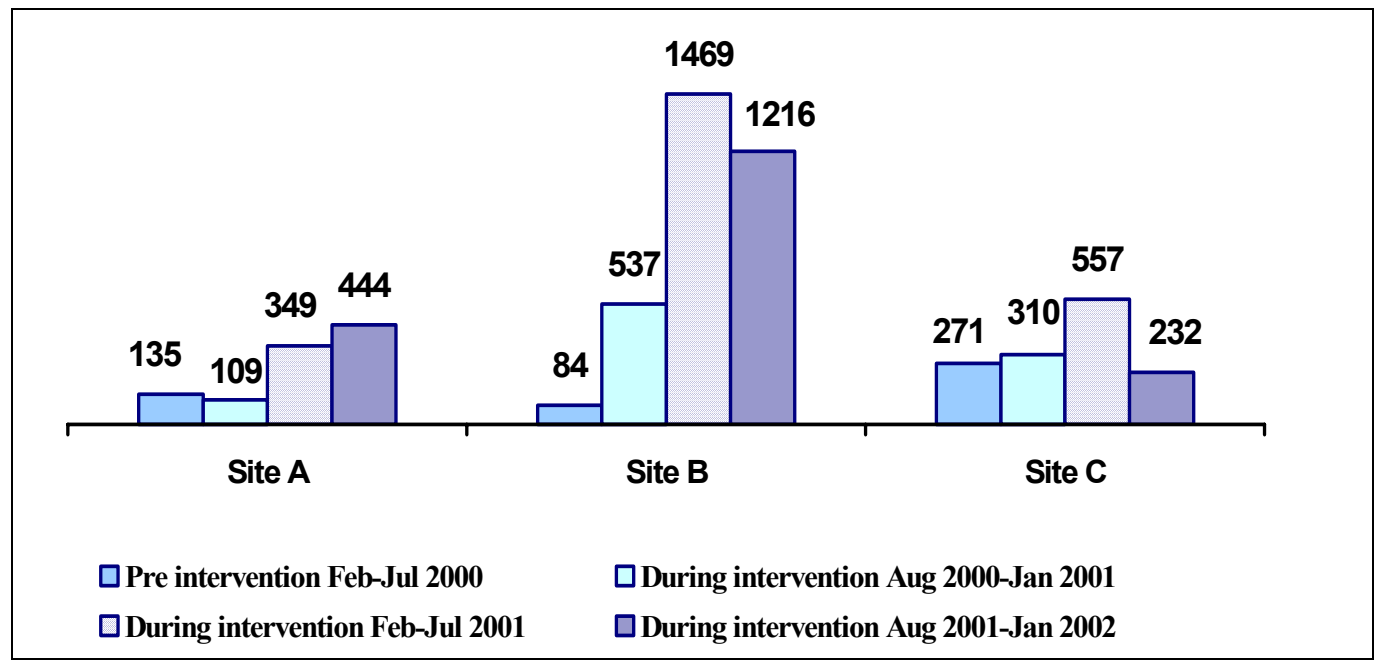

\section{Cost analysis}

The objective of the cost analysis was to calculate the incremental costs of each of the three interventions at the community, school and clinic levels to provide guidance to health, education and other relevant authorities to replicate these interventions in other regions of Bangladesh. In this process the incremental financial costs (the costs of inputs requiring an actual payment by FRONTIERS or the implementing organizations) and non-financial time labor costs (the resources which had already been purchased by other entities but were redirected to the intervention) of the project incurred during the intervention period were identified, recorded and analyzed. 


\section{Methods of cost analysis}

The cost analysis included only the program costs, that is, the costs of the resources used for developing or implementing the interventions. Research costs for measuring the effect of the interventions were not considered because they are irrelevant to decisions about replication or scaling-up.

Customized cost forms for both financial and non-financial data were used to collect information on the various inputs like labor, materials and capital costs of designing and implementing the interventions. The data recorded on the cost forms were then entered into spreadsheets under four broad categories of planning, training, supervision and service delivery under the appropriate interventions in the month in which they were incurred. Most of the costs of the project (91 percent) including personnel costs were determined to be financial in nature. For example, teachers were paid for their additional time spent in training and in taking sessions with adolescents; facilitators and program organizers were recruited and paid for their services. On the other hand, the service providers were already posted at the clinics and served adolescents within their normal course of business. Therefore, the value of their time spent on the intervention was a non-financial cost. The peer educators' time was not considered based on the assumption that if the government were to replicate this project, the peer educators as volunteers were unlikely to receive any payment for their time spent.

\section{Data collection on cost}

The original design of the cost component emphasized prospective data collection methods. The time spent on the new services in clinics and schools was to be measured through monthly interviews of service providers and teachers. Information was to be 
collected on supplies (contraceptives, drugs) pre- and post-intervention, the wage rates of the staff providing the services and the costs of space and equipment. Overhead costs for service delivery organizations were excluded because the interventions were not expected to be large enough to make an appreciable impact on the magnitude or the allocation of administrative resources.

Several circumstances required changes in the above data collection strategy. First, some of the service providers and teachers' training had already taken place before cost data collection instruments and procedures were in place. For this reason a blend of retrospective and prospective data collection approaches were used. For May and June 2000 , retrospective data on program expenditures were extracted from project financial records. In June 2000, the project staff worked with the local implementing organizations to design the data collection procedures. Therefore, starting in July 2000 and continuing to January 2002, expenditure data were collected and reported on a monthly or quarterly basis. As a result, there may be some recall bias for other than the most current figures of the retrospective data. Moreover, the cost of space and supplies like medicine and contraceptives were not collected, as existing resources were used and no additional cost was incurred.

\section{Calculation of financial and non-financial (time labor) cost}

Both financial and non-financial costs of the intervention incurred over the entire study period were calculated under four categories: planning, training, supervision and service delivery. Each of these costs was distributed to the components of intervention, that is, community, school and clinic in the month in which they incurred. At the end of the

projects all costs were converted to constant 2002 Bangladeshi Taka for which the 
Bangladeshi core inflation rates (3.4 percent for 2000 and 1.6 percent for 2001, Bangladesh Bank, 2002)) were used. Thus, the inflation factors ${ }^{2}$ used were 5.05 percent for costs of 2000 and 1.6 percent for costs of 2001. The rate of exchange for the year 2002 was Taka 59.63 per U.S. dollar. The four categories of costs of interventions are described in details in the following section.

\section{Planning costs}

Planning costs included costs of preparing behavior change communication materials (the curriculum and leaflets), sensitization meetings, telephone hotlines, post boxes and bulletin boards. The planning cost was calculated on the basis of both retrospective and prospective data because some of the planning activities had been completed, and some training for the community intervention was underway when the prospective data collection started in July 2000 . Thus, the costs that were incurred prior to the trainings also fell into this category.

\section{Training costs}

The adolescent program provided training to service providers of health facilities, school teachers, facilitators and peer educators to enable them to provide $\mathrm{RH}$ information and services to adolescents. The financial costs of training included per diem and honoraria of instructors, transport, venue, accommodation and other incidental costs. Service providers only received on-the-job refresher training. This is because UFHP had already trained service providers of 16 service delivery partners to render adolescent-friendly services, including health facilities under the operations research intervention. Therefore, the service providers' training under the project only reinforced their previous training.

\footnotetext{
${ }^{2}$ The inflation factor $5.05 \%$ for costs of year 2000 comes by multiplying inflation rates $3.4 \%$ of year 2000 with $1.6 \%$ of 2001 while the inflation factor for cost of 2001 was the same as inflation rate of 2001 .
} 


\section{Supervision costs}

The project directors, clinic managers, adolescent health educators and program organizers were the supervisory personnel. The program organizers were recruited especially to direct and monitor intervention activities and they received monthly stipends and conveyance allowances while the rest of the implementing organizations' personnel received only transportation allowances to monitor the progress of the activities for the project. In addition to these financial costs, the value of time spent on supervision by clinicians who were not paid by the project was treated as a non-financial cost. These expense data were calculated and allocated to specific types of components according to the proportion of involvement by each of the personnel.

\section{Service delivery costs}

Facilitators, teachers, peer educators and service providers rendered services in communities, schools and clinics. The costs incurred by facilitators and community peer educators fell under the community-based interventions while costs for teachers and school-peer educators were allocated to the school-based interventions. The mapping of the costs for service providers involved all three levels, based upon the part(s) of the intervention for which the person had been involved rather than by reported hours worked. The program organizers and facilitators received salaries while teachers received transportation allowances and an honorarium for extra hours worked. These monthly stipends, transportation costs of regular UFHP staff and peer educators, along with costs for cultural shows, sports and clinic promotional activities were treated as service delivery financial costs. The value of the time spent by regular UFHP staff is reported as a non-financial service delivery cost. 


\section{Cost analysis findings}

Table 32 presents information on the incremental financial and non-financial costs of the school, clinic and community based interventions by intervention sites. Total financial costs incurred in Site A and in Site B were Taka 0.69 million and Taka 1.56 million respectively, while the non-financial costs incurred in both the experimental sites were Taka 0.22 million. Thus, total costs of both the sites were about Taka 2.47 million (US\$ 41,388).

The total incremental cost of all the interventions at Site B was more than two times higher than at Site A because of the additional school-based intervention. The incremental cost of over Taka 700,000 for the school-based intervention was mainly due to training of teachers and service delivery expenses while the planning cost involved behavior change communication materials and sensitization meetings. The service delivery expenses for the school intervention were primarily for payments of Taka 500 per month to the teachers and a portion of the program organizer's monthly stipend of Taka 5,000. Other service delivery expenses included transportation costs of UFHP staff and peer educators, and periodic programs like cultural and game events in coordination with the community-level intervention. The non-financial cost mainly involved the clinicians' time spent for planning and supervising the school-based intervention.

The wide difference in financial costs for planning and service delivery of the community-based intervention between the two sites suggests that the interventions were implemented at different levels of intensity. It was reported that there was a greater number of sensitization meetings, cultural and game events conducted at Site B. 
Table 32 Incremental costs of interventions by sites in constant 2002 Taka

\begin{tabular}{|c|c|c|c|c|c|}
\hline \multirow{2}{*}{$\begin{array}{l}\text { Intervention type/ } \\
\text { Cost element }\end{array}$} & \multicolumn{2}{|c|}{ Site A } & \multicolumn{2}{|c|}{ Site B } & \multirow[b]{2}{*}{ Total } \\
\hline & $\begin{array}{c}\text { Financial } \\
\text { Cost }\end{array}$ & $\begin{array}{l}\text { Non- } \\
\text { Financial } \\
\text { Cost }\end{array}$ & $\begin{array}{c}\text { Financial } \\
\text { Cost }\end{array}$ & $\begin{array}{l}\text { Non- } \\
\text { Financial } \\
\text { Cost }\end{array}$ & \\
\hline \multicolumn{6}{|l|}{ School based } \\
\hline Planning & 0 & 0 & 87,847 & 2,847 & 90,694 \\
\hline Training & 0 & 0 & 333,738 & 1,653 & 335,391 \\
\hline Supervision & 0 & 0 & 2,977 & 5,043 & 8,020 \\
\hline Service Delivery & 0 & 0 & 284,277 & 0 & 284,277 \\
\hline Subtotal & 0 & 0 & 708,839 & 9,543 & 718,382 \\
\hline \multicolumn{6}{|l|}{ Clinic-based } \\
\hline Planning & 49,796 & 0 & 50,691 & 0 & 100,487 \\
\hline Training & 4,235 & 11,085 & 4,410 & 7,958 & 27,688 \\
\hline Supervision & 571 & 26,055 & 0 & 2,483 & 29,109 \\
\hline Service Delivery & 43,390 & 28,549 & 30,751 & 20,454 & 123,144 \\
\hline Subtotal & 97,992 & 65,689 & 85,852 & 30,895 & 280,428 \\
\hline \multicolumn{6}{|l|}{ Community based } \\
\hline Planning & 78,060 & 3,000 & 109,541 & 4,867 & 195,468 \\
\hline Training & 228,070 & 3,385 & 280,487 & 3,473 & 515,415 \\
\hline Supervision & 9,714 & 73,588 & 18,522 & 21,889 & 123,713 \\
\hline Service Delivery & 274,801 & 3,452 & 356,316 & 0 & 634,569 \\
\hline Subtotal & 590,645 & 83,425 & 764,866 & 30,229 & $1,469,165$ \\
\hline Grand Total & 688,637 & 149,114 & $1,559,557$ & 70,667 & $2,467,975$ \\
\hline
\end{tabular}

US\$ 1 = Taka 59.63 .

The financial costs of the clinic-based interventions by contrast are quite low in both sites

because they used the existing structures and personnel that were already motivated to serve adolescents. The training cost of the service providers was also the lowest as instead of using a training agency the Population Council staff gave service providers onthe-job training.

\section{Observations for replicating interventions}

One of the main objectives of the cost component was to illustrate the costs of replication and scaling up to a national program. In this regard, it is important to highlight that the clinic-based intervention was the least costly and remarkably low as it incurred an 
average incremental cost of Taka 140,214 compared to the school-based intervention of Taka 718,382 or the average community based interventions of Taka 734,583. However, the high demand of clinical services at Site B was thought to be a result of a combination of effects derived from both the school and community-based interventions. It is unlikely that a stand-alone clinic-based intervention would bring many adolescents to the clinics. Therefore, education interventions either in the community or in the school are effective if launched with the clinic-based intervention.

However, if the government has to choose between the school and community components due to budget constraints, it should consider what additional financial costs are required. For example, if the monthly payments to teachers that were used in this intervention are not payable if the government replicates the model, then the total financial cost of the school based intervention comes down to only Taka 550,339 (experiences from the expansion of the school based intervention in more 34 schools showed that teachers are ready to conduct RH session without extra payment).

Given that the school and community-based interventions incur costs of a similar magnitude, it is important to consider that the former is easier to implement for the government within existing structures. Moreover, if the majority of the cost of the school-based intervention, that is, the training cost, can be accumulated from the existing training budget, then the incremental financial cost is reduced further. On the other hand, replicating the community-based intervention will entail programmatic costs and additional budget allocations; while replicating the school-based and clinic-based interventions requires mostly a re-assignment of existing staff resources from one set of 
activities to another (a non-financial cost). Therefore, it may be easier to replicate the clinic and school-based interventions compared to the community-based one.

\section{UTILIZATION}

Utilization of the results of an operations research study may encompass many areas. It may offer an evidence base for drawing new proposals with dynamic strategies and new openings for launching similar programs. Education materials developed by the research project can also be used as resource materials or directly utilized by other organizations optimizing the expenditure of limited resources. The research findings of this study contributed to all the above areas. For example, in preparing the proposal for the Global Fund to Fight AIDS, Tuberculosis and Malaria (GFATM) in 2002, the findings of the study served as an evidence base and the proposal has already been approved. This proposal also adopted two components of the intervention, that is, imparting $\mathrm{RH}$ education in schools using teachers and integrating adolescent friendly services into existing facilities. In addition, Save the Children, UK in their second phase of the adolescent program, adopted the 'teacher model' instead of using their own staff for conducting RH sessions in schools.

The Population Council also shared the education materials (RH curriculum and leaflets) of the project with various research and service delivery organizations. The GFATM proposal identified the $\mathrm{PC}$ curriculum as one of the resource materials for secondary and higher secondary schools. In addition, Save the Children, UK utilized this curriculum as a resource material in developing their set of RH curricula. In addition, the HIV/AIDS peer education program of UNICEF, the religious leaders program of UNFPA and other 
NGOs such a Nari Unnanyn Shakti and the Khan Foundation have used the curriculum and/or leaflets of the projects in their development initiatives.

\section{CONCLUSIONS AND RECOMMENDATIONS}

The primary objective of the study was to test the feasibility of providing RH education and services to adolescents so that they are better able to manage their reproductive concerns. To achieve this objective, the project imparted RH education to in-school and out-of-school adolescents. The intervention was implemented at three levels with two strategies. Strategy I was to provide RH education to out-of-school adolescents through community outreach linked with adolescent-friendly health facilities, which was implemented in Site A, while Strategy II was to provide RH education through schools and community outreach to in-school and out-of-school adolescents linked with adolescent-friendly health facilities and was implemented in Site B. The key findings and recommendations are described below.

\section{Sources of RH information}

The consequence of having incorrect RH information has adverse effects on adolescents' lives as it exposes them to risky behavior. The study findings show that teachers and facilitators can be effective in providing RH information to adolescents. The source of RH information also has implications for the utilization of services. Site B performed better in providing RH information to adolescents linked with subsequent utilization of health services compared to Site A and Site C. 


\section{RH knowledge}

Knowledge on RH topics such as HIV/AIDS, the fertile period, potential health risks of early pregnancy and contraceptives increased due to the intervention. Bivariate and multivariate results show that adolescents in intervention sites had greater improvement in RH knowledge than the control site. The knowledge of at least three modes of transmission of HIV/AIDS increased in Site A and Site B compared to Site C. However, the improvement was greater in Site B where there was a school-based intervention. The level of knowledge of contraceptives improved across intervention and control sites over the period. However, the improvement was greatest in Site A. The effect of the interventions on knowledge of the fertile period and at least three potential health risks of early pregnancy was also clearly observed with greater improvement in Site B than Site A and no improvement in the Site C. It can be said that the school component in Strategy II contributed to improve the adolescents' knowledge on RH issues by creating an enabling environment in the community towards $\mathrm{RH}$ education program. Comparison of adjusted and unadjusted estimates showed that the intervention had a positive effect on adolescents' RH knowledge.

\section{RH attitude}

Bivariate analysis revealed that over 90 percent of adolescents were supportive of introducing RH education in school irrespective of gender, intervention and control sites. In relation to contraceptive use by unmarried and married adolescents, over 70 percent of boys and 55 percent of girls approved of unmarried adolescents' use of contraceptives while 89 percent of both boys and girls approved of the same for married adolescents across intervention and control sites. Regarding use of the condom by sexually active 
unmarried adolescents for preventing pregnancy as well as infections, over three-fourth of adolescents had favorable attitudes across intervention and control sites. Results also showed that more boys than girls suggested that the condom would be a good method for adolescents. The intervention resulted in more positive attitudes toward health facilitybased services for contraceptive and STI information and services than toward pharmacies across sites.

Comparison of results on attitudes towards the use of contraceptive methods by unmarried adolescents with or without exposure to the interventions from the endline surveys revealed that adolescents exposed to interventions in Site B were more likely to support use of contraceptives than those in Site A. Attitude towards use of contraceptives by married adolescents showed a similar pattern. In relation to use of the condom by unmarried sexually active adolescents to prevent pregnancy as well as infections, the adolescents who were exposed to the intervention showed more favorable attitudes than the non-exposed in both Site A and B. This was also the case regarding suggesting the condom as a good method for adolescents. Adolescents exposed to the intervention in Site B were less supportive than the exposed adolescents in Site A of introducing RH education in school and seeking contraceptive services from a health facility. It may be that those adolescents not exposed to school-based reproductive health education have imagined it to be very useful, while those who have had exposure did not find it met their expectations. These have important programmatic implications that require further investigation. 


\section{RH behavior}

Premarital sexual exposure (ever had sex) among unmarried boys increased significantly in Site $\mathrm{C}$ while it remained statistically unchanged in Sites A and B. The use of the condom also increased in Site A and Site B more than in Site C; the improvement was greater in Site B than Site A. The adjusted and unadjusted estimates indicated that the intervention could not reach unmarried sexually active adolescents effectively.

\section{Utilization of adolescent friendly services}

The participating clinics offered adolescent-friendly services, which included confidentiality, privacy and fees within an affordable range. The utilization of services from the health facilities increased during the intervention two times in Site A and 10 times in Site B compared to Site C. Comparing the two intervention sites, Site B experienced 6 times the utilization of services than Site A. These findings reflect the benefit of adding a school component to a community based $\mathrm{RH}$ education program and establishing linkages with the adolescent friendly services. The results also confirm that if $\mathrm{RH}$ information is provided to adolescents at schools and in the community, and adolescent friendly services are made available at the clinics, adolescents utilize the services.

\section{Cost of the program}

The incremental costs of Site B were two times higher than Site A due to adding the school-based intervention. The average site-wise incremental financial and non-financial costs of the community and school based interventions were almost the same. The adolescent-friendly health service delivery cost was lowest, reflecting use of the existing 
structure with already motivated clinic staff and on-the-job training rendered by the project staff.

In summary, the research findings indicate that on balance, Strategy II produced greater improvement in most outcome measures than did Strategy I.

\section{Recommendations}

- A combination of RH interventions at the school, community and health facility levels accompanied by community sensitization is needed to effectively respond to adolescents' RH needs. Any RH information intervention should be combined with health facility-based services for improving adolescents' overall reproductive health. However, in cases of constrained resources, schools and health facilities should be targeted first for they have existing structures that can be mobilized. Moreover, a large majority of the adolescents were in favor of introducing RH education in school.

- Information providers, such as teachers and facilitators, should be trained to effectively impart RH education to adolescents. Similarly, service providers should be trained on elements of adolescent-friendly services.

- As adolescents showed positive attitudes towards health facilities for contraceptive and STI services, authorities should equip health facilities with adolescent-friendly services. A similar opportunity also exists to promote and distribute condoms for HIV/AIDS and FP programs; over three-fourth of adolescents had favorable attitudes towards condom use for preventing pregnancy as well as infections.

- While the three-pronged interventions suggested several positive impacts, the intervention program did not reach unmarried sexually active adolescents. Future interventions should be designed focusing on unmarried sexually active adolescents. 


\section{REFERENCES}

Azim, T., J. Bogaarts, D.L. Yirrell, A.C. Banerjea, M.S. Sarkar, and G. Ahmed. 2002. "Injecting drug users in Bangladesh: Prevalence of Syphilis, Hepatitis, HIV, and HIV subtypes." AIDS 16:121-123.

Bangladesh Bank. 2002. “Annual Report 2001-2002.” Dhaka, Bangladesh: Bangladesh Bank.

Bangladesh Bureau of Educational Information and Statistics. 2002. "National Education Survey (Post-Primary)-1999 Final Report. 2001." Dhaka, Bangladesh: Ministry of Education, Government of the People's Republic of Bangladesh.

Barkat, A., S. H. Khan, M. Majid, and N. Sabina. 2000. "Adolescent sexual and reproductive health in Bangladesh a needs assessment." Dhaka, Bangladesh: International Planned Parenthood Federation and Family Planning Association of Bangladesh.

Chowdhury, A.Q.M.B., M. R. Chowdhury, and S. Lazzari. 1995. "Responding to HIVAIDS in Bangladesh.” Dhaka, Bangladesh.

Haider, S.J., S.N. Saleh, N. Kamal, and A. Gray. 1997. "Study of adolescents: Dynamics of perception, attitude, knowledge and use of reproductive health care." Dhaka, Bangladesh: Population Council.

Haq, Mahbubul ul. 2002. "Human development in South Asia 2002 agriculture and rural development.” Dhaka, Bangladesh: The University Press Limited.

Nahar, Q, C. Tunon, I. Houvras, R. Gazi, M. Reza, N.L. Huq, and B. Khudal. 1999. "Reproductive health needs of adolescents in Bangladesh: A study report." Working Paper No. 161. Dhaka, Bangladesh: International Centre for Diarrhoeal Diseases Research, Bangladesh (ICDDR, B): Center for Health and Population Research.

National Institute of Population Research and Training (NIPORT), Mitra and Associates, and ORC Macro. 2001. "Bangladesh Demographic and Health Survey 19992000." Dhaka, Bangladesh: National Institute of Population Research and Training, Mitra and Associates and Calverton, Maryland, USA: ORC Macro.

National Institute of Population Research and Training (NIPORT) and ORC Macro. 2002. "Bangladesh Maternal Health Services and Maternal Mortality Survey 2001." Dhaka, Bangladesh: NIPORT and Calverton, Maryland, USA: ORC Macro.

National AIDS and STD Program. 2002. "HIV in Bangladesh: Where is it going?" Background document for the dissemination of the Third Round (2001) of the National HIV and Behavioral Surveillance. Dhaka, Bangladesh: Directorate 
General of Health Services, Ministry of Health and Family Welfare, Government of the People's Republic of Bangladesh.

National AIDS and STD Program. 2003. "HIV in Bangladesh: Is time running out?" Background document for the dissemination of the Fourth Round (2002) of the National HIV and Behavioral Surveillance. Dhaka, Bangladesh: Directorate General of Health Services, Ministry of Health and Family Welfare, Government of the People's Republic of Bangladesh.

Panda, S., P.S. Mallick, M.A. Karim, M. Sharifuzzaman, A.H.T. Ahmed, and P. Baatsen. 2002. "What will happen to us?" National Assessment of Situation and Responses to Opioid/Opiate use in Bangladesh (NASROB). Dhaka, Bangladesh: FHI/IMPACT.

Rob, U., I. Bhuiya, L. Rahman, and N. Yusuf. 2002. "Improving adolescents' reproductive health in Bangladesh." Research Update No. 2. Dhaka, Bangladesh: Population Council.

The World Bank. 2000. "Bangladesh Education Sector Review." Volume I. Dhaka, Bangladesh: The University Press Limited.

. 2000. "Bangladesh Education Sector Review." Volume II. Dhaka, Bangladesh: The University Press Limited.

. 2000. Bangladesh Education Sector Review." Volume III. Dhaka, Bangladesh: The University Press Limited. 


\section{Appendix 1}

\section{Contents and key features of reproductive health curriculum}

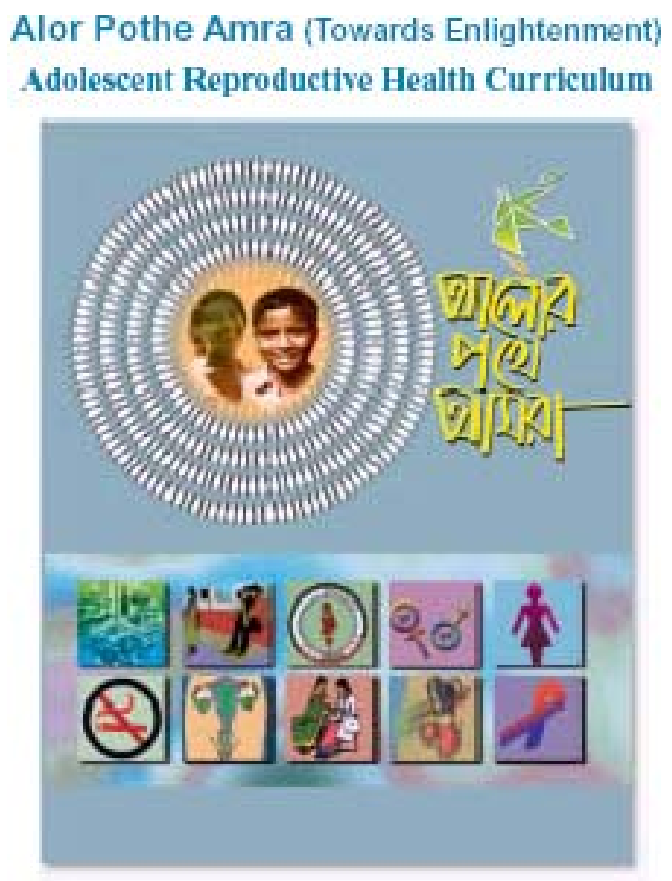

\section{List of contents}

- Changes during adolescence

- Personal hygiene

- Environment and safe water

- Food and nutrition

- Gender

- Population

- Marriage law and legal rights

- Sexual relations and sexual abuse

- Substance abuse

- Reproductive tract infections, sexually transmitted infections and HIV/AIDS

- $\quad$ Childbirth and family planning

- Prenatal, natal and postnatal care

- Child health and immunization

\section{Key features}

\section{Target audience}

- In-school adolescents of grades 8 and 9

- Out-of-school adolescents 13 to 19 years old

Curriculum implementers

- Teachers of grades 8 and 9

- Community facilitators (youth)

- Health ambassadors (peer educators)

\section{Curriculum structure}

- 14 chapters

- 17 sessions

- Average forty-five minutes per session

- Didactic and participatory methods including quiz, stories, poems, cartoons and visual aids

- Session plans for the implementers 


\section{Appendix 2}

\section{Description of adolescent reproductive health leaflets}

\section{A Few Words on Menstruation}

What is menstruation, why women menstruate, when it begins, when it stops, the menstruation cycle, the duration of the menstrual blood flow in a cycle, misconceptions about menstruation, why irregular menstruation, the relationship between menstruation and becoming a mother and what should be done during menstruation

\section{A Few Words on Ejaculation/Wet dreams}

What is ejaculation, when ejaculation occurs, misconceptions about ejaculation, the relationship between ejaculation and becoming a father, what is a wet dream, are wet dreams a disease, misconceptions about wet dreams, what should be done in case of wet dreams, what is masturbation, misconceptions about masturbation and what should be done during adolescence

\section{A Few Words on RTI/STI}

What are reproductive organs, what is RTI, what is STI, routes of transmission and ways of prevention of RTI/STI and HIV/AIDS, consequences of RTI/STIs and HIV/AIDS, the symptoms of STIs and what should be done if someone suffers from RTI/STIs and HIV/AIDS

\section{Parents' Responsibility towards Adolescents}

Who are adolescents, why adolescence is important, the roles of parents during adolescence (educator, supporter, supervisor, friend, counselor, communicator), and reproductive health care needs during adolescence

\section{Availability of Adolescent Friendly Services}

Need for adolescent RH services, types of services available at the clinic, time and duration of services and addresses of clinics 